\title{
Stereotactic treatment of intracerebral hematoma by means of a plasminogen activator
}

Citation for published version (APA):

Teernstra, O. P. M. (2002). Stereotactic treatment of intracerebral hematoma by means of a plasminogen activator. [Doctoral Thesis, Maastricht University]. Datawyse / Universitaire Pers Maastricht. https://doi.org/10.26481/dis.20021212ot

Document status and date:

Published: 01/01/2002

DOI:

10.26481/dis.20021212ot

Document Version:

Publisher's PDF, also known as Version of record

\section{Please check the document version of this publication:}

- A submitted manuscript is the version of the article upon submission and before peer-review. There can be important differences between the submitted version and the official published version of record.

People interested in the research are advised to contact the author for the final version of the publication, or visit the DOI to the publisher's website.

- The final author version and the galley proof are versions of the publication after peer review.

- The final published version features the final layout of the paper including the volume, issue and page numbers.

Link to publication

\footnotetext{
General rights rights.

- You may freely distribute the URL identifying the publication in the public portal. please follow below link for the End User Agreement:

www.umlib.nl/taverne-license

Take down policy

If you believe that this document breaches copyright please contact us at:

repository@maastrichtuniversity.nl

providing details and we will investigate your claim.
}

Copyright and moral rights for the publications made accessible in the public portal are retained by the authors and/or other copyright owners and it is a condition of accessing publications that users recognise and abide by the legal requirements associated with these

- Users may download and print one copy of any publication from the public portal for the purpose of private study or research.

- You may not further distribute the material or use it for any profit-making activity or commercial gain

If the publication is distributed under the terms of Article $25 \mathrm{fa}$ of the Dutch Copyright Act, indicated by the "Taverne" license above, 
STEREOTACTIC TREATMENT OF

INTRACEREBRAL HEMATOMA BY MEANS

OF A PLASMINOGEN ACTIVATOR 
Layout: Datawyse / Universitaire Pers Maastricht

Cover illustration: O.P.M. Teernstra, S. Maris

The main part of this thesis concerns the results of the SICHPA trial, this mial was supported by a grant from the Eund fot Developmental Medicine, Health Insurance Executive Board: Project OG94/042.

The publication of this thesis was financially supported by: AstaZeneca B.\%., B. Braun Aesculap. Carl Zeiss B.V. Codman Johnson and Johnsony, Ortomed Biomet-Merck B.V., Promedics Medical Systems B.V., Rembrandt Medical, Stryker Leibinger

MEST-U Subject headings: Intracerebral hematoma, surgery, cost-benefit analysis, systematic review, rebleeding

ISPN 9052783675

(C) Omo P.M. Teernstra, Maastricht 2002

University Hospital Maastrichr

department of Neurosurgery.

PO Box 5800, 6202 AZ, Maastricht

fo-mail: ote@snch,azm, al 


\title{
Stereotactic treatment of Intracerebral Hematoma by means of a Plasminogen Activator
}

\author{
PROEFSCHRIFT \\ ter verkrijging van de graad van doctor aan \\ de Universiteit Maastricht, \\ op gezag van de Rector Magnificus, \\ Prof. dr. A.C. Nieuwenhuijzen Kruseman \\ volgens het besluit van het College van Decanen, \\ in het openbaar te verdedigen \\ op donderdag 12 december 2002 om 12.00 uur \\ door
}

Onno Pieters Maria Teernstra

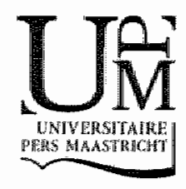




\section{PROMOTOR}

Prof. dr. E.A.M. Beuls

\section{CO-PROMOTORES}

Dr. J. Lodder

Dr. G. Blaauw

\section{BEOORDELINGSCOMMISSIE}

Prof. dr. J. Troost (voorzitter)

Dr. C.L. Franke (Atrium Medisch Centrum Heerlen)

Prof, dr. H.W.M. Steinbusch

Prof. dr. W.P. Vandertop (Vrije Universiteit van Amsterdam)

Prof. dr. J. Wilmink 
"No notable advance was ever made along any line of manipulative handicraft so long as the operator remained merely the tool to execute a procedure directed and conceived by another who alone assumed the responsibility of a diagnosis."

Harvey William Cushing (April 8, 1869 - October 7, 1939) in: "Concerning the results of operations for brain tumor: JAMA. 1915;35:95 


$\begin{array}{ll}\text { AMC } & \text { Amsterdam Medical Center } \\ \text { AMCH } & \text { Atrium Medical Center Heerlen } \\ \text { aPTT } & \text { activated Partial Thromboplastine Time } \\ \text { BI } & \text { Barthel Index } \\ \text { CBF } & \text { Cerebral Blood Flow } \\ \text { CI } & \text { Confidence Interval (95\%) } \\ \text { COOP/WONCA } & \text { charts/questionnaire for quality of life assessment } \\ \text { CPP } & \text { Cerebral Perfusion Pressure } \\ \text { CRF } & \text { Case Record Form } \\ \text { CT } & \text { Computed Tomography } \\ \text { DM } & \text { Diabetes mellitus } \\ \text { EMCR } & \text { Erasmus Medical Center Rotterdam } \\ & \text { (Formerly known as University Hospital Rotterdam) } \\ \text { EQ-5D } & \text { EuroQoL 5 dimensions, health questionnaire } \\ \text { FCM } & \text { Friction Cost Method } \\ \text { HCA } & \text { Human Capital Approach } \\ \text { HRQDL } & \text { Health Related Quality of Life } \\ \text { ICH } & \text { Intracerebral hematoma } \\ \text { ICP } & \text { Intracranial Pressure } \\ \text { ICU } & \text { Intensive Care Unit } \\ \text { IVH } & \text { Intraventricular hematoma } \\ \text { GCS } & \text { Glasgow Coma Scale } \\ \text { GOS } & \text { Glasgow Outcome Scale } \\ \text { CRF } & \text { Clinical Record Form } \\ \text { MIS } & \text { Minmaly Invasive Surgery } \\ \text { MRI } & \text { Magnetic Resonance limaging } \\ \text { MRS } & \text { modified Rankin Scale or Oxford Handicap Scale } \\ \text { MT } & \text { Medical (conservative) Treatment } \\ \text { NIHSS } & \text { National Institutes of Health Stroke Scale } \\ \text { ns } & \text { Non significant (statistically) } \\ \text { OR } & \text { Odds Ratio } \\ \text { PTT } & \text { Partial Thromboplastine Time } \\ \text { PPP } & \text { Quality Adjusted Life Years } \\ \text { QALY } & \text { recombinant tissue Plasminogen Activator } \\ \text { rtPA } & \end{array}$


$\mathrm{SD}$

SF-36

SICHPA

SS-QoL

SSS

STEREO

TLA

UHU

UTHR

UHM

UMCU

UNCL

USUAL
Standard Deviation

Short Form Health Survey 36 items

Stereotactic Treatment of Intracerebral Hematoma

by means of a Plasminogen Activator

Stroke Specific Quality of Life

Scandinavian Stroke Scale or Stroke Severity Scale

SICHPA trial intervention-group (stereotactic treatment)

Transient Ischemic Attack

University Hospital Utrecht

University Hospital Rotterdam ('Dijkzigt')

University Hospital Maastricht

University Medical Center Utrecht

(Formerly known as University Hospital Utrecht)

University Neurosurgical Center Limburg

SICHPA trial control group (conservative treatment) 



\section{CONTENTS}

Abbreviations 6

Chapter 1. General introduction $\quad 11$

Chapter 2. Stereotactic treatment of Intracerebral Hematoma by means of a Plasminogen Activator: A multicenter randomized controlled trial (SICHPA) 19

Chapter 3. Stereotactic thrombolysis and aspiration of primary intracerebral hemorrhage: hematoma volume reduction and its effects on functional outcome. Results from the SICHPA trial. $\quad 37$

Chapter 4. Early hematoma enlargement and rebleeding in intracerebral hemorrhage: analysis of prognostic factors in relation to stereotactic aspiration with the use of urokinase. $\quad 57$

Chapter 5. Cost and quality of life in intracerebral hemorrhage patients: an economic evaluation of the SICHPA study. $\quad 79$

Chapter 6. Meta Analyses in treatment of spontaneous supratentorial intracerebral hematoma. $\quad 105$

Chapter 7. General discussion 125

Chapter 8. Summary 133

Samenvatting 139

Appendix to chapter $6 \quad 147$

Acknowledgments $\quad 149$

Dankwoord 151

Curriculum Vitae $\quad 153$ 

CHAPTER 1

\section{GENERAL INTRODUCTION}


Stroke is a disease with a high impact on both society and the individual. It is a common disease with an annual incidence of first-ever stroke in the general population in the Netherlands of around 150 per 100,000 , even higher in the elderly: almost 700 per 100,000 in patients aged between 65 and 74 years and 1,600 per 100,000 in those aged over 74 years $(1,2)$. It ranks third as a cause of death in the western world and it is one of the most important causes of enduring disability $(1,3)$, often seriously affecting the patient's quality of life (4). The costs of stroke are enormous (5), estimated at $3 \%$ of total health care expenses in western countries (6). Because of the aging population in most western countries, it is expected that stroke incidence numbers will rise (7-9) as will the costs to society in the near future (10) .

Stroke is not a homogeneous disease-entity; apart from the entity subarachnoid hemorrhage ( $\mathrm{SAH}$ ), it can be divided into two subgroups: ischemic stroke (infarction) and hemorrhagic stroke (intracerebral hemorrhage; ICH). With a world wide incidence of 10 to 20 per $100,000(11,12), I C H$ accounts for 10 to 15 percent of all cases of stroke (13-15). It is twice as common as $\mathrm{SAH}(13)$. It has a higher mortality rate of $23 \%-58 \%$ at six months, which is twice that of ischemic stroke, it often leads to severe disability (16-22), and the lifetime costs are higher (23). Although a lot of research has been done on ischemic stroke, with more than 350 randomized clinical therapeutic trials (24) only a few small randomized trials address the issue of treatment of intracerebral hemorrhage (25-3I). Meta analyses have shown that neither medical nor surgical treatment conclusively benefit the patients with intracerebral hemorrhage (32-34).

ICH is classified as either primary or secondary, depending on its underlying cause. Primary ICHs which are the more frequent $(78 \%-88 \%)$, are caused by the rupture of a small penetrating vessel afflicted by the effects of chronic hypertension. Hemorrhages caused by the rupture of small vessels affected by amyloid angiopathy (13) are also included in the primary ICH category. Secondary ICHs are related to vascular pathology (arteriovenous malformations, aneurysms), neoplasms, coagulopathy (drug-induced or otherwise), or substance abuse (alcohol, cocaine) $(35,36)$. Primary ICH occurs most often in the putamen $( \pm 35 \%)$, lobar $( \pm 30 \%)$, cerebellum $( \pm 15 \%)$, thalamus $( \pm 10 \%)$, pons $( \pm 5 \%)$ or caudate $( \pm 5 \%)(37-39)$ and can be accompanied by a ventricular extension of the hemorrhage (IVH). Amyloid angiopathy induced hemorrhages are most frequent in the cerebral lobes, and are often referred to as 'lobar hematomas".

ICH creates a mass lesion in the brain, spreading between the planes of white matter cleavage, which is surrounded by an area of hypoperfused, edematous parenchyma, characterized by neuronal damage, and an inflam- 
matory reaction with invasion of neutrophils and macrophages. It is assumed that most of the perihematomal ischemic damage, caused mechanically at the time of bleeding, is irreversible $(40,41)$. Part of the ischemic damage and the edema adjacent to the ICH may be secondary, and probably due to the coagulation degradation products, especially thrombin, arising from the ICH clot $(42,43)$. A relationship between ICH volume and prognosis is biological plausible, larger ICH volumes are likely to cause more extensive brain tissue damage: firstly by greater anatomical disruption in the primary injury, and secondly by increasing intracranial pressure which can result in reduced cerebral perfusion pressure (CPP) and cerebral blood flow (CBF) (44, 45). There are however, also findings suggesting that $\mathbb{C}$ CH may be sumounded by ischemic damage without changes in CPP $(46,47)$. Thirdly, larger hematomas are more likely to cause late necrosis because of their greater quantity of neurotoxic degradation products.

A deterioration in the level of consciousness within one day post-stroke occurs in $25 \%$ of the patients who are initially alert. Most of them have large ICHs with intraventricular extension of the hemorthage. Expansion of the $\mathrm{ICH}$ is the most common cause of neurological worsening $(33,48,49)$. Deterioration one day post-stroke is related to increasing cerebral edema (49), as is late deterioration (second to third week post-stroke) (50).

Surgical treatment (evacuation by open craniotomy) of $1 \mathrm{CH}$ is recommended in young patients with a moderate or large lobar hemorrhage who are deteriorating clinically (24). This recommendation is supported by levels of evidence ranging from II (randomized trials with high false-positive and low false-negative errors) to $\mathrm{V}$ (data from anecdotal case series). There is no clear evidence that surgical evacuation is better than conservative treatment alone (32-34), and therefore in daily practice a grey area of uncertainty remains in deciding whether or not to operate on an ICH patient $(32,51-53)$.

Surgery by means of a craniotomy has the disadvantage that it causes further traumatization of an already compromised brain. Minimally invasive surgery, like stereotactical ICH clot aspiration and liquefaction with fibrinolytic agents has been drawing more attention over the last decades as a viable surgical alternative. In preliminary studies this method showed a significant mass reduction of the lesion, and a marked reduction of perihematomal edema (54). Investigators using various CT-guided aspiration techniques (with and without the use of thrombolytic agents) have reported average aspiration rates ranging from $30 \%$ to $90 \%$, with rebleeding rates ranging from $0 \%$ to $10 \%$ (24). Definite clinical proof of increased survival or improvement of outcome has however not yet been demon. strated. There are no data on the costs from a societal perspective of surgical intervention compared to best medical treatment. 


\section{CONCLUSION}

Primary intracerebral hemorrhage is a devastating disease with a high mortality, and often lasting disability in survivors. Only a small amount of research has been carried out on the treatment of $\mathrm{ICH}$, and no definite proof favoring either surgical or conservative treatment has so far been provided. Little is known about the costs and deleterious side-effects of surgical treatment. There is therefore a definite need for randomized controlled trials, and given the above-mentioned considerations, especially trials in which a minimally invasive surgical technique (being theoretically the least harmful option) is investigated would be especially welcome. From 1996 to 1999 the SICHPA trial (Stereotactic treatment of Intracerebral Hematoma by means of a Plasminogen Activator), a multicenter, randomized, controlled trial (55, 56) compared the efficacy of stereotactic neurosurgical treatment involving urokinase to usual, best conservative medical care in spontaneous supratentorial ICH patients. The patient population used in the trial consisted of those with a supratentorial primary intracerebral hemorrhage while patients on anticoagulants were also allowed to be included.

Chapter 2 describes the SICHPA trial and addresses the primary outcome measures: Does the stereotactically guided thrombolysis and aspiration of ICH lead to a lower mortality and morbidity rate at six months post-stroke?

Chapter 3 is concerned with the question whether the stereotactic clot-Iysis and evacuation method effectively reduces ICH volume, and whether volume reduction in itself is associated with a more favorable clinical outcome.

In Chapter 4 , the issue of rebleeding as potentially the most harmful side-effect of a surgical technique using thrombolytic agents is addressed.

Chapter 5 evaluates the question whether the SICHPA method is associated with higher costs (from a societal perspective), and how costs relate to quality of life and functional outcome at six months post-stroke.

Chapter 6 reviews all available evidence from the literature (including the results of the SICHPA trial, as the results of this trial were inconclusive, probably due to small patient numbers). The literature is systematically reviewed according to methodological quality, which is assessed with a disease-specific criteria list, and selected studies are pooled in a meta-analysis. The outcome of the analysis is compared to those of available meta-analysis (which use generic-criteria lists). 


\section{REFERENCES}

1. Reirsma JB, Konings-Dalstra JAA. Hart-en vaatziekten in Nederland 1999 , cijfers over ziekte en sterfte. The Hague: Nederlandse Hartstichting; 1999.

2. Herman B, Leyten AC, van Luijk JH, Frenken CW, Op de Coul AA, Schulte BP. Epidemiology of stroke in Tilburg the Netherlands. The population-based stroke incidence register: 2 . Incidence, initial clinical picture and medical care, and three-week case fatality. Stroke 1982;13(5):629-34.

3. Bogousslavsky I, Kaste M, Skyhoj Olsen T. Hacke W. Orgogozo JM. Risk factors and stroke prevention. European Stroke Initiative (EUSD. Cerebrovasc. Dis. 2000,10 Suppl 3:12-21.

4. de Haan R, Limburg M, van der Meulen J. Jacobs HM, Aaronson NK. Quality of life after stroke. Impact of stroke type and lesion location. Stroke 1995;26(3):402-8.

5. Payne KA, Huybrechts KF, Caro JJ, Green TJC, Klittich WS. Long term cost-of-illness in stroke: an international review. Pharmacoeconomics 2002;20(12):313-25.

6. Evers $S M$, Goossens $M E$, Ament $A$, Maarse IA. Economic evaluation in stroke research. An introduction. Cerebrovasc. Dis. 2001;11 (2);82-91.

7. Struijs JN, van Genugten MLL, Evers SMAA, Ament AJHA, Jager JC. Scenarioonderzoek naar het zorggebruik en de kosten van de zorg van CVA patiënten in Nederland tot en met het jaar 2015. Bilthoven: RIVM rapport $\$ / 280751001 / 2001$; 2001 .

8. Struijs IN, van Genugten MLL, Evers SMAA, Jager JC. Puture prevalence and costs of stroke in the Netherlands. In: 16 th Annual Meeting of the International Society of Technology Assessment in Health Care; 2000; The Hague, The Nerherlands; 2000. p. 99.

9. Lodder J. Bouter LM. Future numbers of patients with a cerebrovascular accident in The Netherlands. Ned. Tijdschr. Geneeskd. 1992;136(9):425-8.

10. Meerding WJ, Bonneux L, Polder JJ, Koopmanschap MA, van der Maas PJ. Demographic and epidemiological determinants of healthcare costs in Netherlands: cost of illness study. BMJ 1998:317(7151):111-5.

11. Furlan AI, Whismant JP, Elveback LR. The decreasing incidence of primary intracerebral hemorrhage: a population study. Ann. Neurol, 1979:5(4):367-73.

12. Broderick JP, Brott T, Tomsick T, Huster $G$, Miller R. The risk of subarachnoid and intracerebral hemorrhages in blacks as compared with whites. N. Engl. I. Med. 1992,326011):733-6.

13. Broderick JP, Brott $T$, Tonsick T, Miller R, Huster $G$. Intracerebral hemonhage more than twice as common as subarachnoud hemorrhage. 1. Neurosurg. 1993;78(2): $188-91$.

14. Sacco RL, Boden-Albala B, Gan R, Chen X, Kargman DF, Shea S, Paik MC, Hauser WA, Stroke incidence among white, black, and Hispanic residents of an urban community: the Northern Manhattan Stroke Study. Am. I. Epidemiol. 1998;147(3):259-68.

15. Voelker JL, Kaufman HH. Intraparenchymal hemorrhage. New Horiz. 1997:5(4): $342-51$.

16. Tuhrim S, Horowitz DR, Sacher M, Godbold JH. Validation and comparison of models predicting survival following intracerebral hemorrhage. Crit. Care Med. 1995;23(5):950-4.

17. Sacco RL, Wolf PA, Kannel WB, McNamara PM. Survival and recurrence following stroke. The Framingham study. Stroke 1982;13(3):290-5. 
16. Ojemann RG, Heros RC. Spontaneous brain hemorhage. Stroke 1983; ]4(4):468-75.

19. Lisk DR, Pasteur W, Thoades H, Punam RD, Grotta JC. Early presentation of hemispheric intracerebral hemormage: prediction of outcome and guidelines for treatment allocation. Neurology $1994 ; 4(1): 133-9$.

20. Karnik $R$, Valentin $A$, Ammerer HP, Hochfelner $A$, Donath $P$, Slany J. Outcome in patients with intracerebral hemorthage: predictors of survival. Wien. Klin. Wochenschr. 2000;112(4):169-73.

21. Jorgensen HS, Nakayama H, Raaschou HO, Olsen TS. Intracerebral hemorrhage versus infarction: stroke severity, risk factors, and prognosis, Ann. Neurol. $1995 ; 38(1): 45-50$.

22. Broderick JP, Brott TG, Duldner JE, Tomsick T, Huster G. Volume of intracerebral hemorhage. A powerful and easy-to-use predictor of 30 -day mortality. Stroke $1993 ; 24(7): 987-93$.

23. Taylor TN, Davis PH, Tomer IC, Holmes I, Meyer JW, Jacobson MF. Lifetime cost of stroke in the United States. Stroke 1996:27(9):1459-66.

24. Broderick JP, Adams HP, Ir., Barsan W, Feinberg W, Feldmann E, Grotta I, Kase C, Krieger D, Mayberg M, Tilley B, Zabramski JM, Zuccarello M. Guidelines for the management of spontaneous intracerebral hemorrhage: A statement for healthcare professionals from a special writing group of the Stroke Council, American Heart Association. Stroke 1999;30(4):905-1.5.

25. Auer LM. Ultrasound stereotaxic endoscopy in neurosurgery. Acta Neurochir. Suppl. (Wien). 1992;54:34-41.

26. Batjer HH, Reisch JS, Allen BC, Plaizier LS, Su CJ. Failure of surgery to improve outcome in hypertensive putaminal hemorrhage. A prospective randomized trial. Arch. Neurol. 1990;47(10):1103-6.

27. Juvela $S$, Heiskanen O, Poranen A, Valtonen S, Kuume T, Kaste M. Troupp H. The treatment of spontaneous intracerebral hemorrhage. A prospective randomized trial of surgical and conservative treatment. J. Neurosurg. 1989;70(5):755-8.

28. Morgenstern LB, Frankowski RF, Shedden P, Pasteur W, Grotta JC. Surgical treatment for intracerebral hemorrhage (STICH); a single-center, randomized clinical trial. Neurology 1998;51 (5):1359-63.

29. Zuccarello M, Brott T, Derex L, Kothari R, Sauerbeck L, Tew J, Van Loveren H, Yeh IIS, Tomsick $T$, Pancioli $A$, Khoury J, Broderick J. Early surgical treatment for supra* tentorial intracerebral hemorthage: a randomized feasibility study. Stroke 1999; $30(9): 1833-9$.

30. Tan SH, Ng PY, Yeo TT, Wong SH, Ong PL, Venketasubramanian N. Hypertensive basal ganglia hemorthage: a prospective study comparing surgical and nonsurgical management. Surg. Neurol. 2001;56(5):287-92; discussion 292-3.

31. McKissock W RA. Primary intracerebral haemorthage: a controlled trial of surgical and conservative treatment in 180 unselected cases. Lancet 1961:2:221-226.

32. Femandes HM, Gregson B, Siddique $S$, Mendelow AD. Surgery in intracerebral hemornthage. The uncertainty continues. Stroke $2000 ; 31$ (10):2511-6.

33. Hankey G], Hon C. Surgery for primary intracerebral hemorrhage: is it safe and effective? A systematic review of case series and randomized trials. Stroke 1997;28(11): $2126-32$.

34. Prasad K, Shrivastava A. Surgery for primary supratentorial intracerebral haemorwhage. Cochane Database Syst Rev 2000;2. 
35. Weisberg LA. Computerized tomography in intracranial hemorthage. Arch. Neurol. $1979,36(7): 422-6$.

36. Kase CS. Intracerebral haemornage. Baillienes Clin. Neurol 1995;4(2):247-78.

37. Freytag $E$. Fatal hypertensive intracerebral haematomas: a survey of the pathological anatomy of 393 cases. J. Neurol. Neurosurg. Psychiatry 1968;31 (6):616-20.

38. Foulkes MA, Wolf PA, Price TR, Mohr JP, Hier DB. The Stroke Data Bank: design, methods, and baseline characteristics. Stroke 1988;19(5):547-54.

39. Paillas IE, Alliez B. Surgical treatment of spontaneous intracerebral hemorhage. Immediate and long-term results in 250 cases. J. Neurosurg. 1973;39(2):145-51.

40. Sinar EI, Mendelow AD, Graham DI, Teasdale GM. Experimental intracerebral hemorrhage: effects of a temporary mass lesion. J. Neurosurg 1987;66, (4):568-76.

41. Mendelow AD. Mechanisms of ischemic brain damage with intracerebral hemorrhage. Stroke 1993;24(12 Suppl):1115-7; discussion 1118-9.

42. Xi G, Wagnen KR, Keep RF, Hua Y, de Courten-Myers GM. Broderick JP. Brott TG, Hoff JT, Muizelaar JP. Role of blood clot formation on early edema development after experimental intracerebral hemornage. Stroke 1998;29(12):2580-6.

43. Lee EI, Hung YC, Lee MY. Early alterations in cerebral hemodynamics, brain metabolism, and blood-brain barrier permeability in experimental intracerebral hemorrhage. J. Neurosurg. 1999;91(6):1013-9.

44. Nath FP, Jenkins A, Mendelow AD, Graham DI, Teasdale GM. Early hemodynamic changes in experimental intracerebral hemorrhage. J. Neurosurg 1986;65(5):697703.

45. Yang GY, Betz AL, Chenevert TL, Brumberg JA, Hoff JT. Experimental intracerebral hemorrhage: relationship between brain edema, blood flow, and blood-brain barrier permeability in rats. J. Neurosurg. 1994;81 (1):93-102.

46. Kingman TA, Mendelow AD, Graham DI, Teasdale GM. Experimental intracerebral mass: description of model, intracranial pressure changes and neuropathology. I. Neuropathol. Exp. Neurol. 1988;47(2):128-37.

47. Mayer SA, Thomas CE, Diamond BE. Asymmetry of intracranial hemodynamics as an indicator of mass effect in acute intracerebral hemorrhage. A transcranial Doppler study, Stroke 1996;27(10;:1788-92.

48. Qureshi AI, Safdar K, Weil I, Barch C, Bliwise DI, Colohan AR, Mackay B, Frankel MR. Predictors of early deterioration and mortality in black Americans with spontaneous. intracerebral hemorrhage. Stroke 1995;26(10):1764-7.

49. Mayer SA, Sacco RL, Shi $T$, Molhr JP. Neurologic deterioration in noncomarose patients with supratentorial intracerebral hemornage. Neurology 1994:44(8):137984.

50. Zazulia AR, Diringer MN, Derdeyn CP, Powers WT. Prognession of mass effect after intracerebral hemorrhage. Stroke 1999;30(6):1167-73.

51. Fernandes HM, Mendelow AD. Spontaneous intracerebral haemorrhage: a surgical dilemma. Br. J. Neurosurg. 1999;13(4):389-94.

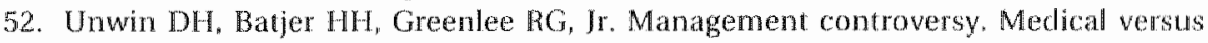
surgical therapy for spontaneous intracerebral hemorthage. Neurosurg. Clin. N. Am. $1992,3(3), 533-7$.

53. Ojemann RG. Spontaneous brain hemorthage: what treatment should we recommend? Stroke $1983 ; 14(4): 467$. 
54. Wagner KR, Xi G, Hua X, Zuccarello M, de Courten-Myers GM, Broderick JP, Brott TG. Uha-early chot aspiration after lysis with vissue plasminogen activator in a porcine model of intracerebal hemorthage: edema reduction and blood brain barrier protection. J. Neurosurg. 1999;90(3):491-8.

55. Teernstra OPM, Evers SMAA, Lodder J, Leffers P, Franke CL, Blaauw G. Stereotactic treatment of Intracerebral Hematoma by means of a Plasminogen Activator: A multicenter randomized controlled trial (SICHPA). Stroke, accepted 2002.

56. Blaauw $G$, Eivers $S$, Franke $C$, Leffers $P$, Lodder J, Teernstra O. Effectiviteit van behandeling van het niet-aneurysmatische, spontane, supratentoriele, intracerebrate hematoom. Ned Tijdschr Neurol 2000;6:418-421. 


\section{Stereotactic treatment of Intracerebral Hematoma by means of a Plasminogen Activator: A multicenter radomized controlled trial (SICHPA)}

O.P.M.Teemstra ${ }^{1}$, S.M.A.A Evers ${ }^{1,2}, 1$. Lodder ${ }^{3}$, P. Leffers ${ }^{4}$, C.L. Franke ${ }^{5}$, G. Blaauw

Dept of Neurosurgery ${ }^{1}$ and Neurology ${ }^{3}$, University Hospital Maastricht, Dept of Neurosurgery ${ }^{1}$ and Neurology ${ }^{5}$ Atrium Medical Center Heerlen, Dept of Health Organization Policy and Economics ${ }^{2}$ and Dept of Epidemiology University of Maastricht ${ }^{4}$, The Netherlands. 


\section{ABSTRACT}

Introduction. Treatment of Intracerebral Hematoma (ICH) is controversial. Advantage of a neurosurgical intervention over conservative treatment of ICH has not been established. Recent reports suggest a favorable effect of stereotactic blood clot removal after liquefaction by means of a plasminogen activator. The SICHPA trial aimed at investigating the efficacy of this treatment.

Methods. A stereotactically placed catheter was used to instill urokinase to liquefy and drain the ICH at 6-hour intervals over 48 hours. From 1996 to 1999, thirteen centers entered 71 patients into the study. Patients were randomized into a surgical group $(n=36)$ and a non-surgical group $(n=35)$ Admission criteria were: age $>45$ years, spontaneous supratentorial $1 \mathrm{CH}$, Glasgow EM score ranging from 2 to 10 , ICH volume $>10 \mathrm{ml}$, treatment within 72 hours. Primary endpoint was death at 6 months. As secondary endpoints $1 \mathrm{CH}$-volume reduction and overall outcome measured by the modified Rankin Scale (mRS) were chosen. The trial was prematurely stopped due to slow patient accrual.

Results. Seventy patients were analyzed. Overall mortality at day 180 post-stroke was $57 \% ; 20$ of $36(56 \%)$ in the surgical group and 20 of 34 patients (59\%) in the non-surgical group. A significant ICH volume reduction was achieved by the intervention $(10-20$ percent, $\mathrm{p}<0.05)$. Logistic regression analysis indicated the possibility of efficacy for surgical treatment (OR: $0.23, \mathrm{Cl} 0.05-1.20, \mathrm{p}=0.08$ ). The Odds Ratio of mortality combined with mRS 5 at 180 days was also not statistically significant (OR: 0.52, CI 1.2-2.3, $\mathrm{p}=0.38)$.

Conclusions. Stereotactic aspiration can be performed safely and in a relatively uniform manner; it leads to a modest reduction of $18 \mathrm{ml}$ of hematoma reduction over 7 days when compared to control, which experiences a $7 \mathrm{ml}$ reduction, and therefore may improve prognosis. 


\section{INTRODUCTION}

Primary Intracerebral Hematoma is associated with a high mortality and severe disability. The treatment of choice is still controversial and may be surgical or non-surgical (conservative) $(1-8)$. Theoretically, clot removal is beneficial because it reduces hemorrhage volume (9-11) may therefore also lower intracranial pressure (12), and reduce the chance of edema formation and improve perfusion in the affected hemisphere (13-16). The effect on perifocal ischemia resulting from hypoperfusion is unclear, as such an ischemia itself is refuted by a recent publication (17).

Secondary enlargement of the hematoma (18-20) and neurotoxic edema due to high levels of thrombin and blood degradation products (21-23) also may be reduced by clot removal. However, a classical open craniotomy may further traumatize brain tissue, and there is no unequivocal evidence that it reduces mortality (24). Minimally invasive surgery (MIS) combines benefits of surgical clot removal with limited tissue damage and shorter surgery duration with the possibility to use local anesthesia. Ultrasound-guided endoscopic clot removal, tested in a clinical randomized trial by Auer et al., suggested improved outcome after MIS (25).

An even less invasive MIS technique is the use of plasminogen activator aiming at clot-lysis. Recently a number of case studies and 4 small trials (26-29) suggested improved survival with this approach. Zuccarello et al. treated four patients with MIS all with good effect $(0 \%$ mortality, all with good recovery at three months), Miller et al. reported on four patients that had deep hemorrhages with favorable results (mean GCS score rise of 6 points with a clot volume reduction of $72.7 \%$ at 48 hours). Montes et al. treated 12 patients ( $25 \%$ mortality and $25 \%$ good recovery at six months) and Rhode et al. observed an ICH volume reduction from 52 to $17 \mathrm{ml}$ within two days in 24 out of 27 patients. To test the hypothesis that Stereotactic treatment of Intracerebral Hematoma by means of a Plasminogen Activator (SICHPA) improves survival and functional outcome the present study was carried out as a randomized multicenter trial.

\section{METHODS}

\section{Patient selection}

Between March 1996 and May 1999, patients with a primary supratentorial intracerebral hemorrhage (from here on abbreviated as $1 \mathrm{CH}$ ), including those on anticoagulants were enrolled in the trial. Inclusion criteria were 
based on a Dutch study on prognosis in ICH (30). They were designed to select a relatively uniform group with an expected mortality of $88 \%$ (when applied to Franke's study population) in order to maximize the chance to detect a treatment effect. Before enrollment all patients had CT scanning for ICH localization and volume estimation. Patients had to be 45 years or older, have an ICH volume exceeding $10 \mathrm{ml}$ and a Glasgow Eye Motor score between 2 and 10 (the verbal score was left out as it is unrevealing in dominant hemisphere lesions), at least one pupil reactive to light and a normal coagulative status (corrected if necessary). Furthermore, surgery within 72 hours after ICH onset had to be possible. The study was in advance approved by the institutional review committees of all participating centers. Before inclusion, a written informed consent had to be obtained from the patient or closest kin. Most participating centers referred the ICH patient directly to a neurosurgical unit where the attending neurosurgeon handled the inclusion procedure. Otherwise, the attending neurologist consulted the neurosurgean on eligibility for potential drainage. An independent external agency was contacted by phone for verification of inclusion criteria and treatment allocation. Patient data were forwarded to the trial office by fax. Eight separate treatment random allocation lists were used based on pre-stratification on GCS $(<9 \geq 10)$. In each list block sizes of two and four in random order were used.

\section{Data collection}

At predesigned intervals during 180 days of follow up, attending physicians and nursing staff filled out Clinical Record Forms (Table 1). These were then sent to the trial office, where the data were entered into a database. On admission the following baseline patient characteristics were recorded: history of "stroke' (a history of TLA and/or stroke), history of 'hypertension,' 'diabetes'(31), 'cardiologic history' (ischemic heart disease, heart failure or cardiac arrhythmias) and history of 'hemorrhagic diathesis' (easy bruising, frequent nosebleeds, epistaxis etc.(32)). Use of 'anticoagulants' (aspirin, warfarims and heparin(33)) on admission was recorded. Laboratory tests were performed to ascertain 'abnormal haemostatic parameters' (low platelet count $\left(<50 \times 10^{9} / \mathrm{L}\right.$ ) and/or aPTT $>50 \mathrm{sec}$ and/or PTT $>11 \mathrm{sec}$.). In addition Glasgow Coma Scale, pupil size and reactivity and blood pressure were recorded. The ICH volume was estimated using a validated practical rule of thumb $(\mathrm{ABC} / 2$ where $\mathrm{A}=$ biggest diameter, $\mathrm{B}=$ diameter at 90 degrees from $A$ and $C=$ number of slices times slice thickness, the presence of intraventricular hemorrhage (IVH) was not included in the equation (34)). This method was checked by comparing its results with results from seven 
Table 1. Patient evaluation during Follow-up

\begin{tabular}{ll}
\hline Test & Time post-stroke (days) \\
\hline CT-scanning & $1,3,7$, \\
Glasgow Coma Scale (GCS) & 1,3 \\
Scandinavian Stroke Scale (SSS) & $1,3,7,14,30,90,180$ \\
Barthel Index (BI) & $3,7,14,30,90,180$ \\
Modified Ramkin Score (mRS) & $30,90,180$ \\
\hline
\end{tabular}

scans whose volumes were calculated on the CT-scanner itself. The 'ABC/2'-measurements were done twice for all the CT-scans by the same individual.

To measure stroke severity the Glasgow Coma Scale (GCS) and the Scandinavian Stroke Scale (SSS, a neurological impairment scale also known as Stroke Severity Scale) were used. Functionall outcome was measured using the Barthel Index ( $\mathrm{BI}$, a disability score) and the modified Rankin Score (mRS, also known as the Oxford handicap scale) (35). Data on various modalities of supportive medical care were recorded (36) (use of drugs: anti-hypertension, anti-arrhythmic, inotropics, steroids, antibiotics, heparins, anti-epileptic, barbiturates and hyperosmolar solutions, also: mechanical ventilation, mild hyperventilation, ventricular drainage and intracranial pressure measurement), as were complications such as convulsions, infections etc. Death, rebleeding and violations of the trial protocol were also recorded and immediately reported to the investigators and monitoring committee, which consisted of an epidemiologist, a neurologist, and a neurosurgeon. Date and cause of death were registered.

Adherence to the trial protocol was evaluated by regular visits of the trial coordinators to the participating centers. During these visits the Case Record Form (including imaging) of all included patients were checked against the patient files for completeness and accuracy. At regular intervals the monitoring committee verified all Case Record Forms (For a copy of the Case Record Form please contact the first author).

\section{Intervention}

Patients in the surgical group were transported by ambulance to one of the four participating neurosurgical centers: University Neurosurgical Center Limburg (UNCL), Amsterdam Medical Center (AMC), Erasmus Medical Center Rotterdam (EMCR), and University Medical Center Utrecht (UMCU). A catheter (PS Medical: $35 \mathrm{~cm} 1.5 / 2.8 \mathrm{~mm}$ inner/outer diameter) was stereotactically placed in the center of the hematoma and as much blood as 
possible was aspirated, 5000 IU urokinase were injected, after which the drain was sealed (37). Internationally between 5000 and 10,000 IU are used in these procedures, $5000 \mathrm{IU}$ was chosen to be 'on the safe side.' After 6 hours the catheter was unsealed and with gentle suction a much as possible (until a light resistance was felt) of the liquefied hematoma was aspirated. Then $5000 \mathrm{IU}$ urokinase dissolved in $1 \mathrm{ml} \mathrm{NaCl} 0.9 \%$ were injected via the catheter, which was subsequently flushed with $1 \mathrm{ml} \mathrm{NaCl} 0.9 \%$ after which it was clamped. After every procedure the aspirated volume was recorded. This evacuation and urokinase injection procedure was performed eight times at six-hour intervals over a period of 48 hours, before the catheter was removed. Epsilon aminocapron acid was allowed to be administered $(0.1$ $\mathrm{mg} / 10 \mathrm{ml}$ hematoma) in case of rebleeding (this was never actually done). ICP measurement was not a standard procedure in our protocol.

Patients in the non-surgical group received standard supportive medical care in the neurological center where they had been initially admitted. Most patients were returned to their referring clinic some time after surgery.

\section{Outcome measures and statistical analysis}

The number of patients needed in each trial arm was estimated at $75(\alpha=0.05$ and $\beta=0.10$ ), assuming a mortality reduction at 6 months from $88 \%$ ( 30 ) in the conservative group to $53 \%$ in the surgical group. Although the analysis was performed based on the 'intention to treat' principle an additional protocol analysis was carried out to test for discrepancies. Statistical significance expressed as $\mathrm{p}<0.05$, is always measured two-tailed. Primary endpoint was death at 6 months. As secondary endpoints, ICH-volume reduction and overall outcome measured by the modified Rankin Scale (mRS) were chosen. Differences between both groups in treatment modalities, complications, and $1 \mathrm{CH}$ volumes on day 1,3 and 7 , were compared with a Mann Whitney U-test. Because the trial-protocol allowed for treatment up to 72 hours after the stroke, we also checked for imbalances between treatment groups in timing of randomization, surgery and CT scanning. Functional outcome in modified Rankin Scale (mRS) scores from 0 to 5 plus death (6) at day 180 post stroke were compared using a Mann Whitney U-test. Survival was examined with Kaplan Meier curves and Cox regression analysis (with the same variables entered as in the logistic analysis). The effect of stereotactic aspiration on mortality and mortality combined with mRS score 5 at 180 days was analyzed using logistic regression analysis to account for imbalance in prognostic variables (38).

The regression analysis omitted seven patients with missing data, therefore decreasing the number of patients in this analysis to 63 out of 70 . All 
variables were entered dichotomized according to their median values. The protocolized logistic regression model (39) included, besides the effect parameter and the 'center of inclusion'-variable (a pre-stratification variable), only variables supposed to have a substantial influence on the outcome parameter ('Age" ( $>70$ years), 'right sided location of $1 \mathrm{CH}$,' 'GCS-score' (<10 points), 'ICH-volume' ( $>59 \mathrm{ml}$ ), "abnormal haemostatic parameters," and 'history of cardiac disease').

\section{RESULTS}

After three years of patient enrollment the trial was stopped. Seventy-one patients had been randomized, 36 to the surgical group and 35 to the non-surgical group. One patient was excluded from the study because of an arteriovenous malformation (AVM). There were nine protocol violations: one patient who had been randomized for stereotactic drainage had craniotomy instead (alive at 180 days); craniotomy was performed in one patient in the non-surgical group (alive at 180 days); one "surgical' patient died during pre-operative CT-scanning; four patients received no stereotactic drainage, two of them due to early neurological recovery (one died at the 45 th day, the other survived 180 days), a third due to fast neurological deterioration resulting in death, and the fourth was not operated upon because of suspected amyloid angiopathy (alive at 180 days). One patient died after three drainages (out of a total of nine drainages). One patient received seven drainages before the catheter broke down (alive at 180 days). Retrospectively the Intensive Care Unit (ICU) length of stay was analyzed in the UNCL, which included $48 \%$ of the patients. There was a significant difference in the ICU stay in the UNCL between the conservative (1.8 days, Standard Deviation (SD) 7.1 days) and the surgical group (3.9 days, SD 6.I days, $p=0.007$ ). This is due to standard ICU care after the stereotactic cranial surgery. To not only account for differences in ICU care, we compared all patients in both groups for different medical supportive care modalities on the whole. Supportive medical care was similar with the exception that patients in the surgical group on average received more often low molecular weight heparin and mechanical ventilation (Table 2). The latter is likely related to the stereotactic procedure. There were no statistically significant imbalances between the conservative- and stereotactic-group concerning mean time to randomization (12.5 and 12.5 hours), time to first CT-scan (9.8 and 13.2 hours), second CT-scan ( 3.1 and 3.0 days), third CT-scan ( 7.0 and 7.8 days). In one third of the surgical patients (UNCL) the time that had elapsed from the moment of stroke to actual surgery could 
Table 2. Treatment modalities and complications

\begin{tabular}{|c|c|c|c|c|c|}
\hline \multirow{3}{*}{$\begin{array}{l}\text { Treatment } \\
\text { Anti-hypertensive drugsi }\end{array}$} & \multicolumn{5}{|c|}{ Treament } \\
\hline & \multicolumn{2}{|c|}{ Non-surgical ${ }^{*}$} & \multicolumn{2}{|c|}{ Surgical } & \multirow{2}{*}{$\begin{array}{l}\text { Significance } \\
0.89\end{array}$} \\
\hline & 48.2 & $(50.9)$ & 50 & $(50.9)$ & \\
\hline Anti-arrhythmic drugs & 10.7 & $(31.5)$ & 16 & $(37.4)$ & 0.57 \\
\hline Inotropic drugs & 11.1 & $(32)$ & 4 & $(20)$ & 0.34 \\
\hline Mechanical ventilation & 10 & $(30.5)$ & 34.5 & (48.4) & 0.025 \\
\hline ICP measurement & 0 & & 0 & & \\
\hline External ventricular catheter & 0 & & 3.2 & $(18)$ & 0.33 \\
\hline Hyperosmolar infusion & 7.1 & (26.2) & 3.2 & (18) & 0.5 \\
\hline Steroids & 13.8 & $(35.1)$ & 31 & $(47.1)$ & 0.12 \\
\hline Hyperventilation & 3.5 & $(16.6)$ & 3.2 & (18) & 0.96 \\
\hline Heparin & 0 & & 0 & & \\
\hline Low Molecular Weight Heparin & 52.2 & $(51.1)$ & 77.8 & $(42.4)$ & 0.059 \\
\hline Pneumatic compression & 0 & & 0 & & \\
\hline Ant-convulsants & 6.7 & $(25.4)$ & 16.7 & $(37.9)$ & 0.23 \\
\hline Antibiotics & 62.5 & $(49,2)$ & 73.3 & $(45)$ & 0.37 \\
\hline Berzodiazepines & 21.4 & $(41.8)$ & 25 & $(44.2)$ & 0.76 \\
\hline Barbiturates & 0 & & 0 & & \\
\hline \multicolumn{6}{|l|}{ Complicarions } \\
\hline Ischemic (stroke) & 5 & $(23,6)$ & 0 & & 0.23 \\
\hline Convulsions & 7.7 & $(27.2)$ & 6.3 & $(24.6)$ & 0.83 \\
\hline Deep venous thrombosis & 0 & & 0 & & \\
\hline Pulmonary embolism & 0 & & 0 & & \\
\hline Cardiological problems & 0 & & 10 & $(30.5)$ & $0.1 \mathrm{I}$ \\
\hline Systemic embolism & 0 & & 0 & & \\
\hline Pnetumonia & 42.9 & $5(0.4)$ & 42.4 & $(50.2)$ & 0.97 \\
\hline Urinary tract infection & 40 & $(50)$ & 28.1 & $(45.7)$ & 0.35 \\
\hline Septic shock & 24 & $(43.6)$ & 20 & $(40.7)$ & 0.72 \\
\hline Decubitus & 4.2 & $(20.4)$ & 3.5 & $(18.6)$ & 0.89 \\
\hline Rebleeding & 0 & & 21.9 & (42) & 0.006 \\
\hline
\end{tabular}

* Figures represent: mean percentage (Siandard dewiation percentage); + Statistical significance (p-value) calculated by Mann Whitney U-test

be determined. With a mean of 12 hours (SD 19 hours) this was within protocol limils ( 72 hours).

Table 3 shows the baseline characteristics of the two treatment groups. Patients in the surgical group more often had a history of cardiovascular disease. They also had worse neurological scores on admission as reflected in the GCS and SSS. On average, the ICH volume was smaller in the non-surgical group, whereas deep hemorrhages and presence of intraventricular blood (IVH) were more frequent in this group. 
Table 3. Buseline characteristics

\begin{tabular}{|c|c|c|c|}
\hline & \multicolumn{3}{|l|}{ Treatment } \\
\hline & Non-surgical" & Surgical & Signilicance \\
\hline Patients & $34(49 \%)$ & $36(51 \mathrm{~g} / \mathrm{w})$ & \\
\hline Male sex & $19(56 \%)$ & $21(58 \%)$ & 0.84 \\
\hline Mean age (years) & $69(71,49-89)$ & $67(68,47-84)$ & 0.38 \\
\hline \multicolumn{4}{|l|}{ Clinical history } \\
\hline Stroke & $9(27 \%)$ & $8(22 \%)$ & 0.63 \\
\hline Hypertension & $16(47 \%)$ & $17\left(47^{8}\right)$ & 0.92 \\
\hline Diabetes mellitus & $4(12 \%)$ & $3(8 \cdot(8)$ & 0.6 \\
\hline Cardiowascular Disease & $7(21 \%)$ & $12(33 \%)$ & 0.26 \\
\hline \multicolumn{4}{|l|}{ Abnormal hemostasts } \\
\hline Anticoagulant use & $14(41 \%)$ & $9(25 \%)$ & 0.17 \\
\hline Clinical signs & $2(6 \%)$ & $7(19 \%)$ & 0.09 \\
\hline Abnormal lab tests & $2(6 \%)$ & $5(14 \%)$ & 0.27 \\
\hline \multicolumn{4}{|l|}{ Clinical condition } \\
\hline Hypertension & $21(62 \%)$ & $22(63 \%)$ & 0.93 \\
\hline GCS score (EMV) & $1.0(9,6-14)$ & $9.5(9.5,4-15)$ & 0.81 \\
\hline Scand. Stroke Scalle score 5 & $16(14,0-41)$ & $13\left(8_{0} 0-50\right)$ & 0.31 \\
\hline \multicolumn{4}{|l|}{ lmaging } \\
\hline Lobar ICH & $14(41 \%)$ & $24(67 \%)$ & 0.03 \\
\hline Right sided ICH & $14(41 \%)$ & $14(42 \%)$ & 0.97 \\
\hline Intraventricular blood & $13(38 \%)$ & $10(27 \%)$ & 0.26 \\
\hline ICH volume (mJ) & $52(49,11-132)$ & $66(73,11-126)$ & 0.03 \\
\hline
\end{tabular}

* Unless mentioned otherwise figures represent: mean (percentage); + Statistical significance ( $p$-walue) calculated by Mann Whitney of test; * Figures represent: Mean (Median, range): $\varsigma$ Minimum score is 0 and maximum 70 points

The $\mathrm{ABC} / 2$ method was compared with seven volumes measured by the CT-scanner, the mean difference was $3 \mathrm{ml}(\mathrm{SD} 6 \mathrm{ml}$ ) which was considered acceptable. A total of $158 \mathrm{ICH}$-volumes were measured twice, the intra-observer variability expressed as Kappa was 0.8 .

Protocol analysis showed that the patients in the conservatively treated group had a mean ICH volume on day 1 of $51.8 \mathrm{ml}$ (SD $32 \mathrm{mll}$ ), $52.2 \mathrm{ml}$ (SD $28.6 \mathrm{ml}$ ) on day 3 , and $42.7 \mathrm{ml}(\mathrm{SD} 24.5 \mathrm{ml}$ ) on day 7 . Patients in the stereotactically treated group had a mean ICH volume on day 1 of $65.4 \mathrm{ml}$ (SD 28.1 $\mathrm{ml}$ ), $47.5 \mathrm{ml}$ (SD $30 \mathrm{ml}$ ) on day 3 , and $44.4 \mathrm{ml}$ (SD $30.7 \mathrm{ml}$ ) on day 7 . The absolute mean volume reductions for both groups are depicted in 


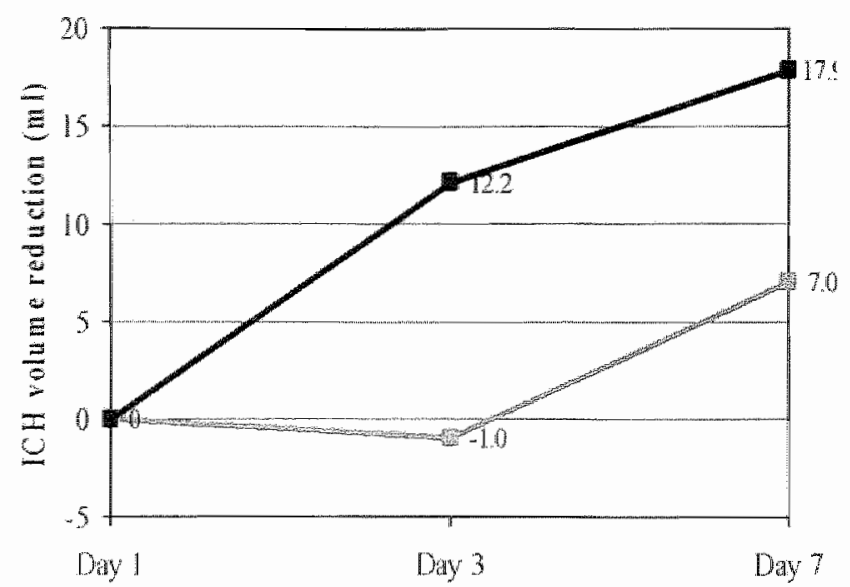

Figure 11 . Hematoma volume reduction

Stereotactic aspiration in black; Conservative treatment in gray.
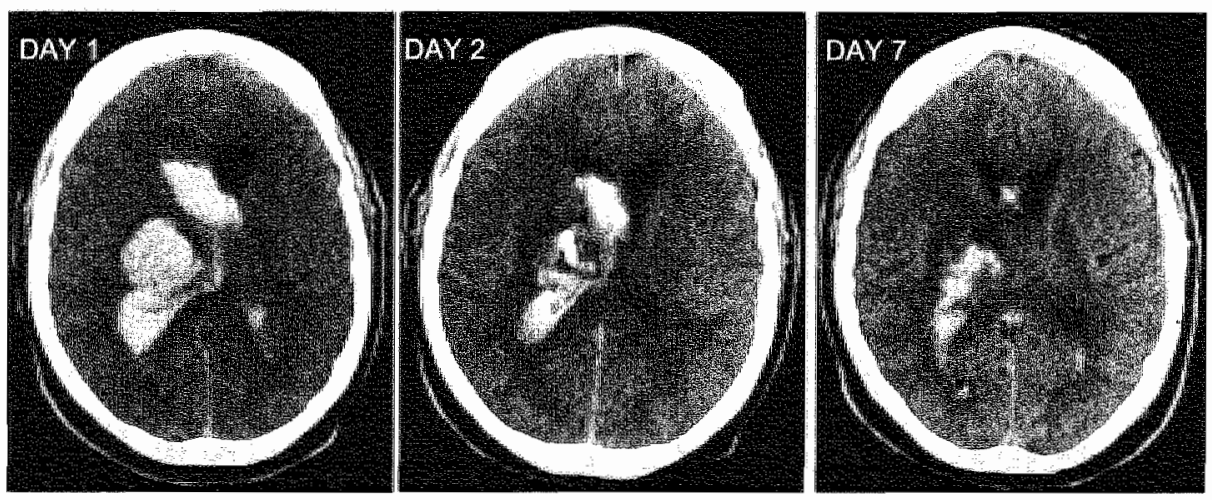

Wigure 2. Fxample of succesful stereotactic drainage

Day 1: on admission. Day 2: just before drain removal. Day 7 : 5 th day after drain removal.

figure 1 . The percentage of $I \mathrm{CH}$ volume reduction in the conservative and stereotactic group was compared with a Mann Whitney U-test. It showed significant diflerences between day 1 and day $3(-8 \%$ and $18 \%$ respectively, $p=0.012)$, and between day 1 and $7(3 \%$ and $10 \%$ respectively, $p=0.015)$. An example of a successful drainage is shown in figure 2.

Overall mortality at day 180 post-stroke was $57 \% ; 20$ of 34 patients $(59 \%)$ in the non-surgical group and 20 of $36(56 \%)$ in the surgical group. There was one missing value in the analysis of functional outcome ( $m R S$ ), leaving $n=69$ in the Mann Whitney U-test. There were no significant differences between treatment groups $(\mathrm{p}=0.7)$ (Figure 2). Kaplan Meier analysis demonstrated 


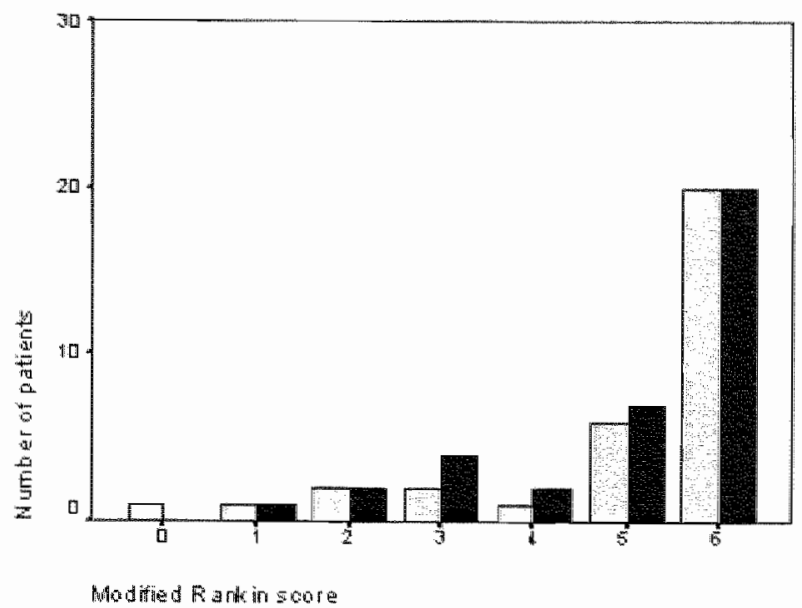

Figure 3. Frequency histogram modified rankin scale plus mortality Stereotactic aspiration in black. Conservative therapy in gray.

similar survival times between the groups $(\mathrm{p}=0.9$ in Breslow test). Cox regression failed to demonstrate a statistical difference between the groups $(\mathrm{p}=0.6)$ (Figure 3).

Apart from the effect parameter 'Stereotactic treatment' and the variable 'center of inclusion' (sub variables for each of the four neurosurgical centers), variables that were entered into the logistic analysis were: 'Age' ( $>70$ years), 'right-sided location of ICH', 'GCS-score' (<10 points), 'TCHvolume' ( $>59 \mathrm{ml}$ ), 'abnormal haemostatic parameters,' and 'history of cardiac disease.'

There was a positive effect of the stereotactic treatment in reducing mortality at 180 days with an Odds Ratio (OR) of 0.23 , but this was not statistically significant (Confidence Interval (Cl) $0.05-1.20, p=0.08$ ). Other factors in the model that had a significant effect were: 'right-sided location of ICH' (OR: $0.10, \mathrm{CI} 0.02-0.58, \mathrm{p}=0.01$ ), 'GCS-score' (<10 points) (OR: 8.24 , CI 1.50-45.23, $\mathrm{p}=0.02$ ), "ICH-volume' ( $>59 \mathrm{ml}$ ) (OR: 9.63, Cl $1.40-66.48, \mathrm{p}=0.02$ ). Because of its imbalanced distribution between the groups the variable 'lobar ICH' was separately tested with this model eventually left out because it did not contribute to the model fit and had only a slight impact on the effect parameter (OR: $0.84, \mathrm{Cl} 0.13-5.56, \mathrm{p}=0.86$ ). Mortality combined with severe handicap ( $m R S$ score 5) at 180 days yielded an OR of 0.52 , a non-significant reduction ( $\mathrm{CI} 1.2-2.3, \mathrm{p}=0.38)$. Other factors in this regression model that tumed out statistically significant were: 'Age' $>70$ years) (OR: 4.8 , CI 1.04-22.24, $\mathrm{p}=0.05$ ) and 'ICH-volume' ( $>59 \mathrm{ml}$ ) (OR: 7.07, $\mathrm{Cl} 1.24$ $-40.19, p=0.03$ ). Both models were also run without the eight protocol viola- 


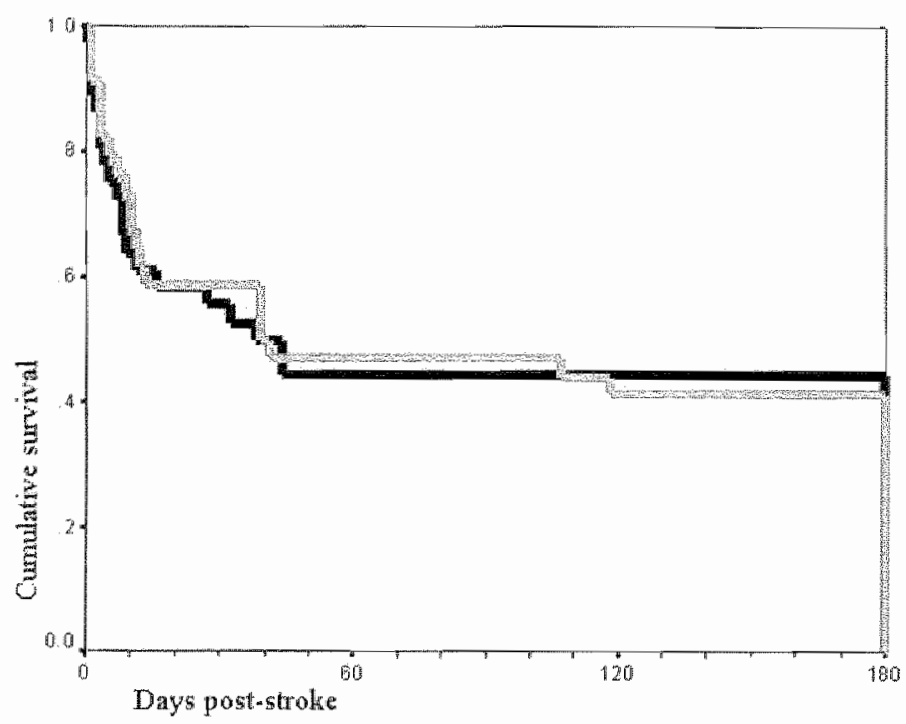

Figure 4. Kaplan Meier survival curve.

Survival is similar for both groups ( $p=0.9$ in Breslow test).

Stereotactic aspiration in black. Conservative therapy in gray.

tion cases, showing no marked changes in results (OR for Stereotactic treatment: 0.26 at $p=0.11$ and 0.35 at $p=0.23$ ). When in 7 cases missing cases values were replaced by the mean of the particular variable the Odds Ratios for stereotactic treatment changed to 0.47 at $p=0.30$ and 0.57 at $p=0.45$ respectively.

Co-morbidity figures were similar between the surgical and conservative group (Table 2). The clinical diagnosis of rebleeding was recorded in seven patients in the surgical group and none in the conservative group. In order to obtain a more uniform and systematic measure for rebleeding we investigated all patients with hematoma enlargement, coinciding with neurological deterioration. Hematoma enlargement, defined as more than ten percent volume increase at any time between CT scanning on day 1, 3 and 7 , occurred in $60 \%$ (SD 50\%) of non-surgical and 38\% (SD 50\%) in surgical patients $(\mathrm{p}=0.14)$. The $10 \%$ threshold was chosen to also include patients with slight $\mathrm{ICH}$-enlargements. Hematoma enlargement combined with neurological deterioration (defined as a more than 10\% drop in SSS-score at any time between day 1,3 and 7 ) or death within the first seven days, occurred in $17 \%$ (SD 39\%) of non-surgical and 35\% (SD 49\%) of surgical patients $(p=0.18)$. 


\section{DISCUSSION}

Although small, the SICHPA trial is up to now the largest mial on the efficacy of stereotactic treatment of primary intracerebral hemorrhage with the use of plasminogen activator. Our study showed that stereotactic aspiration can be performed safely and in a relatively uniform manner.

Next to that, stereotactic aspiration leads to an absolute reduction of 18 ml of hematoma volume over 7 days when compared to control, which experiences a $7 \mathrm{ml}$ reduction. Overall the study resulted in a relative reduction of $34 \%$ in the hematoma volume. Mortality in the intervention group decreased from the predicted $88 \%$ to $56 \%$ and to $59 \%$ in the conservative group. No statistically significant difference in mortality and morbidity at 180 days was found. The complication rate was similar between groups.

The reduction in mortality in the conservative group is difficult to explain. One reason might be a Hawthorne effect. All patients and centers in our study were monitored by both the trial coordinators and the monitoring committee at regular intervals, which might have caused an overall increase in supportive care in the trial. Another possible explanation could be the presence of an a-specific selection bias causing our patients to have amore favorable prognosis compared to those in Franke's study (30).

Compared to spontaneous resolution, stereotactic drainage combined with urokinase-induced clot-lysis significantly reduced ICH volume. Our data show that ICH volume reduction, which is assumed to be associated with lower mortality, is practically achievable by this method. However there may not be a simple relationship between ICH volume reduction, chance at rebleeding, and consequent (functional) outcome; rebleeding more often occurred in the surgical group, fewer surgical patients had hemaroma enlargement, but those who had, more often had an unfavorable outcome than conservatively treated patients with hematoma enlargement. Post-hoc analysis showed a significant association between a $25 \%$ or more volume reduction and chances for a more favorable outcome (40). As ultra-early surgery leads to a higher rate of rebleeding, timing of surgery could be an important part of its effectiveness (41), this factor however, was not included in our trial-design.

The imbalance in prognostically important variables between groups is an unfortunate result of the small number of patients enrolled. The trial was prematurely stopped for four reasons: Firstly, patient acquisition had been projected on the basis of an earlier Dutch epidemiological study , but these incidence estimates might have been too optimistic (42). Secondly, the so-called "gray area of uncertainty" (whether to operate or not(5)) that was discussed and agreed upon in advance with participating neurosurgeons, 
appeared to be much smaller in reality. Thirdly, an intention to treat interim-analysis showed a slight detrimental effect of the experimental procedure. The probability of achieving a statistically significant difference between groups by including more patients was deemed unlikely. This, preplanned interim analysis carried out for safety reasons, did not account for an imbalance in prognostic variables between groups. Finally, we were unable to secure sufficient funding to continue the trial.

Recently Becker et al. (43) pointed out that the most important variable predicting poor outcome in $\mathrm{ICH}$ patients is the level of provided medical support. Perception of futility of aggressive therapy leads to early withdrawal of medical support, which is less likely in ICH patients that are surgically treated. Mayer et al. reported that, in a neurocritical care service over a 3 -year period, of 74 non-brain-dead patients, $32(43 \%)$ were terminally extubated (44). Although in the present study both groups received the same level of supportive care, in no instance early withdrawal of supportive care was reported to the monitoring committee. Although not formally reported, there might have been a tendency to withdraw supportive care less easily in the intervention group, and therefore it is possible that the study was influenced by this potential bias.

The present trial shows that stereotactic aspiration of ICH using urokinase effectively reduces ICH volume. The method used in our trial however was less successful in the magnitude and timing of volume reduction compared to other small trials. Better potential benefits might be achieved by a greater reduction in hematoma volume over a shorter period of time. Since there is no uniform procedure in stereotactic aspiration, a phase 2 study should be initiated in which insight should be gained in the optimal dosage and time span in which urokinase should administered. However, it remains unproven if this leads to a reduction in mortality compared to conservative treatment alone. Additionally, if the phase 2 trial indicates favorable results regarding volume reduction, a large-scale phase 3 clinical trial should subsequently investigate whether ICH volume reduction definitely improves survival as well as functional outcome. To optimize patient accrual rate in a future trial, inclusion should focus on patients where open craniotomy is not preferred by most neurosurgeons, like those with a deep ICH and lowered consciousness. To avoid heterogeneity of data, uniform standards of care should be defined and apply to all patients in such a trial. 


\section{REFERENCES}

1. Unwin DH, Batjer HH, Greenlee RG, Ir. Management controversy. Medical versus surgical therapy for spontaneous intracerebral hemorrhage. Neurosurg. Clin. N. Am. $1992,3(3): 533-7$.

2. Ojemann RG. Spontaneous brain hemotrhage: what treatment should we recommend? Stroke 1983;14(4):467.

3. Kanno T, Sano H, Shinomiya Y, Katada K, Nagata I, Hoshino M, Mitsuyama F, Role of surgery in hypertensive intracerebral hematoma. A comparative study of 305 nonsurgical and 154 surgical cases. I. Neurosurg. 1984;61(6):1091-9.

4. Masdeu JC, Rubino FA. Management of lobar intracerebral hemorrhage: medical or surgical. Neurology 1984;34(3):381-3.

5. Fernandes HM, Mendelow AD. Spontaneous intracerebral haemorrhage: a surgical dilemma. Br. J. Neurosurg. 1999;13(4):389-94.

6. Brambilla GL, Rodriguez y Baena R, Sangiovanni G, Rainoldi F, Locatelli D. Sponta. neous intracerebral hemorrhage: medical or surgical treatment. J. Neurosurg. Sci. $1983 ; 27(2): 95-101$.

7. Hankey GI, Hon C. Surgery for primary intracerebral hemorthage: is it safe and effective? A systematic review of case series and randomized trials. Stroke 1997;28(11): 2126-32.

8. Waga S, Yamamoto Y. Hypertensive putaminal hemorrhage: treatment and results. Is surgical treatment superior to conservative one? Stroke 1983;14(4):480 -5.

9. Kingman TA, Mendelow AD, Graham DI, Teasdale GM. Experimental intracerebral mass: description of model intracranial pressure changes and neuropathology. I. Neuroparhol. Exp. Neurol. 1988,47(2):128-37.

10. Lopez Valdes E, Hernandez Lain A, Callandre L, Grau M, Cabello A, Gomez Escalonilla C. Time window for clinical effectiveness of mass evacuation in a rat balloon model mimicking an intraparenchymatous hematoma. J. Neurol. Sci. 2000; 174(1):40-6.

11. Nehls DG, Mendelow DA, Graham DI, Teasdale GM. Experimental intracerebral hemorthage: early removal of a spontaneous mass lesion improves late outcome. Neurosurgery $1990 ; 27(5): 674-82$.

12. Chambers IR, Banister K, Mendelow AD. Intracranial pressure within a developing intracerebral haemorrhage. Br. J. Neurosurg. 2001;15(2):140-1.

13. Nath FP, Kelly PT, Jenkins A, Mendelow AD, Graham DI, Teasdale GM. Effects of experimental intracerebral hemorrhage on blood now, capillary permeability, and histochemistry. J. Neurosurg. 1987;66(4):555-62.

14. Nehls DG, Mendelow AD, Graham DI, Sinar EI, Teasdale GM. Experimental intracerebral hemorrhage: progression of hemodynamic changes after production of a spontaneous mass lesion. Neurosurgery 1988;23(4):439 44.

15. Mendelow AD. Mechanisms of ischemic brain damage with intracerebrall hemorrhage Stroke 1993;24(12 Suppl):11:15-7.

16. Siddique MS, Fernandes $\mathbb{H}$ M, Arene NU, Wooldridge TD, Fenwick ID, Mendelow AD. Changes in cerebral blood flow as measured by HMPAO SPECT in patients following spontaneous intracerebral haemorrhage. Acta Neurochir Suppl 2000;76:517-20.

17. Zazulia AR, Diringer MN, Videen TO. Adams RE, Yundt K, Aiyagari V, Grubb RL, Jr., Powers WI. Hypoperfusion without ischemia surrounding acute intracerebrat. hemorrhage. J. Cereb. Blood Flow Metab. 2001:21,7):804-10. 
13. Kaxu $\mathrm{S}$, Naritomi $\mathrm{H}$, Yamamoto $H_{3}$ Sawada $\mathrm{T}$, Yamaguchi $\mathrm{T}$. Enlargement of spontaneous intracerebral hemorrhage. Incidence and time course. Stroke 1996;27(10): $1783-7$.

19. Brott T, Broderick J, Kothari R, Barsan W, Tomsick T, Sauerbeck L, Spilker I, Duldner J, Khoury I. Early hemorrhage growth in patients with in tracerebral hemorrhage. Stroke $1997: 28(1): 1-5$

20. Zazulia AR, Diringer MN, Derdeyn CP, Powers WJ. Progression of mass effect after intracerebral hemormage. Stroke 1999;30(6):1167-73.

21. Lee KR, Kawai $N$, Kim $S$, Sagher O, Hoff JT. Mechanisms of edema formation after intracerebral hemorrhage: effects of thrombin on cerebral blood flow, blood-brain barrier permeability, and cell survival in a rat model. J. Neurosurg. 1997;06(2):272-8.

22. Ki G, Wagner KR, Keep RF, Hua $Y$, de Courten Myers GM, Broderick IP, Brott TG, Hoff IT, Muizelaar JP. Role of blood clot formation on early edema development after experimental intracerebral hemorthage. Stroke 1998;29(12):2580-6.

23. Yang GY, Betz AL, Hoff JT. The effects of blood or plasma clot on brain edema in the rat with intracerebral hemorrhage. Acta Neurochir. Suppl. (Wien). 1994;60:555-7.

24. Prasad K, Shrivastava A. Surgery for primary supratentorial intracerebral haemorwhage. Cochrane Database Syst Rev 2000;2.

25. Auer LM, Ascher PW, Heppner F, Ladumer G, Bone G, Lechner H, Tolly E. Does acute endoscopic evacuation improve the outcome of patients with spontaneous intracerebral hemornage? Eur. Neurol. 1985;24(4):254-61.

26. Zuccarello M, Brott T, Derex L, Kothari R, Sauerbeck L, Tew J, Van Loveren H, Yeh HS, Tomsick T, Pancioli A, Khoury f, Broderick I. Early surgical treatment for supratentorial intracerebral hemormage: a randomized feasibility study. Stroke 1999;30(9):1833-9.

27. Miller DW, Barnet GH, Kormos DW, Steiner CP. Stereotactically guided thrombolysis of deep cerebral hemorrhage: preliminary results. Cleve. Clin. J. Med. 1993;60(4): $32 \mathrm{l}-4$.

28. Montes JM, Wong JH, Fayad PB, Awad IA. Stereotactic computed tomographic-guided aspiration and thrombolysis of intracerebral hematoma: protocol and preliminary experience. Stroke 2000;31(4):834-40.

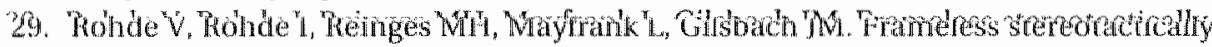
guided catheter placement and fibrinolytic therapy for spontaneous intracerebral hematomas: technical aspects and initial clinical results. Minim. Invasive Neurosurg. $2000 ; 43(1): 9-17$.

30. Franke CL, van Swieten IC, Algra A, van Gijn J. Prognostic factors in patients with intracerebal haematoma. Journal of neurology, neurosurgery, and psychatry $1992 ; 55(8): 653-7$.

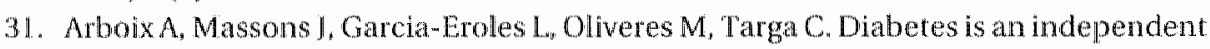
risk factor for in-hospital mortality from acute spontaneous intracerebral hemorrhage. Diabetes Care 2000;23(10):1527-32.

32. Saloheimo P, Juvela S, Hillbom M. Use of aspirin, epistaxis, and untreated hypertension as risk factors for primary intracerebral hemorhage in niddle-aged and elderly people. Stroke $2001 ; 32(2): 399-404$.

33. Wintzen AR, Klasen L, Bussemaker W, Broekmans AW, Loeliger EA. Een retrospectief onderzoek naar oorzaak, behandeling en beloop van hersenbloedingen tijdens orale antistollingsbehandeling. Ned. Tijdschr, Geneeskd. 1988;132(47):2151-4. 
34. Kothar RU, Brott T" Broderick IP, Barsan WG Sauerbeck LR, Zuccarello M, Khoury I. The $A B C s$ of measuring intracerebral hemorthage volumes. Smoke 1996;27(8): $1304-5$.

35. de Haan R, Horn J, Limburg M, van der Meulen I, Bossuyt P. A comparison of five stroke scales with measures of disability, handicap, and quality of life. Stroke $1993: 24(8): 1178-81$.

36. Lainez IM, Pareja $A$. The medical treatment of intracerebral hemonthage. Rev, Neurol. 2000;31(2):174-9.

37. Rainov $N G$, Burkert WL. Urokinase infusion for severe intraventricular haemorrhage. Acta Neurochir. (Wien). 1995;134(1-2):55-9.

38. Pocock S. Clinical Trials: A Practical Approach. 1 ed. New York: John Wiley and Sons; 1991.

39. Kleinbaum D. Logistic regression: a self-learning text. 1 ed. New York: SpringerVerlag Inc; 1994.

40. Teernstra OPM, Lodder J Evers SMAA, Blaauw G. Stereotactic thrombolysis and aspiration of primary intracerebral hemorrhage: hematoma volume reduction and its effects on functional outcome. Results from the SICHPA trial. Submitted 2002.

41. Morgenstem LB, Demchuk AM, Kim DH, Frankowski RF, Grotta JC. Rebleeding leads to poor outcome in ultramearly craniotony for intracerebral hemorrhage. Neurology 2001;56(10):1294-9.

42. Herman B, Leyten AC, van Luijk IH, Frenken CW, Op de Coul AA, Sclualte BP. Epidemiology of stroke in Tilburg the Netherlands. The population-based stroke inci. dence register: 2 . Incidence, initial clinical picture and medical care, and three-week case fatality. Stroke 1982;13(5):629-34.

43. Becker KJ, Baxter AB, Cohen WA, Bybee HM, Tirschwell DL, Newell DW, Winn IAR, Longstreth WT, Jr. Withdrawal of support in intracerebral hemornage may lead to self- fulfilling prophecies. Neurology $2001 ; 56(6): 766-72$.

44. Mayer SA, Kossoff SB. Withdrawal of life support in the neurological intensive care unit. Neurology 1999;52(8):1602-9. 



\section{Stereotactic thrombolysis and aspiration of primary intracerebral hemorrhage: Hematoma volume reduction and its effects on functional outcome}

O.P.M.Tecmstral, I. Lodder ${ }^{3}$, S.M.A.A. Evers ${ }^{1}{ }^{2}$, C.L. Franke, G. Bladuw

Dept of Neurosurgery and Neurology ${ }^{3}$, University Hospital Maastricht, Depr of Neurosurgery and Neurology Atrium Medical Center Heerlen, Dept of Health Organization Policy and Economics ${ }^{2}$, Netherlands

Submitted 


\section{ABSTRACT}

Background and purpose. Volume of spontaneous supratentorial intracerebral hematoma (ICH) is a recognized prognostic factor. So far, attempts to reduce volume by means of surgical evacuation (craniotomy or stereotactic aspiration) have not led to a better clinical outcome.

With the data from the SICHPA-trial (Stereotactic treatment of ICH by means of a Plasminogen Activator, a randomized clinical trial), we investigated the efficacy of this method in reducing ICH volume, and whether ICH volume reduction is associated with improved clinical outcome.

Methods. Between 1996 and 1999, 71 patients from 13 medical centers were included in the SICHPA trial. Inclusion criteria: spontaneous (non-neoplastic, non-aneurysmatic or caused by an arteriovenous malformation) supratentorial $\mathrm{ICH}$ exceeding $10 \mathrm{ml}$ in volume, age $>45$ years, Glasgow EM score ranging from 2 to 10 , treatment within 72 hours following stroke onset, informed consent. One patient with an arteriovenous malformation was excluded leaving 34 patients in the best medical treatment group and 36 in the stereotactic group in which a stereotactically placed catheter was used to instill urokinase to liquefy and drain the ICH at 6-hour intervals over 48 hours. At regular intervals (day 1, 3, 7, 180 post-stroke) functional outcome (mRS: modified Rankin Scale) and ICH volume were assessed (CT-scan, 'ABC/2 method'). Patients who adhered to the study protocol $(n=63)$ were analyzed. Groups were compared using uni-and multivariate analyses for an ICH volume reduction of $25 \%$ or more and of $50 \%$ or more at days 3 and 7 . A logistic regression analysis was used to assess the relationship between a volume reduction of $25 \%$ or more at days 3 and 7 , and an unfavorable outcome (mRS 4, 5 or death). In 15 patients the size of the residual lesion at 180 days was estimated and association with the type of intervention, presence of intraventricular hematoma (IVH), initial ICH size and degree of volume reduction was assessed by Mann Whitney U-testing.

Results. At day three, significant correlations were found between a volume reduction $\geq 25 \%$ and the variables female gender (Odds Ratio (OR): 17.8, 95\% Confidence interval (CI): $1.6-200, p=0.02)$ and the stereotactic intervention (OR: $33.4,95 \% \mathrm{Cr}: 2-549, \mathrm{p}=0.014$ ), and at day seven between stereotactic intervention and a volume reduction $\geq 25 \%$ (OR: $15,95 \% \mathrm{Cl}$ : 1.3-166, $p=0.028$ ) and volume reduction $\geq 50 \%$ (OR: $21,95 \% \mathrm{Cl}: 1.1-391$, $\mathrm{p}=0.043)$. An unfavorable outcome at 180 days correllated at day three with: volume reduction $\geq 25 \%$ (OR: $0.03,95 \% \mathrm{CI}: 0-0.9, \mathrm{p}=0.045$ ), right sided ICH location (OR: $0.13,95 \% \mathrm{Cl}: 0.02-1, \mathrm{p}=0.05$ ), initial $\mathrm{ICH}$ volume $>59 \mathrm{ml}$. (OR: $71.4,95 \% \mathrm{CI}: 3.2-1593, \mathrm{p}=0.007$ ) and at day seven with: volume reduction 
$\geq 25 \%$ (OR: $0.02,95 \% \mathrm{Cl}: 0-0.99, \mathrm{p}=0.049$ ), initial $\mathrm{rCH}$ volume $>59 \mathrm{ml}$. (OR: 70, 95\% Cl: 3.4-1435, $\mathrm{p}=0.006$ ). Patients with larger residual lesions more often had lobar ICHs $(\mathrm{p}=0.025)$ and a volume reduction $225 \%$ at day $3(\mathrm{p}=0.011)$ or $7(p=0.044)$ or $\geq 50 \%$ at day $3(p=0.03)$.

Conclusions. Stereotactic ICH fibrinolysis and aspiration leads to a significant $\mathrm{ICH}$ volume reduction (25\% or more) at both day 3 and day 7 post-stroke. Such a volume reduction significantly reduces chances for an unfavorable clinical outcome (mRS 4,5,6). Greater volume reductions $(25 \%$ and $50 \%$ or more) and lobar ICHs are associated with larger residual lesions, although the value of these findings is limited due to small patient numbers. More research is needed to improve the stereotactic technique in order to maximize volume reduction.

\section{INTRODUCTION}

Intracerebral hemorrhage $(\mathrm{ICH})$ volume is an independent predictor of prognosis (1-7). There is no agreement on whether attempts to surgically reduce $\mathrm{ICH}$-volume improve prognosis, nor is there consensus about the time window in which possible surgery ought to take place (8-10).

A relationship between ICH volume and prognosis is biologically plausible. Larger ICH volumes are likely to cause more extensive brain tissue damage; firstly, there is greater anatomical disruption in the primary injury and secondly they increase intracranial pressure which may reduce cerebral perfusion pressure (CPP) and cerebral blood flow (CBF) (11, 12). However, there are also findings suggesting that $\mathrm{ICH}$ may be surrounded by ischemic damage without changes in CPP $(9,13)$. Thirdly, larger hematomas are more likely to cause late necrosis as a result of a larger quantity of neurotoxic degradation products.

It is assumed that most of the perihematomal ischemic damage, caused mechanically at the time of bleeding, is irreversible $(14,15)$. Part of the ischemic damage and the edema adjacent to the $\mathrm{CH}$ may be secondary and probably due to the coagulation degradation products, especially thrombin, arising from the $I \mathrm{CH}$ clot $(16,17)$. Neurological deterioration, particularly diminished consciousness, is more frequent in large ICHs (7) and is generally considered to be an indication for surgical removal as this is held to lower mortality (evidence class II (18)). Surgical intervention in the form of a craniotomy has the disadvantage of further traumatizing the already compromised brain. Minimally invasive surgery لike stereotactical ICH clot aspiration and liquefaction with fibrinolytic agents has been drawing more attention over the last decades as a viable surgical alternative. In preliminary 
studies this method showed a significant mass reduction of the lesion, and a marked reduction of perihematomal edema (19). Definite clinical proof of increased survival or improvement of outcome has, however not yet been demonstrated.

From 1996 to 1999 the SICHPA trial (Stereotactic treatment of Intracerebral Hematoma by means of a Plasminogen Activator), a multicenter, randomized, controlled trial was condlucted (20). This trial compared the efficacy of stereotactic neurosurgical treatment involving urokinase to usual, conservative medical care on spontaneous supratentorial ICH patients in terms of mortality and morbidity differences over a six-month period. As ICH volume is a known prognostic factor in ICH, it seemed plausible that a volume reduction would improve prognosis. This paper focuses on the question whether this stereotactic clot-lysis and evacuation method effectively reduces ICH volume, and whether volume reduction improves clinical outcome.

\section{PATIENTS AND METHODS}

Over a period of 3 years, the SICHPA trial enrolled 71 patients from the neurosurgical departments of four university hospitals in the Netherlands: Amsterdam Medical Center (AMC), University Medical Center Utrecht (UMCU), Erasmus Medical Center Rotterdam (EMCR) and University Hospital Maastricht / Atrium Medical Center Heerlen (UHM/AMCH). For inclusion all patients had to have a spontaneous (non-neoplastic, nonaneurysmatic or caused by an arteriovenous malformation) supratentorial ICH exceeding $10 \mathrm{ml}$ in volume. Other admission criteria were: age $>4.5$ years, Glasgow EM score ranging from 2 to 10, treatment within 72 hours following stroke onset. All patients were stratified according to their center of inclusion and GCS score before randomization. In all participating centers the trial was approved in advance by their medical ethical committees.

On admission, various base-line characteristics were recorded: history of stroke, history of hypertension, history of cardiological disease (ischemic heart disease, heart failure, and arrhythmias), history of hemorrhagic diathesis (easy bruising, epistaxis) and the use of anticoagulants (aspirin, warfarines or heparin). Glasgow Coma Scalle, pupil size and reactivity and blood pressure were recorded. Also laboratory tests were performed to investigate possible abnormal haemostasis (low platelet count $\left(<50 \times 10^{9} / \mathrm{L}\right.$ ) and/or aPTT $>50 \mathrm{sec}$ and/or PTT $>11 \mathrm{sec}$.), if this was found to be the case it was corrected. 


\section{Treatment}

Surgical treatment consisted of a catheter that was stereotactically placed in the centre of the ICH-clot within 72 hours post-stroke. Still liquid hematoma was aspirated and thereafter 5000 IU urokinase were infused (in $2 \mathrm{ml}$. physiologic saline solution) via the catheter. At six-hour intervals for the next 48 hours, the process of aspiration and urokinase instilment was repeated, and then the catheter was removed.

The alternative treatment consisted of usual conservative medical support (antibiotics, mechanical ventilation, ICP monitoring, steroids etc as indicated). A more detailed description of the surgical- and non-surgical treatment in the SICHPA-trial can be found in the original publication (20).

\section{Follow-up}

The follow-up period lasted for six months post-stroke. At regular intervals ICH volume (CT-scan day $1,3,7$ and 180), functional outcome, degree of disability (Scandinavian Stroke Scale (21), Barthel Index (22-24), Modified Rankin Scale $(25,26)$ ) and quality of life (EuroQoL $(27)$, COOP/WONCA charts (28), Short Form Health Survey 36 items (29)) were measured.

At discharge data on various modalities of supportive medical care in both groups were recorded (30) (use of drugs: anti-hypertension, anti. arrhythmic, inotropics, steroids, antibiotics, heparins, anti-epileptic, barbiturates and hyperosmolar solutions, also: mechanical ventilation, mild hyperventilation, ventricular drainage and intracranial pressure measurement), as were complications such as convulsions, infections etc. Deatly, rebleeding and violations of the trial protocol were also recorded and immediately reported to the investigators and monitoring committee Date and cause of death were registered.

\section{Outcome measurement}

CT-scan appraisal included estimation of edema and shift, presence of intraventricular blood (IVH), location of $\mathrm{ICH}$ and $\mathrm{ICH}$-volume measurement. The ICH volume was measured using the validated ' $A B C / 2$ "-method: $A$ is the length (in centimeters) of the greatest diameter of the $\mathrm{ICH}, \mathrm{B}$ is the length of the diameter perpendicular to $A$ and $C$ is the height of the ICH (number of CT-slides in centimeters) $(31,32)$. Any IVH was not included in the volume measurement. The $\mathrm{ABC} / 2$ method was checked against planimetric measurements in seven patients, made using the CT-scanner during the imaging process. It was applied twice by a single person so that a 
possible intra-observer variance could be calculated (Spearman correlation coefficient). All analyses were done according to adherence to the trial protocol so that any differences detected could be attributed to the actual intervention.

Differences in hematoma volume reduction at days 3 and 7 post-stroke between the surgical and the non-surgical group were investigated using cross-tabulation and Mann Whitney U-tests. To facilitate analysis cut off points were chosen at $25 \%$ or more and $50 \%$ or more volume reduction which represent meaningful reductions in our opinion. Additionally, both groups were compared for these volume reductions in a logistic regression analysis to account for possible confounding. Apart from baseline characteristics (age, gender) the analysis included other plausible variables that could possibly influence change in hematoma volume: stereotactic evacuation, diabetes mellitus (33), hypertension, initial ICH greater than $59 \mathrm{ml}$. (a cut-off point representing the median volume of all patients, chosen for dichotomization to facilitate analysis), presence of IVH, lobar (versus deep) ICH, abnormal haemostatic parameters (low platelet count $\left(<50 \times 10^{9} / \mathrm{L}\right.$ ) and/or $\mathrm{aPTT}>50 \mathrm{sec}$ and/or $\mathrm{PTT}>11 \mathrm{sec}$.).

To measure outcome the modified Rankin Scale (mRS $0=$ no neurological complaints, completely independent to $5=$ severe disability, bedridden and totally dependent) was adapted to include a score 6 for death. Outcome was divided into a 'favorable-outcome'-group with mRS scores from 0 to 3 (pre-stroke condition to moderate disability needing some assistance in daily activities) and a 'unfavorable-outcome'-group with scores 4 (serious neurological deficit, dependent), 5 and 6 .

This outcome variable was tested in a logistic regression analysis that included baseline characteristics (gender, age), the volume-reduction variable ( $\geq 25 \%$ and $\geq 50 \%$ reduction) and other biologically plausible factors that could possibly affect clinical outcome: stereotactic evacuation, Glasgow Coma Scale score $<10$ points, initial ICH greater than $59 \mathrm{ml}$., right-sided localization of the $\mathrm{ICH}$.

The residual lesion from the ICH in the brain at 180 days post-stroke (15 cases) was estimated according to three categories (mild: barely detectable to limited lesion, moderate: clearly visible involving more brain tissue and, extensive: gross anatomical changes as a result of the lesion), by a vascular neurologist, using a method for lesion size estimation in ischemic stroke (34, $35)$.

The data were examined with cross-tabulation statistics. To illustrate ICH volume reduction in each individual case the scans of these patients were added. 


\section{RESULTS}

An initial check of the ' $\mathrm{ABC} / 2$ '-method results, comparing them with volume calculations using the CT-scanner planimetric software $(n=7)$ demonstrated a Spearman's rho correlation coefficient of 0.89 ( $\mathrm{p}$-value= 0.007 ). A total of $159 \mathrm{CT}$-scans were analyzed twice over an interval of several months by the same person, with a good intra-observer-rating (Pearson correlation coefficient of $0.98, p<0.0001$ ).

Eight patients of a total of 71 were omitted from the analysis: two had a craniotomy instead of stereotactic aspiration, one died during preoperative CT-scanning, one had improved neurologically to such a degree that the procedure was abandoned, one patient deteriorated rapidly and no surgery was performed, one patient was suspected of having an underlying amyloid angiopathy, and so allocated surgery was not carried out, one patient had an arteriovenous malformation and was therefore excluded, and one patient did not receive surgery for a non-disclosed reason.

Of the remaining 63 patients 19 had died $(10$ in the non-surgical and $9 \mathrm{in}$ the surgical group), and in four CT-scanning, on day 7 post-stroke, had not been performed, leaving 44 patients with CT scans on day 3 , and 40 on day 7 post-stroke for analysis. Of the 19 deceased patients 10 had large initial $1 \mathrm{CH}$ volumes (greater than $59 \mathrm{ml}$.) but they were equally distributed over both groups. Table 1 shows that volume reduction at day 3 and 7 post-stroke was significantly larger in the stereotactically treated patients.

Table 1. 25\% and 50\% volume reductions and treatment

\begin{tabular}{|c|c|c|c|c|}
\hline \multirow[b]{2}{*}{ Treatment } & \multicolumn{4}{|c|}{ Volume reduction $^{\text {;i }}$} \\
\hline & $\geq 25 \%$ at day 3 & $\geq 50 \%$ at day 3 & $\geq 25 \%$ ad dy 7 & $\geq 50^{\circ}$ acday 7 \\
\hline Total & $15 / 44(34.10 \%)$ & $5 / 44(11,40 \%)$ & $16 / 40(40 \%)$ & $10 / 40(25 \%)$ \\
\hline Conservative & $2 / 20[10 \%]$ & $0 / 20(0 \%)$ & $3 / 20(15 \%)$ & $1 / 20(5 \%)$ \\
\hline Stereotaxy & $13 / 24(54.2 \%)$ & $5 / 24(20 \%)$ & $13 / 20(65 \%)$ & $9120\left(45^{4 \%}\right)$ \\
\hline $\mathrm{D}$-value & 0.002 & 0.032 & 0.001 & 0.009 \\
\hline
\end{tabular}

* $A \geq 25$ or $\geq 50 \%$ volume reduction at day 3 and 7 post-stroke. $\|$ Number of patients $/$ total in surgical or non-surgical group (percentage); $\$ 2$-Tailed significance obtained by Mann-Whitney $U$-test (p-value $\leq 0.05$ is statistically significant).

At day seven $65 \%$ of the surgical group had a volume reduction of $25 \%$ or more and $45 \%$ a reduction of $50 \%$ or more, compared to $1.9 \%$ and $5 \%$, respectively, in the non-surgical group. Mann-Whitney $U$-testing showed all differences to be statistically significant. Tables $2 \mathrm{a}$ and $2 \mathrm{~b}$ show the results of the logistic regression analysis with $25 \%$ and $50 \%$ ICH volume reduction at days 3 and 7 respectively, as dependent variable. 


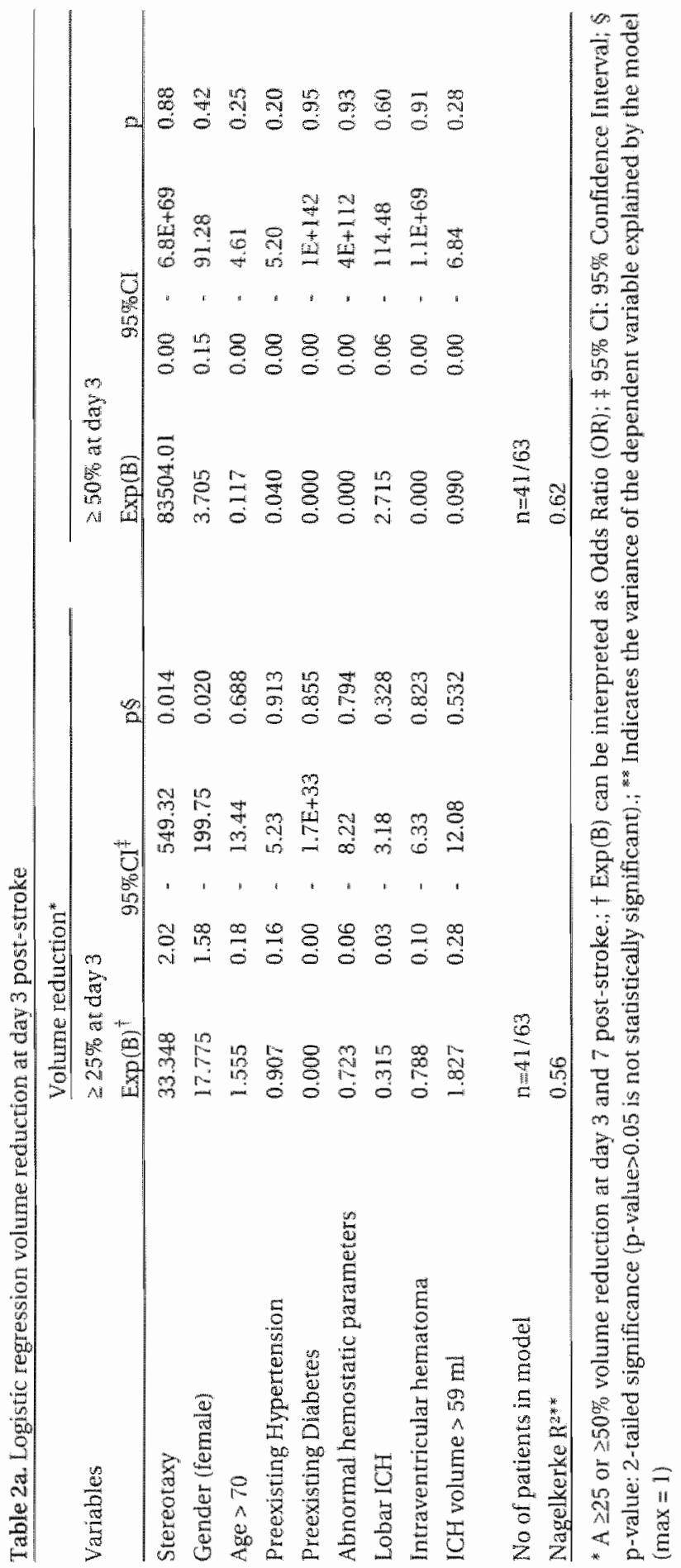




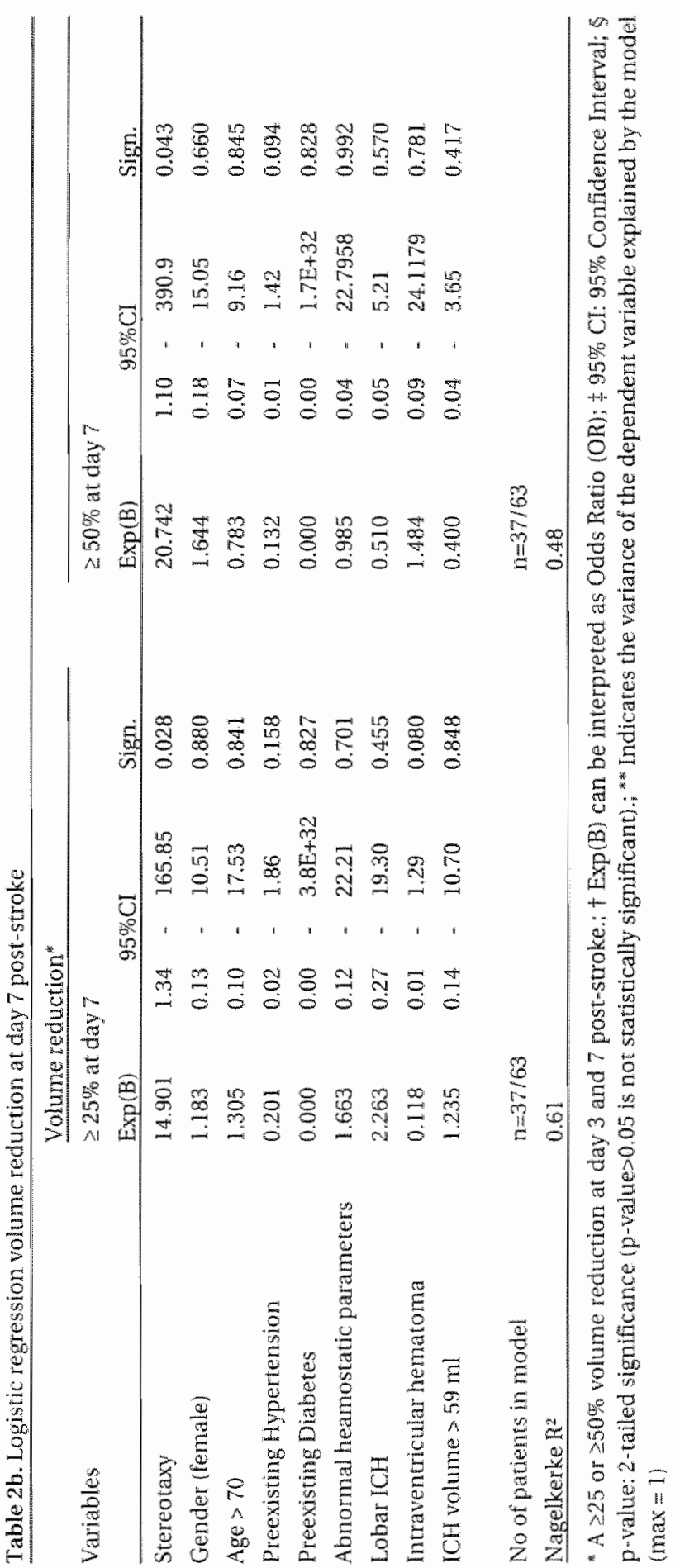


Because of patients having died $(n=15$ on day 3 and $n=19$ on day 7 post-stroke) and because of missing data the number of patients was reduced to 41 at day 3 and 37 at day 7 . In the day 3 analysis, female gender appeared as an independent predictor for $\geq 25 \%$ volume reduction. Stereotactic clot removal emerged as a strongly and independently associated factor with the degree of clot volume reduction, both in the day 3 and day 7 analysis.

Table 3 shows the cross-tabulation of volume reduction and outcome. Although the outcome was more favorable (mRS $0,1,2,3$ ) in the group with larger clot volume reductions, the differences were not statistically significant.

Table 3. Cross-tabulation volume reduction and outcome

\begin{tabular}{lllll}
\hline \multicolumn{5}{l}{ Volume reduction $^{*}$} \\
Outcome & $\geq 25 \%$ at day 3 & $\geq 50 \%$ at day 3 & $\geq 25 \%$ at day 7 & $\geq 50 \%$ at day 7 \\
\hline Total & $15 / 44(34 \%)$ & $5 / 44(1.1 \%)$ & $16 / 40(40 \%)$ & $9 / 40(22.5 \%)$ \\
mRS 0,1,2,3 & $6 / 11(54.5 \%)$ & $2 / 11(18 \%)$ & $7 / 12(58.3 \%)$ & $4 / 12(33.3 \%)$ \\
mRS 4,5.6 & $9 / 33(27.3 \%)$ & $3 / 33(9 \%)$ & $9 / 28(32.1 \%)$ & $5 / 28(17.9 \%)$ \\
p-value $^{*}$ & $0.102(\mathrm{~ns})$ & $0.416(\mathrm{~ns})$ & $0.126(\mathrm{~ns})$ & $0.289(\mathrm{~ns})$ \\
\hline
\end{tabular}

" A $\geq 25$ or $\geq 50 \%$ wolume reduction at day 3 and 7 post-stroke, 1 mRS: modified Rankin Scale, 0 to 3 : (relatively) independent, 4,5: heavily dependent, 6: deceased.; Number of patients / total in surgical or non surgical group (percentage); $\$ 2$-Tailed significance obtained by Mann Whitney $u$-test ( $p$-value $>0.05$ is not statistically significant).

An initial ICH volume larger than $59 \mathrm{ml}$ was an independent predictor of unfavorable outcome (OR: $71.3,95 \% \mathrm{CI}: 3.2-1593, \mathrm{p}=0.007$ ). Right-sided location of the hematoma was associated with a favorable outcome in the 3-day post-stroke $25 \%$ or more volume reduction analysis (OR: $0.05,95 \% \mathrm{CI}$ : $0.016-1, p=0.05)$. A $25 \%$ or more volume reduction emerged as an independent predictor of favorable outcome both in the day 3 and 7 post-stroke analysis with respective Odds ratios of 0.025 (95\% Cl: $0.001-0.924, \mathrm{p}=0.045$ ), and 0.016 (95\%CI: $0-0.986, p=0.049$ ). Although the point estimates are compatible with a more favorable outcome, the volume reduction of $50 \%$ or more never made up for a statistically significant improvement: day 3 post-stroke OR: 0.43 (95\%CI: $0.034-5.43, p=$ ns.), day 7 OR: 0.49 (95\%CI: $0.05-5.87, p=n s$.). This group is not shown in table 4 , because of the small numbers (a total of a mere 5 and 9 patients, respectively).

At day 180 post-stroke 31 out of 71 included patients had survived (43.7\%), 20 of whom had undergone repeated CT-scans. Five of them were from the 8 patients who did not receive the treatment in the way it was intended (see above) and their CT-scans were not involved in this analysis, hence 15 patients with CT-imaging at day 180 were left. The cross-tabula- 


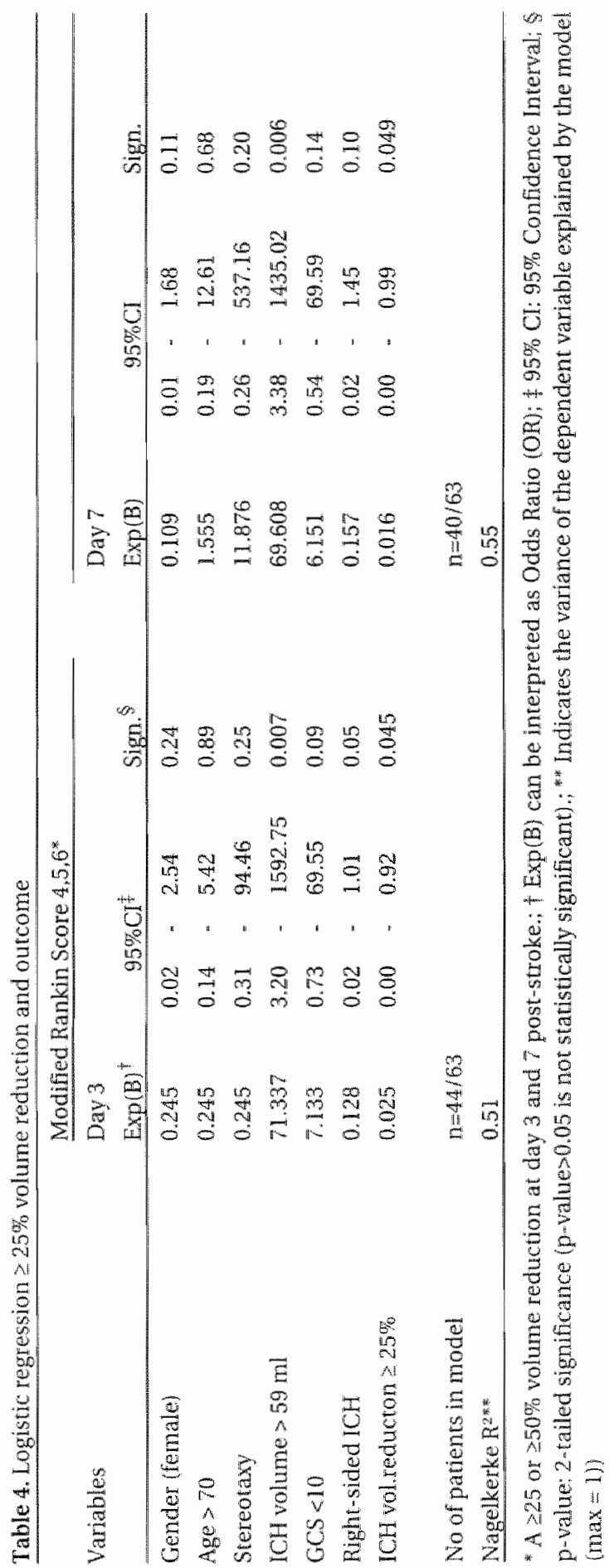


Table 5. Residual lesions at day 180 post-stroke

\begin{tabular}{|c|c|c|c|c|c|c|c|c|}
\hline \multirow[b]{2}{*}{ Characteristics } & \multicolumn{8}{|c|}{ Residual fesion $(n=15)$} \\
\hline & & small & & moderate & & lar & ge & $p-$ Yalue \\
\hline Stereotaxy - conservative & $2 / 8$ & $-6 / 8$ & $4 / 6$ & -216 & $\mathbb{1}$ & - & 0 & ns \\
\hline Lobar ICH - deep ICH & $1 / 8$ & -718 & $4 / 6$ & $-\quad 216$ & $\mathbb{1}$ & - & 0 & 0.025 \\
\hline IVH present - absent & $3 / 8$ & -518 & $1 / 6$ & -516 & 0 & - & 1 & ns \\
\hline ICH volume $\geq 59 \mathrm{ml}-<59 \mathrm{ml}$ & $0 / 8$ & -818 & $2 / 6$ & $-4 / 6$ & 0 & - & $\mathbb{1}$ & ns \\
\hline ICH $225 \%$ vol. reduction day $3^{7}-<25 \%$ & $1 / 18$ & $-7 / 8$ & $4 / 5$ & $-1 / 5$ & $\mathbb{1}$ & - & 0 & 0.011 \\
\hline $1 \mathrm{CH} 225 \%$ vol. reduction day $7-<25 \%$ & $1 / 8$ & $-7 / 8$ & $3 / 5$ & -215 & $\mathbb{1}$ & - & 0 & 0.044 \\
\hline$\llbracket \mathrm{CH} \geq 50 \%$ wol, reduction day $3-<50 \%$ & $0 / 8$ & $-8 / 8$ & $2 / 5$ & $-3 / 5$ & $\mathbb{1}$ & - & 0 & 0.030 \\
\hline 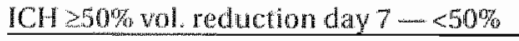 & $1 / 8$ & -718 & $2 / 5$ & -315 & 1 & - & 0 & ns. \\
\hline
\end{tabular}

* 2 -Tailed significance obtained by Mann-Whitney test ( $p$-value $>0.05$ is not statistically significant, the one patient with an extensive residual lesion was incorporated in the group with moderate lesions for practical reasons.; \#olume reduction relative to initiall ICH wolume, greater than $25 \%$ berween day 1 and 3 and between day 1 and 7 .

tion (table 5) shows the characteristics of this group related to residual CT-lesion size.

In order to perform a Mann Whitney U-analysis, for practical reasons the one patient having an extensive residual lesion was added to the group with moderate residual lesions. It showed that a volume reduction of $25 \%$ or more at day 3 or at day 7 post-stroke and a $50 \%$ or more reduction at day 7 post-stroke statistically significant related to larger residual lesion size. Such a relation also existed between lobar ICHs and a larger residual lesion. The number of patients in each of the two groups is too small for an ordinal regression analysis, even when divided into two groups regression analysis was impossible. Although the numbers are small the data suggest that the group with small residual lesions at day 180 post-stroke, initially had more often small, and deeply situated ICHs; only a quarter of them underwent stereotactic evacuation and with exception of one case there was no ICH volume reduction greater than $25 \%$. In the group with moderate residual lesions, there are more patients with a stereotactic intervention and in this group greater ICH volume reduction is recorded. Comparing patients with or without stereotactic intervention for residual lesion size at day 180 post-stroke, yielded an OR of 0.13 (95\%CI: $0.01-2.92, \mathrm{p}=\mathrm{ns}$.).

The 15 patients from this analysis are depicted in figure 1 with their respective CT-scans showing different stages of hematoma resolution. Hematoma reduction is obviously most marked in the stereotactic group with the exception of no. 10. Interesting is also the presence of a new lobar left-sided ICH on day 180 in patient no. 5 . 
Fügure 1. CT imaging at day $1,3,7$ and day 180 (residual lesion)

CONSERVATIVE THERAPY

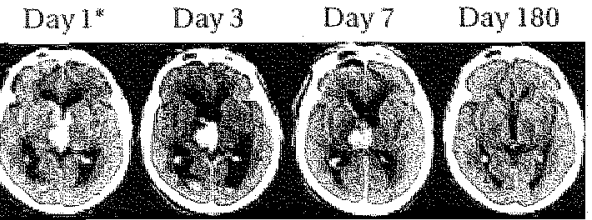

1. male 75 years, deep $1 \mathrm{CH} 16 \mathrm{ml}$, mPS 0

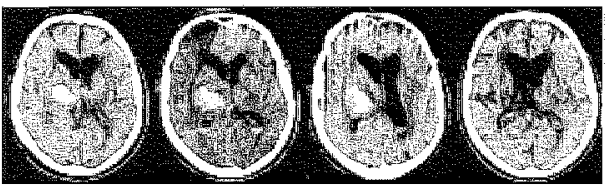

3. male 79 years, deep ICH $15 \mathrm{ml}$, mRS 5

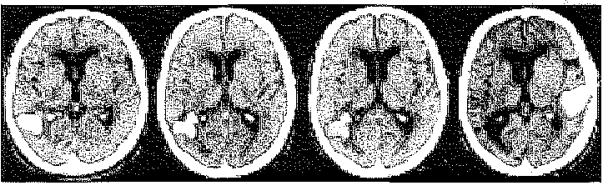

5. male 70 years, lobar ICH $19 \mathrm{ml}$, mRS 2

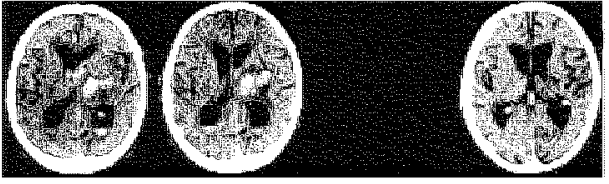

7. malle 84 years, deep $1 \mathrm{CH} 17 \mathrm{ml}$, mRS 5

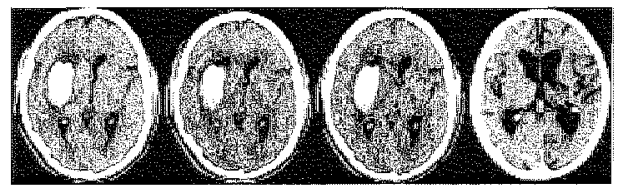

9. male 49 years, deep ICH $47 \mathrm{ml}$, mRS 3

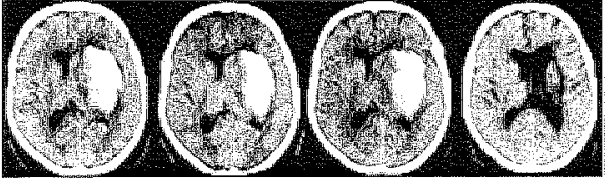

11. female 48 years, deep ICH $68 \mathrm{ml}$, mRS 4

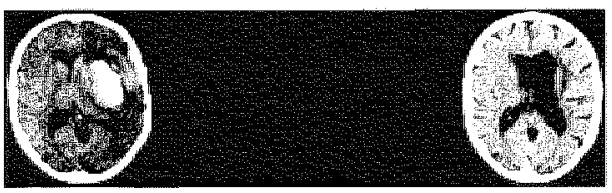

13. female 67 years, lobar/deep ICH $35 \mathrm{ml}$, mRS 5

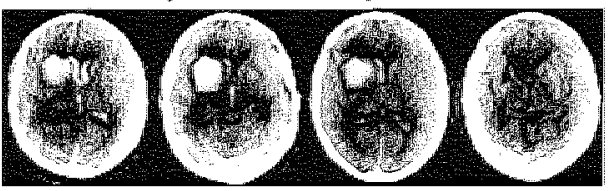

15. female 50 years, deep $\mathrm{ICH} \| 7 \mathrm{ml}$, mRS 5
STEREOTACTIC THERAPY

Day 1 Day 3 Day 7 Day 180

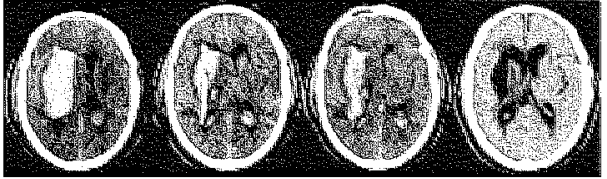

2. male 60 years, lobar/deep ICH $77 \mathrm{ml}$, mRS 5

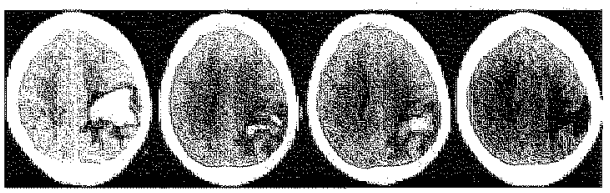

4. female 68 years, lobar ICH $36 \mathrm{mll}, \mathrm{m}$ RS 3

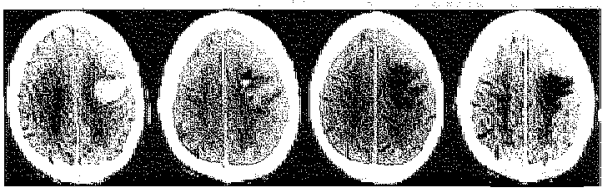

6. male 73 years, lobar $1 \mathrm{CH} 18 \mathrm{ml}_{1} \mathrm{miRS}_{3}$

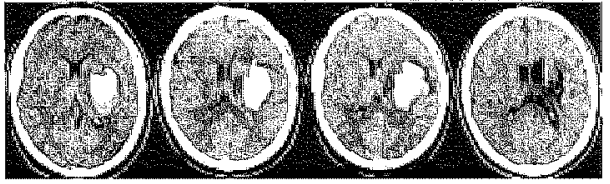

8. male 52 years, deep ICH $37 \mathrm{ml}, \mathrm{mRS} 4$

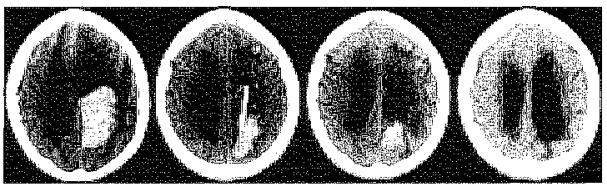

10. femalle 66 years, lobar ICH $45 \mathrm{ml}_{4} \mathrm{mRS} 5$

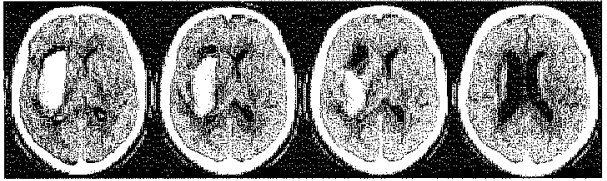

12. male 57 years, deep ICH $39 \mathrm{ml}$, mRS 4

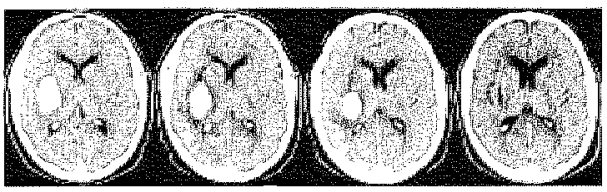

14. male 49 years, deep ICH $23 \mathrm{mI}, \mathrm{mRS}$ ।

*CT day 1 : on admission, CT day 3 : just before drain removal in stereotactic group, CT day $7: 1$ week comrol, CT day 180: end of follow up. 


\section{DISCUSSION}

Stereotactic ICH fibrinolysis and aspiration led to a significant ICH volume reduction ( $25 \%$ or more) at both day 3 and day 7 post-stroke. Such a volume reduction significantly reduced chances of an unfavorable clinical outcome (mRS $4,5,6)$. Greater volume reductions (25\% and $50 \%$ or more) and lobar ICHs were associated with larger residual lesions, although the value of these findings is limited due to small patient numbers in the analysis.

The 'ABC/2'-method proved to be a useful practical way of reliably calculating ICH volumes. It correlated well with the CT-scanner volume calculations. A possible drawback of this method is inter-observer disagreement, which is not inconceivable considering that sometimes heterodense, and irregularly shaped ICHs had to be measured. The 159 CT-scans that were analyzed twice by the same person had a good intra-observer-rating.

A significant finding was the statistically significant relationship between the stereotactic method and ICH volume reduction (25\% or more and $50 \%$ or more) at both day three and day seven post-stroke. When other factors influencing hematoma reduction were accounted for in a logistic regression analysis this relationship was significant for a $25 \%$ or more volume reduction at day three and seven post-stroke and just significant for $50 \%$ or more at day seven post-stroke. The confidence intervals are however wide, which indicates the dissimilarity of the data values. The number of patients entered into the analysis was small; this was partly due to the fact that only patients who survived up to day three or day seven post-stroke could be included. This constitutes a risk of selection bias possibly leaving out the worst-off patients in one of the groups. A missing value analysis however, showed that the 23 patients that were left out of the analysis were equally distributed over both groups. Our findings sustain the plausibility of the idea that if reduction of ICH clot-volume could be achieved by an intervention, prognosis in ICH patients may be improved. Furthermore, the discussed stereotactic aspiration maybe such an intervention as we have shown that it indeed reduces ICH clot volume as measured on day 3 and day $7 \mathrm{CT}$ scans.

However, the volume reduction achieved by the stereotactic intervention used in this study is quite moderate (median $24 \%$ at 1 week) when compared to the reductions accomplished by comparable minimally invasive surgery (MIS). The latter generally achieve between 30 and $90 \%$ reduction of ICH volume (36-43). Only a few small randomized studies are available: Zuccarello et al. (44) treated four patients with MIS resulting in a median ICH volume reduction of $39 \%$ at 24 hours and good effect $(0 \%$ mortality, all with good recovery at three months); the median reduction in his craniotomy group $(\mathrm{n}=5)$ was $76 \%$. A mean clot volume reduction of $72.7 \%$ at 
48 hours in four patients with deep hemorrhages resulting in a mean GCS score rise of 6 points was published by Miller et al. (39). Montes et al. (41) achieved an average reduction of $57 \%$ in 12 patients (25\% mortality and $25 \%$ good recovery at six months). Rhode et al. (45) realized a mean reduction of $63 \%$ within two days in 24 out of 27 patients.

The discrepancy between the reported volume-reductions indicates that where thrombolytic aspiration of ICH is concerned, there are many variations on a theme. Most apparent variables that could influence the volume of the clot reduction are: time to surgery, surgical technique (stereotactic frame or frameless), general or local anesthesia, dosage and type of plasminogen activator, number and frequency of installments/aspirations, open or closed catheter. Time to surgery is still a subject of debate. Advocates of ultra-early clot removal refer to animal studies that show improved survival when an artificial mass lesion (microballoon) is taken away early (deflation within 4 hours) $(15,46,47)$. Another argument favoring early removal is the frequent occurrence of ICH growth within the first hours post-stroke (48-50); ultra-early evacuation prevents further damage (44). On the other hand the same factors that cause early ICH growth can also lead to increased re-bleeding and mortality in ultra-early evacuation (within 4 hours) (10). Frame-based or frameless stereotactic surgery can often be performed under local anesthesia without compromising the patient's airways. The drug that has been used the most in the procedure is Urokinase, in dosages ranging from $5000 \mathrm{IU}$ to $10.000 \mathrm{IU}$, usually $6000 \mathrm{IU}$. These dosages are as empirical and arbitrary as the number (up to 10) and frequency of installments (every 6 to 8 hours). Recombinant synthesis tissue plasminogen activator ( $\mathrm{rtPA}, 2$ to $8 \mathrm{mg} /$ day) is now being favored $(19,45,51$, 52) over urokinase due to impurity problems concerning the latter agent. The optimal dosage scheme is still to be ascertained by further dose-escalation studies. Most reported procedures involve an aspiration period of 48 to 72 hours with CT scanning up to twice daily. Facilitation of hematoma drainage by leaving the catheter unclamped between rtPA installments has been mentioned in recent publications $(36,41,51)$. With ICH volume reduction being an important prognostic variable, studies should be undertaken to further improve the technical procedure.

Mortality is the most frequent choice of primary endpoint in the majority of published studies (range $30 \%-70 \%$ ). The in/exclusion criteria of a study partly determine the mortality rate; in case of the SICHPA study an ICH-patient subgroup with a poor prognosis was selected. This was to some extent translated in a high mortality: 20 out of $35(59 \%)$ in the non-surgical group and 20 of $36(56 \%)$ in the surgical group (20). In our opinion, outranking mortality as endpoint and more important from a human and 
societal view is functional outcome. We used a dichotomized modified Rankin Scale; one group included merely independent patients (mRS 0-3), the other severely dependent patients or those who had died (mRS 4-6). At first glance, no significant relationship was detected between volume reduction and better outcome. Given the small number of patients (5 and 9] within the group of 50 percent or more volume reduction and the crosstabulation showing no indication of a significant relationship between this group and the outcome variable, it was omitted from further analysis. After adjusting for confounding using logistic regression analysis, a volume reduction of $25 \%$ or more, measured at day 3 or on day 7 post-stroke, statistically significantly reduced the chance of an unfavorable outcome (mRS 4-6). Again, a limitation of this analysis is that only patients that survive the first three or seven days were included. The data of all those who were not included checked for imbalanced distribution of their variables with Mann Whitney U-testing, there were no significant differences between groups. Another good indicator of the reliability of the model is the fact that a prognostic variable such as the initial volume of the ICH had a statistically significant relationship with outcome. A significant effect of right hemisphere location leading to reduced dependency (mRS 0-3) is in line with the widely accepted opinion that patients with intact speech and language abilities are prone to be scored as having a better outcome after stroke.

An analysis of residual lesions at day 180 post-stroke concerned a mere 15 patients. Although statistical calculations with such small numbers may not be valid, it is interesting to see that the largest group of these 180-day survivors had small residual lesion, which was associated with conservative therapy and small deep ICHs without much volume reduction during the first week.

There are many different variables that may influence outcome in ICH patients; only a large study will be sufficiently powered to balance these factors between treatment and control group. A technique that accomplishes the largest clot volume reduction may have the largest impact in reducing the number of $\mathrm{ICH}$ patients who will ultimately die or remain severely disabled and clependent. However, such an effect may also depend on the magnitude of unfavorable side-effects of the intervention, like tissue destruction or increased chance of re-bleeding, etc. . Although our study demonstrated that the stereotactic aspiration reduced ICH volume, and that such a reduction is associated with improved outcome, an earlier analysis (20) failed to show decisively a favorable effect of this intervention on outcome. 


\section{CONCLUSION}

This study which uses the data from the SICHPA trial (20) demonstrated that the stereotactic aspiration of urokinase-thrombolyzed ICH leads to a $25 \%$ or more volume reduction measured at the third or the seventh day after bleeding. Further analysis showed that such a volume reduction of $25 \%$ or more significantly reduces chances for death or dependency six months after the stroke. The results of surgical intervention of this study (median of $24 \%$ volume reduction at 1 week post-stroke) is at the lower end of internationally reported reduction percentage figures. The in- and exclusion criteria used in this study are probably partly to blame for this. Possibly the technique that was used can be improved. Several aspects of this relatively new surgical procedure are still undetermined; in order to achieve maximum ICH volume reduction with a low complication rate these need to be investigated and optimized. 


\section{REFERENCES}

1. Brambilla GL, Sangiovanni G. Rainoldi F. Spontaneous cerebral hematomas. Treatment and follow up studies. Minerva Med. 1986:77(25):1209-14.

2. Broderick JP, Brott TG, Duldner JE, Tomsick T, Huster G. Volume of intracerebral hemorrhage. A powerful and easy-to-use predictor of 30 -day mortaliry. Stroke 1993,24(7),987-93.

3. el Chami B. Milan C Giroud M, Sautreaux NL, Faivre I. Intracerebral hemorrhage survival: French register data. Neurol. Res. 2000;22(8):791-6.

4. Franke CL, var Swieten JC, AJgra $A_{\text {, }}$ van Gijn J. Prognostic factors in patients with intracerebral haematoma. J. Neurol. Neurosurg. Psychiatry 1992:55(8):653-7.

5. Helweg-Larsen $S$, Sommer $W$, Strange P, Lester I, Boysen $G$ Prognosis for patients treated conservatively for spontaneous intracerebral hematomas. Stroke 1984;15(6): 1045 8.

6. Maiuri F, Corriero G, Passarelli F, Cirillo S, Astarita G. CT indications for surgery and evaluation of prognosis in patients with spontaneous intracerebral haematomas. $\mathrm{Br}$. J. Neurosurg. 1990;4(2):155-60.

7. Mayer SA, Sacco RL, Shi T, Moht JP. Neurologic deterioration in noncomatose patients with supratentorial intracerebral hemorthage. Neurology 1994;44(8): 1379-84.

8. Fenandes $\mathrm{HM}$, Mendelow AD. Spontaneous intracerebral haemorrhage: a surgical dilemma. Br. J. Neurosurg. 1999;13(4):389-94.

9. Mayer $S A$, Thomas CE, Diamond BE. Asymmetry of intracranial hemodynamics as an indicator of mass effect in acute intracerebral hemorrhage. A transcranial Doppler study. Stroke 1996;27(10):1788-92.

10. Morgensten LB, Demchuk AM, Kim DH, Frankowski RF, Grotta JC. Rebleeding leads to poor outcome in ultra-early craniotomy for intracerebral hemorrhage. Neurology 2001:56(10):1294-9.

11. Nath FP, Jenkins A, Mendelow AD, Graham DI, Teasdale GM. Early hemodymamic changes in experimental intracerebral hemorhage. J. Neurosurg. 1986;65(5): 697-703.

12. Yang GY, Betz AL, Chenevert TL, Brunberg JA, Hoff JT. Experimental intracerebral hemorthage: relationship between brain edema, blood flow, and blood-brain barrier permeability in rats. I. Neurosurg 1994;81(1):93-102.

13. Kingman TA, Mendelow AD, Graham DI, Teasdale GM. Experimental intracerebral mass: description of model intracranial pressure changes and neuropathology. I. Neuropathol. Exp. Neurol. 1988;47(2):128-37.

14. Mendelow $\mathrm{AD}$. Mechanisms of ischemic brain damage with intracerebral hemorrhage. Stroke $1993: 24(12$ Suppl):1115-7; discussion 1118-9.

15. Sinar Dil. Mendelow AD, Graham DI. Teasdale GM. Experimental intracerebral hemorhage: effects of a temporary mass lesion. I. Neurosurg. $1987 ; 66(4) ; 568-76$.

16. Lee Ey Hung YC, Lee MY. Early alterations in cerebral hemodynamics, brain metabolism, and blood-brain barrier permeability in experimental intracerebral hemorrhage ). Neurosurg. 1999;91(6):1013-9.

17. Xi G, Wagner KR, Keep RF, Hua Y, de Courten-Myers GM, Broderick JP, Brott TG, Hoff IT, Muizelaar IP. Role of blood clot formation on early edema development after experimental infracerebral hemorrhage. Stroke 1998;29(12):2580-6. 
18. Broderick JP, Adams HP, Jr. Barsan W. Feinberg W. Feldmann E, Grotta J, Kase C, Krieger D, Mayberg M. Tilley B, Zabramski JM, Zuccarello M. Guidelines for the management of spontaneous intracerebral hemorihage: A statement for healtheare professionals from a special writing group of the Stroke Council, American Heart Association. Strolke 1999;30(4):905-15.

19. Wagner KR, Xi $G$, Hua Y, Zuccarello M, de Courten-Myers GM, Broderick JP, Brott TG. Uitra-early clot aspiration after lysis with tissue plasminogen activator in a porcine model of intracerebral hemorrhage: edema reduction and blood-brain barrier protection. J. Neurosurg. 1999;90(3):491-8.

20. Teemstra OPM, Evers SMAA, Lodder J. Leffers P, Franke CL, Blataw G. Stereotactic treatment of Intracerebral Hematoma by means of a Plasminogen Activator: A multicenter randomized controlled trial (SICHPA). Stroke, accepted 2002.

21. de Haan $R$, Hom J, Limburg $M$, van der Meulen J, Bossuyt P. A comparison of five stroke scales with measures of disability, handicap, and quality of life. Stroke $1993 ; 24(8): 1178-81$.

22. Collin $\mathrm{C}$, Wade DT, Davies $\mathrm{S}$, Horne V. The Barthel ADL Index: a reliability study. Int. Disabil. Stud. 1988;10(2):61-3.

23. Mahoney F, Barthel D. Functional evaluation: The Barthel Index. Maryland State Med I 1965; 14(3):61 -65.

24. Wade DT, Collin C. The Barthel ADL Index: a standard measure of physical disability? Int. Disabil. Stud. 1988;10(2):64-7.

25. de Haan $\mathbb{R}_{n}$ Limburg $M$, Bossuyt $P$, van der Meullen J, Axronson $N$. The clinical meaning of Rankin 'handicap' grades after stroke. Stroke 1995;26(1 1):2027-30.

26. Rankin J. Cerebral vascular accidents in patients over the age of 60: II. Prognosis. Scot Med J $1957 ; 2: 200-215$.

27. EuroQoL Group. A new facility for the measurement of the health -related Quality of Life. Health Policy 1990(16):199-208.

28. van Weel C, Konig-Zahn C, Touw-Otten FWMM, van Duijn NP, Meyboom-de Jing B. Measuring functional health status with COOP/WONCA charts. Groningen: Noordelijk Centrum voor Gezondheidsvraagstukken/ World Organization of family Doctors (WONCA), European Research Group on Health Outcomes (ERGHO), Northern Centre for Health Care Research (NCH); 1995.

29. Anderson $C_{\text {, }}$ Laubscher $S$, Bums $\mathbb{R}$. Validation of the Shont form 36 ( $S F-36$ ) health survey questionnaire among stroke patients. Stroke 1996;27(10):1812-6.

30. Lainez. IM, Pareja $A$. The medical treatment of intracerebral hemorthage Rev. Neurol. $2000 ; 31(2): 174-9$.

31. Kothari RU, Brott T, Broderick JP, Barsan WG, Satuerlock LR, Zuccarello M, Khoury J. The ABCs of measuring intracerebral hemorhage wolumes, Stroke 1996;27 (8):1304 -5.

32. Gebel $\mathbb{M}$, Sila CA, Sloan MA, Granger CB, Weisenberger IP, Green Cl., Topol El, Mahaffey KW. Comparison of the $\mathrm{ABC} / 2$ estimation technique to computer-assisted volumetric analysis of intraparenchymal and subdural hematomas complicating the GUSTO-1 trial. Stroke 1998;29(9):1799-801.

33. Broderick JP. Hagen T, Brott T, Tomsick T. Hyperglycemiand hemorrhagic transformation of cerebral infarcts. Stroke 1995;26(3):484-7.

34. Franke CL, van Swieten JC, van Gijn I. Residual lesions on computed tomography after intracerebral hemorrhage. Stroke $1991: 22(12): 1530-3$

35. Heuts-van Raak L, Lodder J, Kessels F. Late seizures following a first symptomatic brain infarct are related to large infarcts involving the posterior area around the lateral sulcus. Seizure 1996;5(3):1.85-94. 
36. Lippitz BE, Mayfrank L, Spetzger U, Warnke IP. Bertalanffy H, Gilsbach IM. Lysis of basal ganglia hemematoma with recombinant tissue plasminogen activator (rPA) after stereotactic aspiration: initial results. Acta Neurochir. (Wien). 1994;127(3-4):157-60.

37. Liu ZH, Kang GQ, Chen XH, Tian ZM, Cai HZ, Zhang $Y_{*}$ Li SY. Evacuation of thypertensive intracerebral hematoma by a stereotactic technique. Stereotact. Funct. Neurosurg. 1990;54-55:451-2.

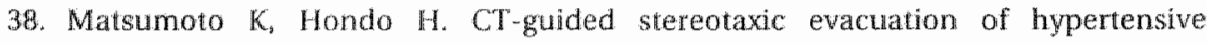
intracerebral hematomas. J. Neurosurg. 1984;61(3):440-8.

39. Miller DW, Bamett GH, Kormos DW, Steiner CP. Stereotactically guided thrombolysis of deep cerebral hemorrhage: preliminary results. Cleve. Clin. J. Med. 1993;60[4):321-4.

40. Mohadjer M, Braus DF, Myers A, Scheremer R, Krauss JK. CT-stereotactic fibrinolysis of 5 pontaneous intracerebral hematomas. Neurosurg. Rev. 1992;15(2):105-10.

41. Montes IM, Wong JH, Fayad PB, Awad A. Stereotactic computed tomographicguided aspiration and thrombolysis of intracerebral hematoma : protocol and preliminary experience. Stroke 2000;31(4):834-40.

42. Nguyen JP, Decq P, Brugieres $\mathrm{P}$, Yepes $\mathrm{C}$, Melon E, Gaston A, Keravel $Y$. A technique for stereotactic aspiration of deep intracerebral hematomas under computed tomographic control using a new device. Neurosurgery 1992;31 (2):330-4.

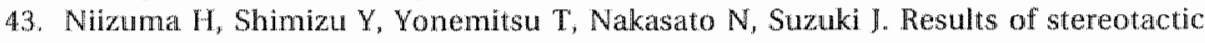
aspiration in 175 cases of putaminal hemorrhage. Neurosurgery $1989 ; 24(6) ; 814-9$.

4.4. Zuccarello M, Brott 'T, Derex L, Kothari R, Sauerbeck L, Tew I, Van Loveren H, Yeh HS, Tomsick T, Pancioli A, Khoury J, Broderick J. Early surgical treatment for supratentorial intracerebral hemorrhage: a randomized feasibility study. Stroke $1999,30(9): 1833-9$.

45. Rohde V, Rohde I, Reinges MH. Mayfrank L, Gilsbach JM. Frameless stereotactically guided catheter placement and fibrinolytic therapy for spontaneous intracerebral hematomas: technical aspects and initial clinical results. Minim. Invasive Neurosurg. $2000 ; 43[1]: 9-17$.

46. Lopez Valdes E, Hernandez Lain A, Calandre L, Grau M, Cabello A, Gomez Escalonilla C. Time window for clinical effectiveness of mass evacuation in a rat balloon model mimicking an intraparenchymatous hematoma. J. Neurol. Sci. 2000;174(1):40 6.

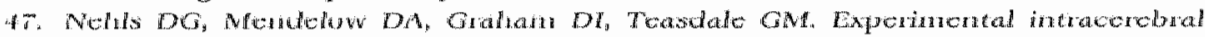
hemorthage: early removal of a spontaneous mass lesion improves late outcome. Neurostirgery 1990;27(5):674-82.

48. Broderick JP. Brot TG, Tomsick T. Barsan $W$, Spilker J. Uhra-early evaluation of intracerebral hemorthage. J. Neurosurg. 1990;72(2):195-9

49. Brott 'T, Broderick J, Kothari R, Barsan W, Tomsick T, Sauerbeck L, Spilker J, Duldner J. Khoury I. Early hemorrhage growth in patients with intracerebral hemorrhage. Stroke $1997 ; 28(1): 1-5$

50. Kazui S, Naritomi H. Yamamoto H, Sawada T, Yamaguchi T. Enlargement of spontaneous intracerebral hemorrhage. Incidence and time course Stroke 1996;27(10): $1783-7$

51. Schaller C, Rohde V, Meyer B, Hassler W. Stereotactic puncture and lysis of spontaneous intracerebral hemonthage using recombinant tissue plasminogen activator. Nounosurgery 1995;36(2):328-33.

52. Deinsberger W, Vogel I, Fuchs C, Auer LM, Kuschinsky W, Boker DK. Fibrinolysis and aspiration of experimental intracerebral hematoma reduces the volume of ischemic brain in rats. Neurol. Res. 1999;21(5):517-23. 


\section{Early hematoma enlargement and rebleeding in intracerebral hemorrhage: Analysis of prognostic factors in relation to stereotactic aspiration with the use of urokinase.}

O.P.M.Teernstra ${ }^{1}$, J. Lodder ${ }^{2}$, G. Blaaum ${ }^{1}$

Dept of Neurosurgery ${ }^{1}$ and Neurology ${ }^{2}$, University Hospital Maastricht, Dept of Neurosurgery ${ }^{1}$ Atrium Medical Center Heenen, The Netherlands

Submitted 


\section{ABSTRACT}

Recent evidence has shown that spontaneous intracerebral hematoma (ICH) is not a monophasic event. In up to $50 \%$ of cases, hematoma enlargement occurs in the acute phase, mostly by continuous bleeding within the first hours post-stroke. In a quarter of these, it will result in early neurological deterioration. With the introduction of stereotactic methods that use thrombolytic agents to liquefy the clot, it is necessany to identify a possible increased risk for hematoma enlargement or early rebleeding.

Methods. From 1996 to $1999,7 \perp$ patients were included in the SICHPA trial (Stereotactic treatment of intracerebral hematoma by means of a plasminogen activator), a multicenter randomized clinical trial. After dismissing one patient with an arteriovenous malformation and 7 because of protocol violations, 63 remaining were analysed 33 in the conservative and 30 in the stereotactic group). The patients were divided into a group with substantial hematoma enlargement $(\geq 40 \%)$ during the first week and one without. Apart from the treatment variable, several other variables that are reported to be related to an increased risk of hematoma enlargement were selected: age (>70), gender, GCS score $(<10)$, history of diabetes mellitus or stroke, systolic blood pressure ( $\geq 195 \mathrm{mmHg}$ ) on admission, initial ICH size, ICH location (lobar or deep), intraventricular blood, impaired coagulation. Uni- and multivariate testing (Mann Whitney U-test, logistic regression analysis) was performed with these variables. Furthermore, these analyses were done separately with surgical patients, while surgery-related variables were added: time to surgery, total aspiration volume larger than initial ICH volume, volume at last aspiration exceeding average aspiration volume. To identify eany rebleeding and recurent bleeding (instead of early hematoma enlargement in the acute phase), all patients reported with rebleeding were analyzed and discussed case by case.

Results. Of the 59 patients analyzed 63 minus 4 due to missing CT-scans), $5(19 \%)$ in the conservative group and $7(25 \%)$ in the stereotactic group had substantial hematoma enlargement within one week post-stroke. Seven parients (58\%) with such a substantial enlargement deteriomated neurologically (defined as a $25 \%$ drop in score or more on Scandinavian Stroke Scale) duing the first week, compared to $21(47 \%)$ in the group without ICH enlargement. In the overall analysis, as well as the surgical subgroup analysis, none of the variables could be identified as a statistically significant, independent risk factor for hematoma enlargement during the first week post-stroke.

From the 8 cases that were reported to have rebleeding, 4 patients with actual rebleeding were verified after case by case analysis, 3 with early 
rebleeding in the surgical group (10\%) and one with recurrent bleeding in the conservative group ( $3 \%$ ).

Discussion. The $20 \%$ rate for early hematoma enlargement, with a $58 \%$ rate for early neurological deterioration in these patients, and $10 \%$ early rebleeding in surgical patients, is well within the range of figures reported by previous studies. The stereotactic treatment with urokinase used in the SICHPA trial, could not be linked to an increase in either hematoma enlargement or rebleeding. Possibly the number of patients $(n=59)$ was too small too detect such a relationship.

Stereotactic treatment of $1 \mathrm{CH}$ using thrombolytic agents theoretically poses a potentia risk of hematoma enlargement. However, it also provides an opportunity to drain the ICH in the acute phase, preventing hematoma enlargement and subsequent neurological deterioration. Future research will determine if this holds true. 


\section{INTRODUCTION}

Spontaneous intracerebral hematoma (ICH) is twice as common as subarachnoid hemorrhage, afflicting 10 to 20 persons per 100,000 annually $(1,2)$. ICH is a devastating disease with a high mortality rate of $23 \%-58 \%$ at six months (twice that of ischemic stroke) and it often results in severe disability in survivors (3-9). Most deaths occur within two days after stroke; the 2-day mortality rate is reported to be as high as $44 \%(10)$. There is still debate about which treatment should be recommended, as there is no proof that surgery is better than conservative medical treatment alone $(11,12)$. New minimally invasive surgical techniques have been developed to remove the ICH clot but studies on these remain inconclusive (13).

Intracerebral hemorrhage was until recently thought to be a monophasic event, assuming that active bleeding had stopped minutes after onset. The frequently seen early neurological deterioration and high mortality in the first days post-stroke were attributed to progression of cerebral edema and mass effect of the ICH (14-16). This has been refuted by new evidence that hematoma enlargement caused by ongoing bleeding occurs in up to $38 \%$ of cases in the acute stage (17-19). Hematoma enlargement is of prognostic importance, as it is held mainly responsible for the early neturological deterioration seen within the first day post-stroke in up to 25 percent of $I C H$ patients, who initially present as being fully alert $(16,18,20,21)$.

Analysis of factors involved in hematoma enlargement or in hematoma recurrence has up to now only been performed retrospectively $(22,23)$ or in a non-randomized prospective manner $(18,24)$. Hematoma enlargement is associated with fluctuating high blood pressure ( $\geq 195 \mathrm{mmHg}$ systolic) on admission, coagulation disorders, liver disease, a history of brain infarction, large hematoma $(\geq 25 \mathrm{ml}$.), lowered conscious level, poorly controlled diabetes (fasting plasma glucose $\geq 141 \mathrm{mmol} / \mathrm{l}$ or glycosylated hemoglobin Alc $\geq 5.1 \%)$ combined with high systolic blood pressure $(\geq 200 \mathrm{mmHg})(22$, $25-30$ ). There have been several randomized studies that investigated the efficacy of surgery in ICH patients compared to best medical supportive care alone $(1,12)$ but apart from reporting the frequency of rebleeding there has as yet been no further analysis of factors involved.

ICH volume and ICH volume reduction is independently related to (functional) outcome $(10,20,31)$. When lowering the mortality rate of ICH is the primary goal of a newly developed surgical method, most gain can be achieved by substantial ICH volume reduction within the first days post-stroke. One such relatively new technique involves the use of a stereotactic frame and thrombolytic agents to liquefy the ICH clot. This method has one clear drawback, as it is not possible to directly observe 
hemostasis by confirming the initial source of bleeding. This shortcoming is of even greater interest when thrombolytic drugs like urokinase or recombinant tissue plasminogen activators ( $r$ PA) are used. This kind of surgery maybe effective in ICH clot reduction (31), but in some patients it may also inadvertently bring about a substantial $I \mathrm{CH}$ enlargement caused by prolonged bleeding or eliciting early rebleeding. Hematoma enlargement can then be interpreted, not just as a normal event in the natural course of the disease, but also as a harmful side-effect of surgery.

Given the fact that hematoma enlargement occurs mainly within the first hours after stroke onset, timing of (stereotactic) surgery needs to be considered carefully to prevent ongoing bleeding after surgery. Morgenstein et al. concluded that an unacceptable increased risk for early rebleeding and ensuing high mortality exists when ICH patients were operated upon within 4 hours after stroke onset (32). It has been suggested that aspiration and thrombolysis be avoided in the initial 6 to 24 hours after ICH onset (33).

ICH-patients who survive their initial ICH, are known to have an increased risk of rebleeding either at the site of the initial ICH (33\%) or elsewhere in the brain (24). The natural incidence rate of such a recurrent bleeding varies between 2.4 and $24 \%(9,23,24,34-37)$. Rebleeding in ICH is not uniformly defined. Generally, recurrent bleeding is reported as renewed hemorrhage that occurs at least 30 days after the first ICH. Within the direct period after the first hemorrhage the term 'early rebleeding' is sometimes used to describe substantial hematoma enlargements based on increased hemorrhaging within the hematoma $(32,38)$.

With the introduction of stereotactic surgery combined with the use of local thrombolytic drugs, a definite need exists to determine if this constitutes the introduction of an extra risk factor for hematoma enlargement and rebleeding. From 1996 to 1999 the SICHPA study (Stereotactic treatment of ICH by means of a Plasminogen Activator), a randomized, clinical trial was conducted to evaluate the efficacy of this treatment compared to supportive medical treatment (13). The main goal of this paper is to determine whether our intervention was associated with possible complications such as hematoma enlargement in the acute phase or with an increased risk for rebleeding later on. Firstly, possible independent risk factors, including stereotactic surgery, associated with substantial ICH enlargement in the first week post-stroke, are investigated. Secondly, we try to identify, within the surgical arm of the SICHPA trial-population, specific stereotactic surgery-related independent risk factors of $\mathrm{ICH}$ enlargement in the first post-operative week. Thirdly, cases of reported rebleeding are analyzed in order to determine if rebleeding represents a complication of our surgical intervention. 


\section{METHODS}

The SICHPA trial included 71 patients from four neurosurgical departments of major university hospitals in The Netherlands. The goal of the analysis was identifying risk factors and frequency of rebleeding; therefore, only patients who abided by the study protocol and the allocated intervention were selected. Inclusion criteria were: a spontaneous (non-neoplastic, non-aneurysmatic or caused by an arteriovenous malformation) supratentorial ICH. ICH volume $>10 \mathrm{ml}$, age $>45$ years, Glasgow EM score ranging from 2 to 10 , treatment possible within 72 hours post-stroke, informed consent. Pre-stratification was performed for center of inclusion and Glasgow Coma Score on admission before patients were randomized by an independent office (blinded). Base-line characteristics that were recorded: history of diabetes mellitus (DM), history of stroke, history of hypertension, history of cardiological disease (ischemic heart disease, heart failure, arrhythmias), history of hemorrhagic diathesis (easy bruising, epistaxis) and the use of anticoagulants (aspirin, warfarines or heparin), Glasgow Coma Scale, pupil size and reactivity and blood pressure, and laboratory tests for possible abnormal haemostasis (low platelet count \& $50 \times 10^{9} / \mathrm{L}$ ) and/or aPTT $>50 \mathrm{sec}$ and/or PTT $>11 \mathrm{sec}$.). A CT scan provided data on ICH volume, location, IVH and edema. For specific details regarding the procedure and baseline characteristics of the patients, the reader is referred to the original publication (13).

Surgical treatment consisted of a stereotactic procedure in which a catheter was placed in the center of the ICH-clot. After aspiration of as much of the ICH as possible, 5000 IU urokinase were infused. At six-hour intervals for the next 48 hours, the process of aspiration and urokinase instilment was repeated, and then the catheter was removed. The altemative treatment consisted of usual conservative medical support (antibiotics, mechanical ventilation, (CP monitoring, steroids etc as indicated).

At regular intervals in the 6-month follow-up measurements were done (CT-scan day 1, 3, 7 and 180, functional outcome, degree of disability (Scandinavian Stroke Scale, Barthel Index, Modified Rankin Scale and quality of life). Modalities of supportive medical care as well as complications such as convulsions, infections etc. in both groups were also recorded. Death, rebleeding and violations of the trial protocol were recorded and immediately reported to the investigators and monitoring committee. Date and cause of death were registered.

The first part of this paper concerns ICH enlargement as a possible early complication of surgery. To investigate hematoma enlargement systematically, $\llbracket C H$ volumes on subsequent $\mathrm{CT}$-scans during the first week 
post-stroke were compared. ICH volume was measured with a validated rule of thumb: $\mathrm{ABC} / 2$, where $\mathrm{A}$ is the largest diameter of the $\mathrm{ICH}, \mathrm{B}$ is the diameter perpendicular to $A$ and $C$ is the height (number of slices times slice thickness) (39). Intraventricular extension (IVH) was not included in the measurements. A more detailed description of this procedure can be found in Teernstra et al. (31).

The cut-off point for a substantial ICH volume enlargement was chosen as an increase of $40 \%$ or more between two subsequent measurements (initial volume compared to volume at day 3 , and the volume at day 3 compared to that at day 7 post-stroke). This point seems a reasonable enlargement, it lies between the cut-off points taken by Brott et al. (33\%) (18) and those of Kazui et al. $(19,22)(40 \%$ or absolute volume increase of $=12.5$ ml.) and Fujii et al. (30) (50\%). The distribution of variables that can hypothetically alter the risk of hematoma enlargement in the first week post-stroke, was compared between the group with rebleeding and the one without. They included: age, gender, stereotactic or conservative treatment, GCS score, history of diabetes mellitus or stroke, systolic blood pressure on admission, initial ICH size, ICH location (lobar or deep), the presence of IVH, impaired coagulation (the use of anticoagulant medication or abnormal laboratory investigations: low platelet count $\left(<50 \times 10^{9} / \mathrm{L}\right)$ and/or aPTT $>50 \mathrm{sec}$ and/or PTT>1 $1 \mathrm{sec}$.). To asses whether the hematoma enlargement coincided with a substantial neurological deterioration, patients with a $25 \%$ drop or more in their Scandinavian Stroke Scale at the time of volume measurement (day 3 or day 7) were identified. A separate analysis was performed only on the surgical patients. In this analysis, apart from the above-mentioned, also surgery-specific variables were included: time to surgery, ratio of total aspirated volume and the initial ICH volume combined with the total volume of infused urokinase solution, and the ratio of the last aspirated volume and the average volume for each aspiration in the patient.

Data are expressed as mean with a $95 \%$ Confidence interval $(95 \% \mathrm{Cl})$, statistical significance is tested two-tailed and expressed as $\mathrm{p}<0.05$. Univariate (cross-tabulations and Mann Whitney U-tests) and multivariate testing (logistic regression analysis) were used to compare the two groups. To enter variables into the logistic analysis, some were dichotomized: age > 70 (according to the median value), initial GCS score $<10$ points (median value), high systolic blood pressure on admission ( $\geq 195 \mathrm{mmHg}$ ), large $\mathrm{ICH}$ size (> $59 \mathrm{ml}$.; median value, well above the $25 \mathrm{ml}$ used by Kazui et al. (22)), time to surgery $<6$ hours (time of most ongoing bleeding), a total volume aspirated of $100 \%$ or more compared to the initial $1 \mathrm{CH}$ volume plus the total amount of infused urokinase solution (a possible cause of ongoing bleeding during the procedure), and a $50 \%$ or greater increase in the last aspirated 
volume compared to the average volume aspirated (signifies a possible rebleeding at the end of the procedure).

The second part of this paper concerns rebleeding after the acute phase of hematoma enlargement (within 48 hours post-stroke). The attending consultants in the participating centers diagnosed rebleeding, a priori defined in the study protocol as a sudden neurological deterioration followed by a CT scan showing a substantial increase in $I C H$ volume. The findings in these patients, which were later verified using the data records, are discussed in separate case reports. Based on the time of onset and a possibly different pathological mechanism, rebleeding was reclassified into early rebleeding and recurrent bleeding. Early rebleeding was defined as a new $\mathrm{ICH}$, or renewed bleeding in the original ICH causing hematoma enlargement after 48 hours up to 30 days post-stroke. Recurrent (late) rebleeding was defined as a new ICH in the same location as the initial one, or located elsewhere in the brain during the rest of the follow-up period after 30 days.

\section{RESULTS}

\section{Part 1: Riskfactors in hematoma enlargement}

Of the 71 patients who were randomized, one was excluded because later diagnostic investigations demonstrated an arteriovenous malformation to be the cause of the $\mathrm{ICH}$. As this analysis aims at identifying risk factors and frequency of rebleeding only patients who abided by the study protocol and the allocated intervention were selected. In all there were 7 protocol violations leaving 63 patients for analysis, 30 in the stereotactic group and 33 in the conservative group ( $A$ more detailed description can be found in the original publications (13)).

Data concerning 59 of the 63 patients could be analyzed, 12 of whom had a hematoma enlargement of $40 \%$ or more within the first week post-stroke. In four cases missing CT-scan data prohibited analysis, two of them received stereotactic surgery and the other two conservative treatment, in none of these cases however was rebleeding reported. Table 1 presents an overview of the distribution of different possible risk factors involved in hematoma enlargement during the first week post-stroke.

In the stereotactic group 7 out of $28(25 \%)$ patients had substantial hematoma enlargement within the first week post-stroke compared to 5 out of $31(19 \%)$ in the conservative group. In all the patients only 'history of stroke' showed a statistically significant over-representation $(p=0.038)$ in 
Table 1. Riskfactors in ICH enlargement during first week

\begin{tabular}{|c|c|c|c|c|c|c|c|}
\hline \multirow[b]{3}{*}{ Variables } & \multicolumn{7}{|c|}{ ICH volume increase first week post-stroke } \\
\hline & \multicolumn{3}{|c|}{ Absent or small $(<40 \%)$} & \multicolumn{4}{|c|}{ Substantial $(240 \%)$} \\
\hline & $\mathrm{n}^{\dagger}$ & Meana & $\mathrm{SD}$ & n & Mean & SD & $\operatorname{sig}$ \\
\hline Gender $=$ female & 47 & $42.6 \%$ & & 12 & 33.3 & & 0.565 \\
\hline Age on admittance & 47 & 68.1 & 9.5 & 12 & 58.7 & 10.8 & 0.792 \\
\hline History of diabetes mellitus & 46 & $1.3 .0 \%$ & & 11 & $0.0^{\mathrm{yg}}$ & & 0.209 \\
\hline History of stroke & 46 & $28.3 \%$ & & 12 & $0.0 \%$ & & 0.038 \\
\hline Stereotactic treatment & 47 & $48.9 \%$ & & 12 & $58.3 \%$ & & 0.564 \\
\hline Abnormal hemostasis & 44 & $43.2 \%$ & & 11 & $27.3 \%$ & & 0.340 \\
\hline Systolic blood pressure & 46 & 186.5 & 34.1 & 12 & 194.2 & 40.1 & 0.470 \\
\hline Glasgow Coma Score & 47 & 9.4 & 2.7 & 12 & 10.6 & 2.7 & 0.178 \\
\hline Initial ICH volume $(\mathrm{ml})$ & 44 & 61.7 & 30.7 & 12 & 44.2 & 26.5 & 0.086 \\
\hline Lobar localization ICH & 47 & $55.3 \%$ & & 12 & $41.7 \%$ & & 0.402 \\
\hline WH present & 47 & $38.3 \%$ & & 12 & $16.7 \%$ & & 0.161 \\
\hline SSS $25 \%$ drop in score & 45 & $46.7 \%$ & & 12 & $58.3 \%$ & & 0.476 \\
\hline Survival (days) & 47 & 88.8 & 82.4 & 12 & 80.9 & 88.0 & 0.570 \\
\hline
\end{tabular}

* See methods section of the text for a more detailed description; $\$ n=$ number of patients, $\mathrm{SD}=$ Standard Deviation, sïg = two-tailed statistical significance in Mann Whitney $U$ - test expressed as pinvalue

the group with no or small hematoma enlargement (13 patients) compared to the group with substantial enlargement ( 0 patients). Initial $\mathbb{I C H}$ volume was a mean of $62 \mathrm{ml}$ in the non-substantial, compared to $44 \mathrm{ml}$ in the substantial ICH enlargement group, just not statistically significant $(p=0.086)$. Diabetes, a history stroke, abnormal hemostasis, large initiall $\mathrm{ICH}$ volumes and the presence of intraventricular hemorrhage were, albeit not statistically significant, more frequent in the group without substantial ICH enlargement. In both groups, about half of the patients experienced a neurological deterioration (defined as a $25 \%$ drop or more in SSS score) during the first week. The average survival of 80 to 90 days post-stroke was also similar. Logistic regression analysis with the same variables, and ICH increase of $40 \%$ or more as the dependent variable, failed to demonstrate statistical significance (best p-value in the model greater than 0.2 ) in the effects of any one of them. The stereotactic intervention had an Odds Ratio (OR) of 1.164 with a wide $95 \%$ confidence interval (95\%Cl: 0.164 to 8.244) which was not statistically significant $(\mathrm{p}=0.879)$.

The 30 surgical patients of the SICHPA trial were separately analyzed for possible surgery-related risk factors for $\mathrm{ICH}$ enlargement during the first week post-stroke. 
Table 2 shows the distribution of possible risk factors.

Univariate analysis (Mann Whitney U-test) showed no statistically significant differences between the group with, and the one without substantial ICH enlargement. Most of the distribution of the variables in the surgical arm of the SICHPA trial was comparable to that of all of its patients. Patients with a history of stroke, DM or ones with intraventricular bleeding are absent from the group with substantial hematoma enlargement during the first post-stroke week. More patients in the group with enlargement ( $86 \%$ compared to $50 \%)$ have a neurological deterioration $(\geq 25 \%$ drop in SSS score) in this period. The mean survival time was shorter for patients with substantial $\mathbb{} \mathrm{CH}$ enlargement $(65$ compared to 100 days, $\mathrm{p}=0.06)$. Concerning the surgical variables, a total aspirated volume exceeding the initial ICH volume, a volume at the last aspiration greater than the average aspirated volume, and a longer time to surgery, were encountered more

Table 2. Riskhactors in firs week ich enlargement surgical patiens

\begin{tabular}{|c|c|c|c|c|c|c|c|}
\hline \multirow[b]{3}{*}{ Variahloses } & \multicolumn{7}{|c|}{ ICH wolume increase finst week post-stroke } \\
\hline & \multicolumn{3}{|c|}{ small $(<40 \%)$} & \multicolumn{4}{|c|}{ substantial $(\geq 40 \%)$} \\
\hline & $\mathrm{nt}$ & Mean & $\mathrm{SD}$ & $\mathrm{n}$ & Meran & $\mathrm{SD}$ & $\operatorname{sig}$ \\
\hline Gender = Comale & 23 & $39.1 \%$ & & 7 & $28.6 \%$ & & 0.701 \\
\hline Age on admuluance & 23 & 66.0 & 9.0 & 7 & 68.9 & 8.1 & 0.501 \\
\hline History of stroke & 23 & $21.7 \%$ & & 7 & $0.0 \%$ & & 0.413 \\
\hline History of diabotes mellitus & 22 & $9.1 \%$ & & 7 & $0.0 \%$ & & 0.746 \\
\hline Abnomal hemostasis & 22 & $36.4 \%$ & & 6 & $16.7 \%$ & & 0.494 \\
\hline Systolic blood pressure (mmHg) & 22 & 193.6 & 29.5 & 7 & 191.4 & 38.5 & 0.980 \\
\hline Glasgow Coma scone & 23 & 9.4 & 2.9 & 7 & 9.6 & 2.8 & 0.962 \\
\hline 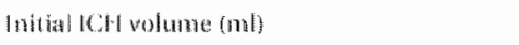 & 21 & 69.7 & 30.7 & 7 & 53.7 & 23.6 & 0.189 \\
\hline Loban localization ret & 23 & $60.9 \%$ & & 7 & $71.4 \%$ & & 0.701 \\
\hline IVH present & 23 & $39.1 \%$ & & 7 & $0.0 \%$ & & 0.131 \\
\hline SSS $\geq 25 \%$ drop nn sono & 22 & $50.0 \%$ & & 7 & 85.79 & & 0.165 \\
\hline Survion (dings) & 23 & 100.7 & 85.2 & 7 & 34.67 & 65.4 & 0.061 \\
\hline \multicolumn{8}{|l|}{ Surgienl parammaters } \\
\hline 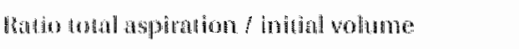 & 21 & 1.26 & 0.74 & 7 & 1.20 & 1.33 & 0.381 \\
\hline 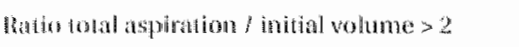 & 21 & $19.0 \%$ & & 7 & $14.3 \%$ & & 0.780 \\
\hline 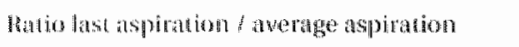 & 23 & 1.56 & 1.21 & 7 & 1.19 & 1.28 & 0.339 \\
\hline Bat to last aspinatom / awerage aspination 20.5 & 23 & $47.8 \%$ & & 7 & $28.6 \%$ & & 0.376 \\
\hline Mino lo sumperg (Honurs & 23 & 18.9 & 17.3 & 7 & 9.4 & 6.1 & 0.386 \\
\hline Tine usurgery $<$ b thrs & 23 & $30.4 \%$ & & 7 & $28.6 \%$ & & 0.962 \\
\hline lime lo surgery $<12$ hours & 23 & $56.5 \%$ & & 7 & $7 \mathrm{l} .4 \%$ & & 0.564 \\
\hline
\end{tabular}


frequently in the group without a substantial ICH enlargement. However none of these differences was statistically significant. Logistic regression analysis showed no statistically significant effect of either one of the variables, on the risk of a substantial hematoma enlargement (best p-value $>$ 0.2). Time to surgery of less than 6 hours had an OR of $1.5(95 \% \mathrm{CI}: 0.07-35.4$, $\mathrm{p}=0.79$ ), a total aspirated volume of twice the initial $\mathrm{CH}$ volume had an OR of $0.12(95 \% \mathrm{Cl}: 0.002-7.4, \mathrm{p}=0.31$ ), and a last aspiration volume greater than the average aspirated volume had an OR of $2.2(95 \% \mathrm{CI}: 0.34-14.9, p=0.40)$. The analysis was repeated with a variable time to surgery less than 12 hours post-stroke' (instead of 6 hours). There were no significant changes compared to the earlier model; the OR for this variable was $1.6195 \% \mathrm{CI}$ : $0.06-45.6, p=0.78)$.

\section{Part 2: rebleeding after the acute phase: 8 case reports}

Seven patients were reported to have hematoma growth coinciding with neurological deterioration. One conservatively treated patient without neurological deterioration had a recurrent hematoma in the contralateral hemisphere 178 days after the primary ICH, although he was not officially reported to have a rebleeding. Specific details of all eight patients are discussed in the following case reports; their CT-scans are shown in figure $1 \mathrm{a}$ and $1 \mathrm{~b}$. In one case there was increased edema, and thee had hematoma enlargement in the acute phase, accompanied by a progressive neurological deterioration (not considered as rebleeding). Of the remaining four patients, three in the stereotactic group (10\%) had early rebleedings and one in the conservative group ( $3 \%$ ) had a recurrent bleeding.

\section{Case reports of rebleeding}

Case 1, a 50-year-old male with no history of elevated blood pressure, stroke or DM, presented 3 hours post-stroke with a GCS score of E2M6V3, left-sided hemiparalysis, a blood pressure of 220 over $104 \mathrm{mmHg}$ and normal hemostasis. A CI-scan 3.5 hours post-stroke, showed an $1 \mathrm{CH}$ in the right thalamus, volume $48 \mathrm{ml}$, with a ventricular component. Stereotactic aspiration was perfomed 7 hours post-stroke and over the course of two days $135.5 \mathrm{ml}$ blood was aspirated. CT-scans 21,43 and 141 hours post-stroke showed an ICH volume decrease to $13 \mathrm{ml}$, but a small new hematoma had accurred alongside the route of the catheter. At day 3 post-stroke the GCS had improved to EAM6V4 and he had regained strength in his $l e f t$ leg at the end of follow-up at 180 days. The occurrence of a small, subclinical hemorrhage in the trajectory of a stereotactical procedure is a 

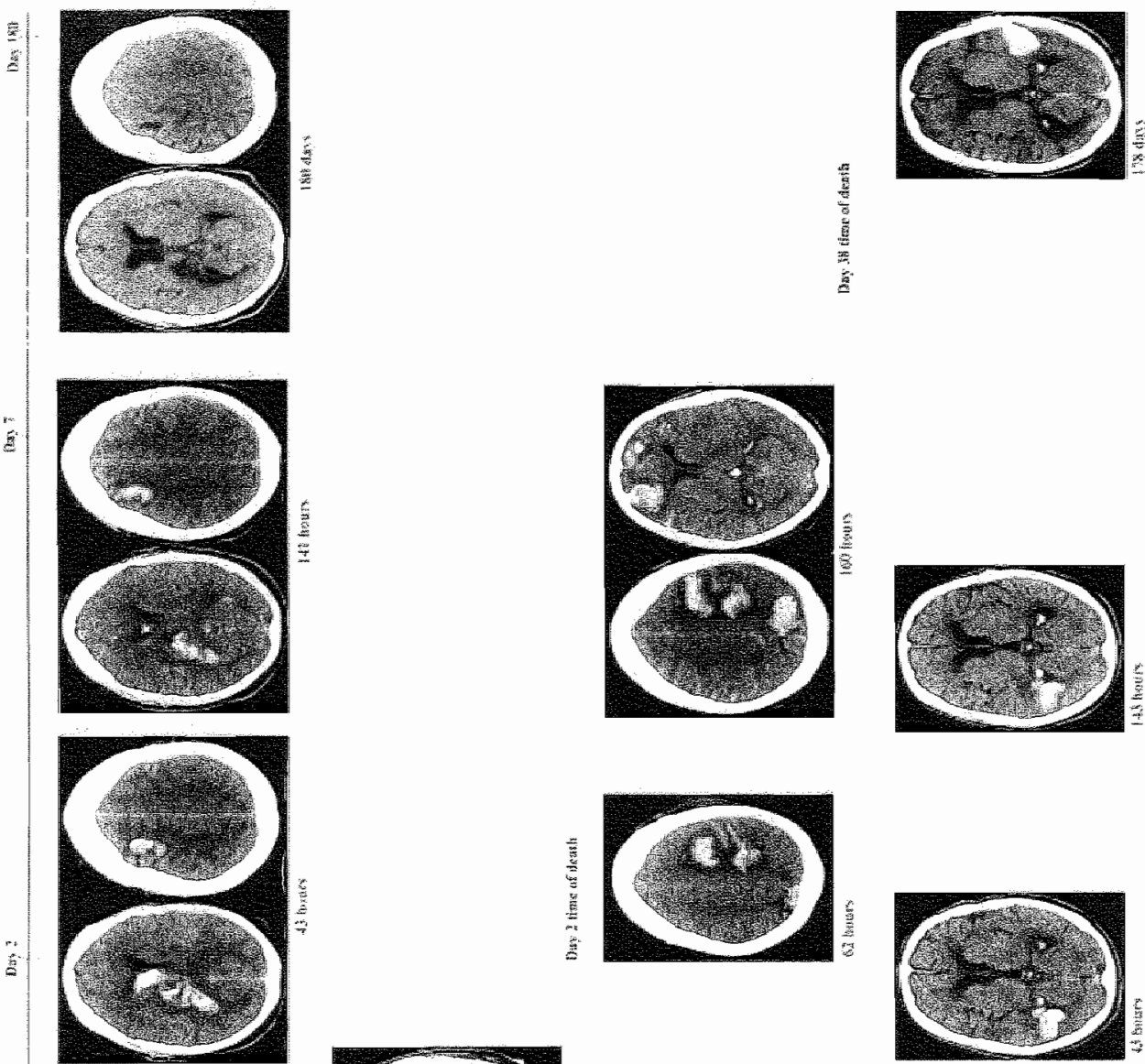

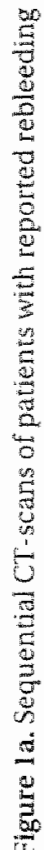
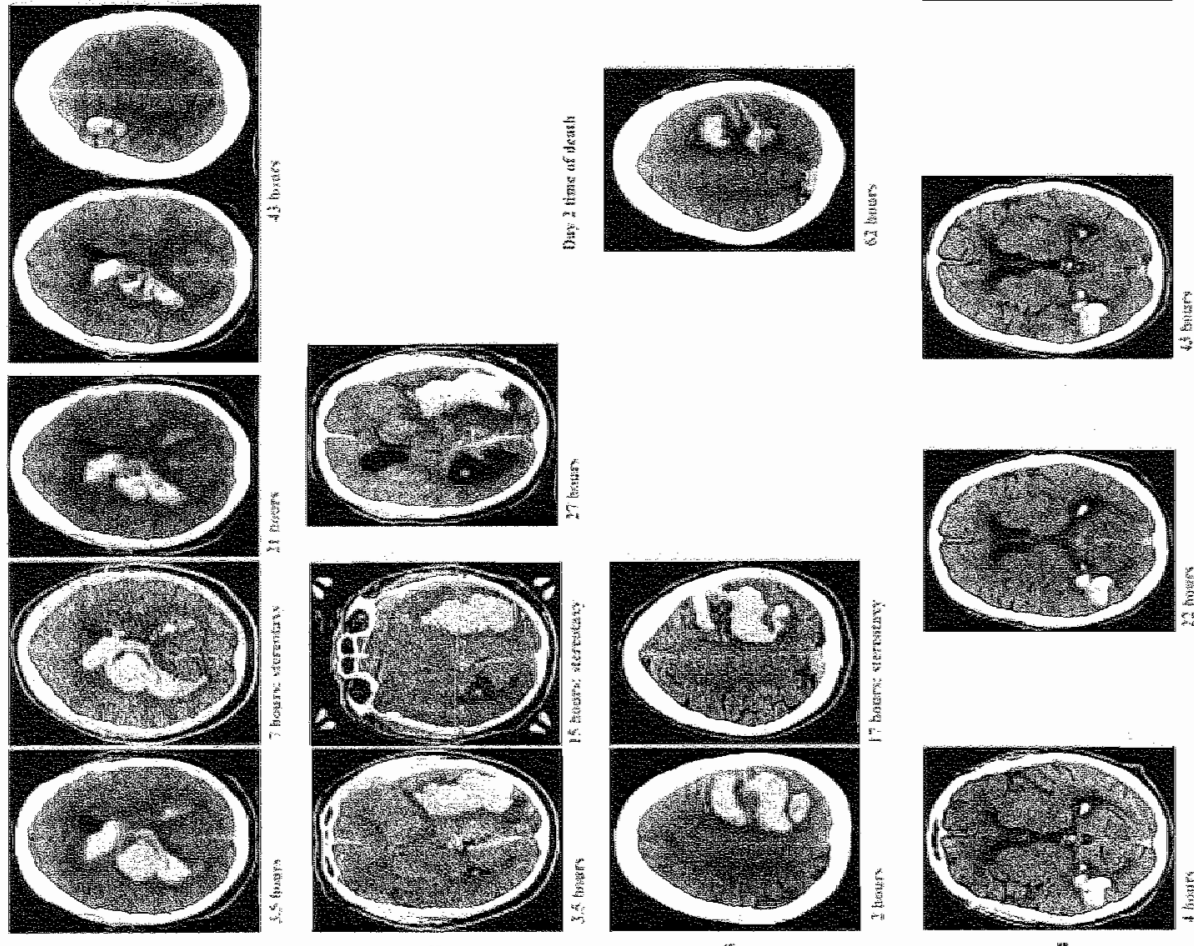

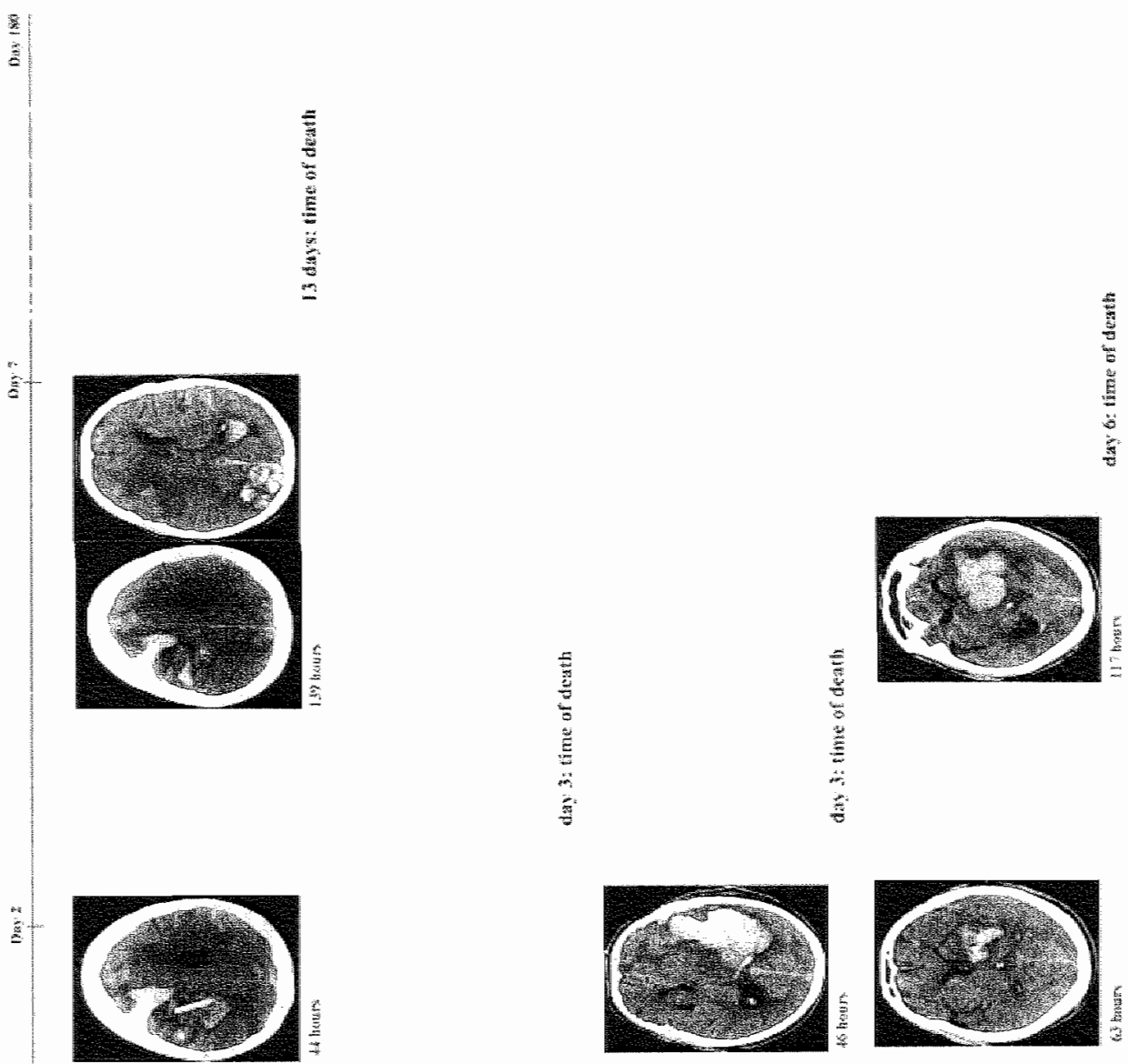

专 
well-known complication (in approximately $2 \%$ of cases) with this kind of surgery. In our opinion this case should not therefore be considered as a case of rebleeding,

Case 2, a 73-year-old male with a history of elevated blood pressure, was admitted 2 hours post-stroke in a deteriorating neurological condition: GCS of E1M4V2, a blood pressure of 190 over $95 \mathrm{mmHg}$. CT-scanning 3.5 hours post-stroke, showed a right sided lobar hematoma with volume of $73 \mathrm{ml}$ and the presence of subarachnoid blood. At 15 hours post-stroke stereotactic aspiration was initiated. After 3 aspirations (total $101 \mathrm{mll}$ ), the patient's deterioration had still not been halted. Ensuing CT-scanning (27 hours post-stroke) showed brain herniation with an increase in edema, midline shift and dilatation of the contralateral ventricle, but with a small reduction of the ICH (to $68 \mathrm{ml}$ ). The patient died the next day. In this case hematoma enlargement was absent, and surgery could not prevent further deterioration which was probably caused by the effects of increased edema.

Case 3, a 70-year-old female patient, was admitted 1 hour post-stroke with a right-sided hemiparalysis, GCS score of E4M5VI and a normal blood pressure of 120 over $85 \mathrm{mmHg}$. CT-scan on admission ( 2 hours post-stroke) showed a massive left-sided parietal ICH $(76 \mathrm{ml}), 16.5$ hours post-stroke stereotactic aspiration took place, a total of $47 \mathrm{ml}$ was aspirated reducing the ICH volume to $37 \mathrm{ml}$ at 62 hours post-stroke. The patient experienced a sudden neurological deterioration, and a CT-scan (158 hours post-stroke and 91.5 hours after the last urokinase administration) showed a further reduction of the original $\mathrm{ICH}$ but also new $\mathrm{ICH}$ located bifrontally and left occipitally. No new surgery was performed, the patient's neurological condition did not worsen further but nor did it improve. The patient died 38 days post-stroke from a complicated pneumonia. This case illustrates early rebleeding with 3 new ICHs at different locations within one week after stroke onset.

Case 4, a 70-year-old male patient, with a history of ischemic stroke, presented with a GCS score of E4M5V2 and a slight right-sided hemiparesis. A CT-scan 4 hours post-stroke revealed a small right-sided lobar ICH (19 $\mathrm{ml}$ ). The patient was treated conservatively (according to randomization). The neurological condition improved to an almost pre-morbid level at the end of follow up. CT-scans at 22,43 and 143 hours post-stroke showed little change in ICH volume (to $21 \mathrm{ml}$ ). However, with no neurological deterioration at 178 days post-stroke, the CT-scan (according to trial protocol) coincidentally gave evidence of a small new lobar $\mathrm{TCH}$ in the contralateral hemisphere. This is a case of subclinical recurrent hemorrhage.

Case 5, a 74-year-old female patient was presented to the neurology department 2 hours post-stroke, with a history of transient ischemic attack 
for which she used aspirin on a daily basis. Her initial GCS score was E2M4V2, and blood pressure measured 180 over $140 \mathrm{mmHg}$. A CT-scan 2.5 hours after stroke onset, showed a right sided lobar ICH (volume $94 \mathrm{ml}$ ), with midline shift and intraventricular bleeding. Stereotactic surgery was performed 8 hours post-stroke, and over two days $151 \mathrm{ml}$ was aspirated. There was no clinical improvement in neurological condition, despite ICH volume reduction (to $63 \mathrm{ml}$ ) seen on CT-scanning 44 hours post-stroke. 139 hours after stroke onset a CT-scan demonstrated a further reduction of the original hematoma (to $29 \mathrm{ml}$ ) but also a new lobar $\mathrm{ICH}$ with a right occipital location and ventricular blood in the left occipital horn and the presence of SAH. From this day onwards, her neurological condition gradually worsened. At 21 days post-stroke, a sudden decline of consciousness occurred as result of a large new ICH located in the contralateral (left) hemisphere. 1 week later she died from septic shock as a result of complicated pneumonia. This case was considered an early rebleeding, in which a possible association with the stereotactic surgery could not be dismissed.

Case 6, a 67-year-old woman, was admitted 1 hour after stroke onset with a rapidly deteriorating neurological condition (from E4M6V5 to E1M2V1 within hours). CT-scanning showed a lobar hematoma in the left hemisphere $(72 \mathrm{ml})$. She used anticoagulants (warfarin); laboratory investigations demonstrated an INR of 3.01. Hemostasis was quickly corrected to normal. Stereotactic aspiration took place 8 hours post-stroke; $125 \mathrm{ml}$ were aspirated over the next 48 hours. Three days post-stroke she had a slightly better GCS score of E1M4V1, but this was only to last for a short time as she soon deteriorated further to a state of deep coma. CT-scan (from radiologist's report as CT-scan printout itself is missing) at three days showed a modest increase of the hematoma. The patient died the same day. In this case ongoing, active bleeding within the hemorrhage causing ICH enlargement was suspected, rather than a sudden early rebleeding, possibly related to warfarin use, although this had quickly been corrected. Any relationship with surgery is unclear, but seems unlikely as the rapid neurological deterioration started and mainly took place before the operation.

Case 7, a 74-year-old male, with a history of hypertension, was admitted 3 hours after stroke onset. He had an elevated blood pressure of 210 over 113 , and a GCS score of E3M5V3 and a slight right-sided hemiparesis. A CT-scan performed 3.5 hours post-stroke revealed a left parietotemporal ICH $(58 \mathrm{ml})$. Stereotactic aspiration started at 9 hours post-stroke, removing $41 \mathrm{ml}$ in total over the next two days. On the second day the neurological condition worsened (EIM3V1); CT-scans (28 and 46 hours post-stroke) showed an enlargement of the hematoma (to $123 \mathrm{ml}$ ). The following day the patient died. This case represents hematoma enlargement by ongoing 
bleeding within the acute phase (of which too small a part could be aspirated) and was not considered an actual rebleeding.

Case 8 , is a 67 year old male patient of Chinese origin who used warfarins after heart surgery 4 years earlier. He presented half an hour after stroke onset, with an elevated blood pressure of 180 over $110 \mathrm{mmHg}$ and a reduced consciousness (E3M4V1). CT scanning one hour post-stroke showed a small left-sided putaminal ICH $(7 \mathrm{ml})$. The anticoagulative action of the warfarins (INR 2.54) was corrected for. The next day a repeated CT scan (14 hours post-stroke) showed a slight increase to $11 \mathrm{ml}$. At 22 hours post-stroke, stereotactic aspiration was started. Total aspiration was $115 \mathrm{ml}$ over two days; by that time the patient had experienced a slight neurological improvement (E2M5V2). A CT-scan (63 hours post-stroke) however, did not show much volume change (tol3 ml). At 117 hours after stroke onset, 45 hours after the last urokinase infusion, there was an abrupt neurological deterioration. A CT-scan at that time revealed a substantial hematoma enlargement as the underlying cause. The patient died the next day. Early rebleeding seems to be the most probable cause of hematoma enlargement in this case. It is not clear whether this was associated with the use of warfarins (the hypocoagulative state was however quickly corrected after admission), or with the stereotactic procedure itself.

\section{DISCUSSION}

The stereotactic aspiration procedure used in the SICHPA trial could not be identified as an independent risk factor for hematoma enlargement (40\% or more) during the first week post-stroke. An overrepresentation of factors associated with hematoma enlargement (age, GCS score, history of diabetes mellitus or stroke, systolic blood pressure on admission, initial ICH size, ICH location (lobar or deep), the presence of IVH, impaired coagulation) was expected, but not found, in patients with an ICH volume increase of $40 \%$ or more during the first week post-stroke.

The mean time to surgery in patients with substantial hematoma enlargement was half that in the group without such an enlargement, but this difference was not statistically significant. Nor did any other variables related to the stereotactic procedure present as independent predictors for substantial hematoma enlargement. The relatively small number of patients analyzed may have caused the absence of statistical significance in the results. Analysis of reported rebleeding in the SICHPA trial could verify three patients with possible early rebleedings, all in the surgical arm of the trial. 
Initially intracerebral hemorrhage was believed to be a monophasic event, limited by the effects of clotting and tamponade by surrounding brain tissue (14-16). However, over the last decades, more evidence has emerged suggesting continuous bleeding of cerebral hemorrhage in the acute phase. Angiographic studies $(40,41)$ showed extravasation of contrast medium into the hemorrhage during the first hours after onset, as a sign of active bleeding. Computed tomography (CT) studies of Brott et al. (18) and Kazui et al. (19) demonstrated a more frequent expansion of hematomas within the first 3 hours after stroke ( $26 \%$ of 103 patients within 1 hour and $36 \%$ of 74 patients within 3 hours). Magnetic resonance imaging (MRI) confirmed these findings (42). Early hematoma enlargement is attributed to ongoing bleeding of the primary source and as a result of the tearing of blood vessels in the hematoma path. Active bleeding in ICH is believed to cease within a few hours after onset $(14,17,43)$. The incidence of hematoma enlargement is dependent on the timing of the first CT scan after stroke onset $(18,19,30)$. Fujii et al. (30) reported an incidence rate of $26.1 \%(n=4.19)$ when CT-scanning was done within one hour after onset, and only $1.4 \%$ when CT scanning took place after six hours or more. In the SICHPA study (13), 19\% in the conservative group and $25 \%$ in the stereotactic group had a substantial hematoma enlargement within the first week after stroke. This result is within the range of the above-mentioned studies, even somewhat lower than the $38 \%$ of 103 patients who had more than $33 \%$ hematoma growth within 24 hours after stroke onset in Brott's study (18). A limitation of this study, which is partly embedded in the nature of the disease studied, is the lack of control leading to variance in time intervals between stroke onset and the time of presentation at the emergency department (time of first CT-scan). The mean time interval from stroke to CT-scan was 9 hours in the SICHPA study. As the major part of hematoma enlargement occurs within the first 6 hours after stroke it may very well be that our findings represent underestimates.

In $58 \%$ of the patients with substantial hematoma enlargement during the first week (compared to $47 \%$ without) a neurological deterioration was observed. These figures are in accordance to those reported by Mohr et al. (16) who saw early deterioration in $56 \%$ of $115 \mathbb{1 C H}$-patients, and Brott et al. (18) with nearly $50 \%$ in patients with hematoma growth, but they are higher than the $23.1 \%$ reported by Qureshi et al. (20).

In a surgical approach, timing is essential; a rapid ICH volume reduction could prevent further neurological deterioration caused by hematoma enlargement in the acute phase, even within the first few hours post-stroke. However, such a rapid surgical intervention can also harm the patient, as an increased risk of early rebleeding may exist. Morgenstern et al. (32) investi- 
gated with a prospective randomized trial the ultra-early evacuation of ICH (within 4 hours after onset). After interim analysis, the trial was stopped with 11 patients having been operated on within 4 hours. A recurrence rate of $40 \%$ was found in this group compared to $12.8 \%$ in the group with patients operated between 4 and 12 hours after stroke onset. Four patients operated within 4 hours were reported to have postoperative rebleeds; three of them died as a result. This $75 \%$ mortality rate was significantly related to early surgery $(p=0,03)$.

Increased risk of early rebleeding especially needs to be taken into account when stereotactic aspiration techniques are used in combination with thrombolytic agents. In the SICHPA study an increased risk of hematoma enlargement was found in patients who were operated early (within 6 hours and 12 hours post-stroke the OR was respectively 1.5 and 1.6) but this was not statistically significant. Other factors related to the stereotactic aspiration such as the aspirated volume compared to the initial $\mathrm{ICH}$ volume could also not be related to hematoma enlargement.

The definition of rebleeding is not always clearly defined in literature. Hematoma enlargement or hemorrhage growth can be gradual as a result of ongoing bleeding especially in the first hours after stroke onset. It can also occur secondarily during the first days because of early rebleeding from the original source. Rebleeding may also refer to a recurrent hemorrhage after resolution of the primary hemorrhage or at another location in the brain. Renewed bleeding 30 days or more after the onset of the primary intracerebral hemorrhage is commonly recognized as 'recurrent' $(23,24,44)$. The natural incidence rate of recurrent ICH was reported as $2.4 \%$ to $24 \%$ per year, with a 3.8 -fold increased risk for patients with lobar $\operatorname{ICH}(9,23)$. Recurrent ICHs have a worse prognosis than first time ICHs $(44,45)$. Risk factors associated with recurrent ICH are uncontrolled high blood pressure $(46,47)$ and younger age of the patient (45).

In this study early rebleeding (after 48 hours up to 30 days post-stroke) was observed in 3 out of 30 patients of the surgical group (10\%), compared to one ( $3 \%$ ) recurrent bleeding (from 30 days to end of follow-up) in the conservative group, a statistically insignificant difference. Three percent recurrent bleeding is well within range with most reported rates. The $10 \%$ rebleeding rate is at the high end of internationally reported rates. Incidences of rebleeding were reported, but usually not further analyzed in studies that applied the stereotactic thrombolytic method. From the first large study published by Doi et al. in 1980, who reported $4 \%$ rebleeding in 241 cases (48), several rebleeding rates were published (table 3 ). 
Table 3. Stereotactic aspiration with thrombolysis: rebleeding rates

\begin{tabular}{lccc} 
Author & Year & Pateits $^{3}$ & Rebleding(\%) \\
\hline Doi et al. (48) & 1980 & 241 & 4 \\
Kaneko et al. (49) & 1983 & 93 & 13 \\
Matsumoto et al. (50) & 1984 & 51 & 3.9 \\
Yamanaka et al. (51) & 1988 & 69 & 2.9 \\
Nizuma et al. (33) & 1989 & 175 & 7.4 \\
Hondo et al. (52) & 1990 & 437 & 4 \\
Mohadjer et al. (53) & 1992 & 51 & 0 \\
Lippitz et al. (54) & 1994 & 10 & $10^{\dagger}$ \\
Marquardt et al. (55) & 2001 & 46 & 5.1 \\
\hline
\end{tabular}

* Patients in the stereotactically treated group; 1 Recombinant tissue plasminogen activator was used

A substantial part of early neurological deterioration and mortality is attributed to substantial hematoma enlargement in the acute phase of $\| \mathrm{CH}$. Stereotactic thrombolysis and aspiration of $1 \mathrm{CH}$ theoretically involves an increased risk of prolonging ongoing hemorrhaging or eliciting early rebleeding. However, the catheter that is used to aspirate thrombolyzed clot over the course of several days, can also serve as an outlet for any additional blood, therefore theoretically preventing hematoma enlargement. Investigation of this potentially beneficial effect may be the challenge for future research. The stereotactic method can be modified for this additional purpose by, for example, leaving the catheter open between the moments of urokinase infusions with clot aspirations, or continuing the aspiration procedures until only little amounts of liquefied clot can be aspirated and CT-scanning verifies substantial ICH volume reduction.

\section{CONCLUSION}

Our data sustain the recent evidence that hematoma enlargement is often seen in the acute phase of spontaneous intracerebral hematoma, with an incidence rate as high as $20 \%$ during the first week post-stroke. Stereotactic aspiration with urokinase-induced clot-lysis could not be linked to increased risks of hematoma enlargement or rebleeding. Possibly, due to small numbers, no statistically significant predictors for hematoma enlargement were found, but at least our data suggest that the procedure does not submit the patient to an undue risk of hematoma enlargement. 


\section{REFERENCES}

1. Furlan AJ, Whisnant JP, Elveback LR. The decreasing incidence of primary intracerebral hemorrhage: a population study. Ann. Neurol. 1979;5(4):367-73.

2. Broderick IP, Brott T, Tomsick T, Miller $\mathrm{R}_{v}$ Huster $\mathrm{G}$. Intracerebral hemorrhage more than twice as common as subarachnoid hemorrhage. J. Neurosurg. 1993;78(2):188-91.

3. Tuhrim S, Horowitz DR, Sacher M, Godbold $1 H$. Validation and comparison of models predicting survival following intracerebral hemorrhage. Crit. Care Med. $1995 ; 23(5): 950-4$

4. Sacco RL, Wolf PA, Kannel WB, McNamara PM. Survival and recurrence following stroke. The Framingham study. Stroke 1982;13(3):290-5.

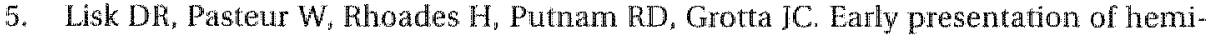
spheric intracerebral hemorrlyage: prediction of outcome and guidelines for treatment allocation. Neurology 1994;44(1):133-9.

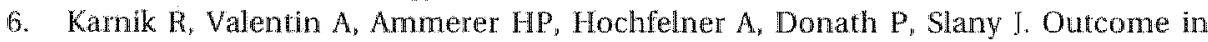
patients with intracerebral hemorrhage: predictors of survival. Wien. Klin. Wochenschr, 2000;112(4):169-73.

7. Jorgensen HS, Nakayama H, Raaschou HO, Olsen TS. Intracerebral hemornage versus infarction: stroke severity, risk factors, and prognosis. Ann. Neurol. $1995 ; 38(1): 45-50$.

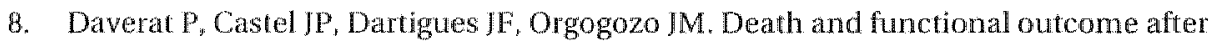
spontaneous intracerebral hemorrhage. A prospective study of 166 cases using multivariate analysis. Stroke 1991;22(1): I-6.

9. Fogelholm R, Nuutila M. Vuorela AL. Primary intracerebral haemorhage in the Jyvaskyla region, central Finland, 1985-89. incidence, case fatality rate, and functional outcome. I. Neurol. Neurosurg. Psychiatry 1992;55(7):546-52.

10. Brodenick JP, Brott TG, Duldner IE Tomsick T, Huster G. Volume of intracerebral hemorhage. A powerful and easy-to-use predictor of 30-day mortality. Stroke $1993 ; 24(7): 987-93$.

11. Fermandes HM, Gregson B, Siddique $S$, Mendelow AD. Surgery in intracerebral hemorrhage. The uncertainty continues. Stroke 2000;31(10):2511-6.

12. Prasad $k$, Shrivastava $A$. Surgery for primary supratentorial intracerebral haemorrhage. Cochrane Database Syst Rev $2000 ; 2$.

13. Teernstra OPM, Evers SMAA, Lodder J, Leffers P, Franke CL, Blaauw G. Stereotactic treatment of Intracerebral Hematoma by means of a Plasminogen Activator: A multicenter randomized controlled trial (SICHPA). Stroke accepted 2002

14. Herbstein DJ, Schaumberg HH. Hypertensive intracerebral hematoma. An investigation of the initial hemorrhage and rebleeding using chromium Cr 51 -labeled erythrocytes. Arch. Neurol. 1974;30(5):4112-4.

15. Hier DB, Davis KR, Richardson EP, Jr, Mohr JP. Hypertensive putaminal hemorthage. Ann. Neurol. 1977;1(2):152-9.

16. Molu JP, Caplan LR, Melski JW, Goldstein RJ, Duncan GW, Kistler JP, Pessin MS, Bleich HL.. The Harvand Cooperative Stroke Registry: a prospective registry. Neurology $1978 ; 28(8): 754-62$.

17. Fujitsu K, Muramoto M, Ikeda Y, Inada Y, Kim I, Kuwabara T. Indications for surgical treatment of putaminal hemorrhage. Comparative study based on serial CT and time-course analysis. J. Neurosurg. 1990;73(4):518-25. 
18. Brott T, Broderick J, Kothari R, Barsan W, Tomsick T, Sauerbeck L, Spilker I, Duldner), Khoury I. Early hemorrhage growth in patients with intracerebral hemorthage. Stroke $1997 ; 28(1): 1-5$.

19. Kazui S, Naritomi H, Yamamoto H, Sawada T, Yamaguchi T. Enlaryement of spontaneous intracerebrail hemorrhage. Incidence and time course. Stroke 1996;27(10): $1783-7$.

20. Qureshi AI, Safdar K, Weil J, Barch C, Bliwise DL, Colohan AR, Mackay B, Frankel MR. Predictors of early deterioration and monality in black Americans with spontameous intracerebral hemorrhage. Stroke 1995;26(10):1764-7.

21. Mayer SA, Sacco RL, Shi $T$, Mohr JP. Neurologic deterioration in noncomatose patients with supratentorial intracereloral hemorrhage. Neurology 1994,44(8): $1379-84$.

22. Kazui S, Minematsu K, Yamamoto H, Sawada T, Yamaguch T. Predisposing factors to enlargement of spontaneous intracerebral hematoma. Stroke 1997:28(12):2370-5.

23. Hill MD, Silver FL, Austin PC, Tu JV. Rate of stroke recurrence in patients with primary intracerebral hemorrhage Stroke 2000;31(1):123-7.

24. Passero S, Burgalassi L, D'Andrea $\mathbb{P}$, Battistini $N$. Recurence of bleeding in patients with primary intracerebral hemorrhage. Stroke 1995;26(7):1189-92.

25. Maruishi $M$, Shima $T$, Okada $Y$, Nishida $M$, Yamane K. Involvement of fluctuating high blood pressure in the enlargement of spontaneous intracerebral hematoma. Neurol. Med. Chir. (Tokyo). 2001;41 (6):300-4; discussion 304-5.

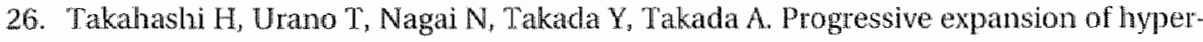
tensive intracerebral hemorrhage by coagulopathy. Am. J. Hematol. 1998;59(2):110-4.

27. Broderick JP, Brott TG, Tomsick $T$, Barsan W, Spilker J. Ultra-early evaluation of intracerebral hemorrhage. J. Neurosurg. 1990;72(2):195-9.

28. Kelley RE, Berger $J R$, Scheinberg $P$, Stokes $N$. Active bleeding in hypertensive intracerebral hemorrhage: computed tomography. Neurology 1982;32(8);852-6.

29. Fujii $Y$, Takeuchi S, Sasaki $O$, Minakawa T, Tanaka R. Multivariate analysis of predictors of hematoma enlargement in spontaneous intracerebral themorhage. Stroke $1998 ; 29(6): 1160-6$.

30. Fujii $Y$, Tanaka $R$, Takeuchi $S$, Koike T, Minakawa 'T, Sasaki O. Hematoma enlargement in spontaneous intracerebral hemorrhage. J. Neurosurg. 1994;80(1):51-7.

31. Teernstra OPM, Lodder J, Evers SMAR, Blatuw G. Stereotactic thombolysis and aspiration of primary intracerebral hemorhage: hematoma volume reduction and its effects on functional outcome. Result from the SICHPA rial. Submitted 2002.

32. Morgenstern LB, Demchuk AM, Kim DH, Frankowski RF, Grotta IC. Rebleeding leads to poor outcome in ultra-early craniotomy for intracerebral hemorhage. Neurology 2001;561 101:1294-9.

33. Nizuma H, Shimizu $Y$, Yonemitsu T, Nakasato $N$, Suzuki I. Results of stereotactic aspiration in 175 cases of putaminal hemorrhage. Neurosurgery 1989;24(6):814-9.

34. Bae H, Jeong D, Doh J, Lee K, Yun I, Byun B. Recurrence of bleeding in patients with hypertensive intracerebral hemorrhage. Cerebrovasc. Dis. 1999;9(2):102-8.

35. Chen ST, Chiang CY, Hsu CY, Lee TH, Tang LM. Recurrent hypertensive intracerebral hemorthage. Acta Neurol. Scand. 1995;91(2):128-32.

36. Eriksson $\mathrm{SE}_{n}$ Olsson IE. Survival and recurrent strokes in patients with different subtypes of stroke: a fourteen-year follow-up study. Cerebrovasc. Dis. 2001;12(3): $171 \cdots B 0$. 
37. Gonzalez-Duarte A, Cantu C, Ruiz-Sandoval JL, Barinagarrementeria F. Recurrent primary cercbral hemorrhage: frequency, mechanisms, and prognosis. Stroke $1998 ; 29(9): 1802-5$.

38. Wijdicks EF, Fulgham IR. Acute fatal deterioration in putaminal hemorhage. Stroke $1995 ; 26(10): 1953-5$.

39. Kothari RU, Brott T, Broderick IP, Barsan WG, Sauerbeck LR, Zuccarello M, Khoury J. The ABCs of measuring intracerebral hemorrhage volumes. Stroke 1996;27(8): $1304-5$.

40. Becker KI, Baxter AB, Bybee HM, Tirschwell DL, Abouelsaad T, Cohen WA. Extravasation of radiographic contrast is an independent predictor of death in primary intracerebral hemorrhage. Stroke 1999;30[10):2025-32.

41. Kowada $M$, Yamaguchi $K$, Matsuoka S, Ito Z. Extravasation of angiographic contrast material in hypertensive intracerebral hemombage. J. Neurosurg. 1972;36(4):471-3.

42. Murai $Y$, lkeda $Y$, Teramoto A. Tsuji Y. Magnetic resonance imaging-documented extravasation as an indicator of acute bypertensive intracerebral hemorhage. I. Neurosurg. 1998;88(4):650-5.

43. Zazulia $A R$, Diringer MN, Derdeyn $C P$, Powers WJ. Progression of mass effect after intracerebral hemorthage. Stroke 1999;30(6):1167-73.

44. Maruishi $M$, Shima $T$, Okada $Y$, Nishida $M$, Yamane $K$, Okita S. Clinical findings in patients with recurrent intracerebral hemorrhage. Surg. Neurol. 1995;44(5):444-9.

45. Neau IP, lngrand P, Couderq $C_{y}$ Rosier MP, Bailbe M, Dumas $P_{\text {, Vandermarcq }}$, Gil R. Recurrent intracerebral hemorrhage. Neturology 1997:49011:106-13.

46. Kubota S, Miyoshi A, Tatara N, Kumaido K, Matsutani M. Recurrent hypertensive intracerebral hemormage: characteristics and risk factors. No Shinkei Geka. $1997 ; 25(11): 993-9$.

47. Lee KS, Bae HG, Yun IG. Recurrent intracenebral hemorrhage due to hypertension. Neurosungery 1990;26(4):586-90.

48. Doi $\mathrm{E}$, Moriwaki H, Komai N, Iwamoto M. Stereotactic evacuation of intracerebral hematomas. Neurol. Med. Chir. (Tokyo). 1982;22(6):461-7.

49. Kaneko $M$, Tanaka $K$, Shimada $T$, Sato $K$, Uemura $K$. Long-term evaluation of ultra-early operation for hypertensive intracerebral hemorrhage in 100 cases. J. Neurosurg. 1983;58(6):838-42.

50. Matsumoto $K$, Hondo H. CT-guided stereotaxic evacuation of hypertensive intracerebral hematomas. I. Neurosurg. 1984;61(3):440-8.

51. Yanaka $K$. Egashira $T$, Okazaki $M$, Takano $S$, Kukita $C$, Yoshizawa $T$, Nose $T$. Stereotactic aspiration using coordinate software for hypertensive intracerebral hematomas. No Shinkei Geka. 1990;18(7):623-9.

52. Hondo H. CT-guided stereotactic evacuation of hypertensive intracerebral hematomas.-A new operative approach. Tokushima I. Exp. Med. 1983;30(1-2):25-39.

53. Mohadjer M, Braus DF, Myers A, Scheremet R, Krauss JK. CT-stereotactic fibrinolysis of spontaneous intracerebral hematomas. Neurosurg. Rev. 1992;15(2):105-10.

54. Lippitz BE, Maytrank L, Spetzger U, Wamke JP, Bertalanffy H, Gilsbach JM. Lysis of basal ganglia haematoma with recombinant tissue plasminogen activatol (rtPA) after stereotactic aspiration: initial results. Acta Neurochir 1994:127(3-4):157-60.

55. Marquardt $G$, Wolff R, Sager A, Hartung A, Lorenz R. Manual stereotactic aspiration of spontaneous deep-seated intracerebral haenatomas in non-comatose patients. Br. I. Neurosurg. 2001;15(2):126-31. 


\section{Cost and quality of life in intracerebral hemorrhage patients: An economic evaluation of the SICHPA study}

O.P.M.Teenstra', S.M.A.A. Evers ${ }^{1,2}$, A.J.H. A. Ament PhD ${ }^{2}$ and G. Blaamw

Dept of Neurosurgery 1 , University Hospital Maastricht, Atrium Medical Center Heerlen, Dept of Health Organization Policy and Economics ${ }^{2}$ University of Maastricht, The Netherlands

Submitted 


\section{ABSTRACT}

Introduction. Strokes, especially hemorrhages, have a high social and economic impact on the patient and their surroundings, while almost no therapy is avalable. In a 3 -year randomised clinical trial, the cost-effectiveness of stereotactic therapy (STEREO) was compared to care as usual (USUAL). The intention of this trial was to treat patients who have suffered a spontaneous, non-aneurysmatic, supratentorial, intracerebral hemorrhage and who have a poor prognosis. In the STEREO group the hematoma was stereotactically removed using plasminogen. Patients who were allocated to USUAL received a broad spectrum of therapies ranging from craniotomy to neurological support.

Methods. In this multicenter, randomised, controlled trial both groups were followed 6 months. Prior to enrolment, patients were stratified according to the severity of illness (EM-score) and neurosurgical center. During the trial, the functional status (Scandinavian Stroke Scale, Barthel Index, Modified Rankin Scale/Oxford Handicap Scale) and the quality of life of patients (EuroQoL, COOP/WONCA charts, SF-36) in both groups was monitored. In addition, to allow a cost-effectiveness analysis, all expenses incurred by these patients related to the trial were measured. This cost-effectiveness analysis was performed from a societal perspective, and included both direct and indirect costs.

Results. From March 1996 to November 1998, 71 patients enrolled in the trial. The study estimated the treament costs to be $€ 68,131$ for the STEREO group and $€ 70,535$ for the USUAL group. The total direct health care costs of the STEREO were $€ 275$ higher than those for USUAL. Indirect costs for the two groups were not significantly different. At 3 and 6 months there were no significant differences in either functional status or quality of life. On the basis of the slow inclusion rate and an interim analysis the trial was prematurely stopped.

Conclusion. Although the study population was small, making it hand to detect statistically significant differences, it could be concluded that there is no indication that patients with an intracerebral hemorrhage treated by means of the STEREO method are better off than their USUAL-treated counterparts in terms of (functional) outcome, health-related quality of life or costs from a societal perspective. In order to detect changes in the quality of life in both patients and their close relatives, it is suggested that future, larger trials, should use disease-specific instruments alongside generic ones. 


\section{INTRODUCTION}

Stroke is a disease with a vast social and economic impact not only on the patient and surroundings but also on society. Besides ranking third as a cause for mortality in Europe it is one of the diseases which contributes to enduring disability $(1,2)$, often with serious impairment of the patient's quality of life (3). Also the costs of stroke are enormous (4); in the Western countries the medical costs of stroke are estimated to be $3 \%$ of total health care expenses (5).

About $15 \%$ of all strokes consist of intracerebral hemorrhages (ICH), with an incidence of 15 per 100,000 annually (6-8). This subset of the diseaseentity 'stroke' has an even higher lethality of around $50 \%$ often leading to severe and lasting disability (9-12). Recent studies also show that the lifetime costs for survivors of an intracerebral hemorrhage are higher than for all other types of stroke $(13,14)$.

Stroke is more prevalent in the elderly. Looking at the top 10 diseases in terms of costs in The Netherlands in 1994, stroke is ranked seventh overall (irrespective of age) and second in the elderly $(\geq 65$ years) $(15,16)$. It is expected that incidence figures and therefore the costs of stroke will rise over the coming decades, as the proportion of elderly people in society increases. In the Netherlands it is projected that, mainly due to an aging population, the number of stroke patients and related costs will increase substantially until 2015. Depending on the scenario applied, the increase in these Dutch health care costs will vary between $33 \%$ and $48 \%(17-19)$.

Recently more and more emphasis has been put on the costs of stroke, alongside an interest in the effectiveness of new and existing interventions. Despite the considerable burden and costs associated with stroke, in particular with $\mathrm{ICH}$, and the increasing need to allocate health care resources more efficiently, only a few economic evaluations of treatments have been undertaken (20). An economic evaluation consists of comparing both the costs and effects of interchangeable health care services (21). The results of economic evaluation studies can provide a decision-making lramework which policy makers, health care insurers, health care providers and patients can use to assess the value of an intervention compared with other (competing) alternatives. The results of an economic evaluation study can be expressed in cost per effect-measure, the so-called ratio (22).

This article describes an economic evaluation trial (in particular cost-effectiveness analysis), in which a new intervention for ICH patients was compared with standard practice. This SICHPA trial (Stereotactic treatment of Intracerebral Hematoma by means of a Plasminogen Activator), a multicenter, randomized, controlled trial was initiated in October 1995. 
During the period from 1996 to 1999, this trial compared the efficacy of a new stereotactic treatment (STEREO) to usual, conservative medical care (USUAL) in spontaneous supratentorial ICH patients. Efficacy was measured in mortality and morbidity differences between the groups over a six-month period and the results are reported elsewhere (23). This economic evaluation study was a preplanned integral part of the study.

The main question addressed in this economic evaluation is whether STEREO therapy is cost-effective when compared to USUAL therapy alone from a societal perspective. Because of the diversity of both social and economic consequences of $1 \mathrm{CH}$ and the subsequent intervention, a societal perspective was chosen. In a societal perspective, all relevant costs and outcomes are determined within the framework of the economic evaluation. The Fund for Developmental Medicine of the Dutch Health Insurance Executive was to use this study to advise on inclusion of this therapy in the basic package of social insurance. The relationship between costs and quality of life in both groups as well as the association between costs and functional outcome (including mortality) is investigated. To our knowledge, this is the first economic evaluation of this treatment modality of ICH.

\section{METHODS}

\section{Study design}

In the SICHPA trial, 71 patients with spontaneous ICH's were selected from four major neurosurgical centers in the Netherlands: Amsterdam Medical Center (AMC), Utrecht University Hospital Utrecht (UHU), University Hospital Rotterdam (UHR) and University Hospital Maastricht / Atrium Medical Center Heerlen (UHM/AMCH). Each center's medical ethics committee approved the trial beforehand. Patients with a spontaneous (non-aneurysmatic, non-neoplastic) supratentorial ICH with a poor prognosis were selected. Admission criteria were: age $>45$ years, spontaneous supratentorial ICH, Glasgow EM score ranging from 2 to 10 , ICH volume $>10$ $\mathrm{ml}$, treatment within 72 hours following stroke onset, informed consent. Prior to randomization, patients were stratified according to illness severity and neurosurgical centre. Both groups (STEREO and USUAL) were followed for six months. At 3 months (T1) and at 6 months (T2) post-stroke an interview was conducted with the patient and their contact person (relative or friends) in which all costs and consequences (i. e. quality of life) were measured that occurred during this follow-up period. To ensure high response an experienced interviewer administered the questionnaire in a 
face-to-face interview at the patients' residence (at home, rehabilitation center, etc.)

\section{Intervention}

Patients were randomly allocated to either the STEREO group $(n=35)$ or the USUAL care group $(n=36)$. The STEREO group consisted of an intervention according to protocol. This consisted of the stereotactic insertion of a catheter centrally into the $\mathrm{ICH}$ and using this to aspirate hematoma which was still liquid. Subsequently, a urokinase solution was infused and liquefied ICH was aspirated over a period of 48 hours after which the catheter was removed.

This new treatment was compared to existing therapy in the USUAL group, i. e. the most commonly used treatment. Normally ICH is treated either by surgery (craniotomy with clot evacuation) or conservative medical treatment alone (most common care in The Netherlands). In this USUAL comparator each medical center could apply the best available standard practice for this group of patients in their center. Depending on the severity of illness and the center, the USUAL care included a variation of normal supportive medical care such as antibiotics, steroids, mechanical ventilation, intracranial pressure monitoring etc. A more detailed description concerning the medical treatment in both groups is provided in Teernstra et al. (23).

\section{Costs}

In our economic evaluation analysis we followed the guidelines as described in several handbooks $(21,24)$. In order to calculate the costs for STEREO and USUAL therapy all relevant cost-items were selected which were then measured for each patient and later valued. Direct costs are all the goods, services and other sources that are consumed in the treatment of ICH. They were divided into direct health care costs (costs of the STEREO and USUAL treatment, nursing home, drugs, etc.) and direct non-health care costs (like transportation to/from medical services, volunteer aid, aids \& appliances, and out-of-pocket expenses, etc). In the SICHPA trial direct health care costs were divided into inpatient- and outpatient costs. Studying costs from a societal perspective means that in addition to all relevant direct costs, the indirect costs must also be included. Indirect costs refer to lost productivity suffered by the national economy as a result of the employee's absence from the workplace due to $\mathrm{ICH}$. Table 1 provides an overview of unit prices of important cost components in 1999. The costs in 1999 in Dutch Guilders 
Table 1. Costs tigures used in the SICHPA study in 1999 (in Euros)

\begin{tabular}{|c|c|c|c|}
\hline Cosi category & Volume & Price & Source* \\
\hline \multicolumn{4}{|l|}{ Direct health care: Inpatient } \\
\hline \multicolumn{4}{|l|}{ STEREO } \\
\hline Diagnostic investigations and consultants ${ }^{t}$ & Total & $2,104.02$ & UHM \\
\hline Surgical and other treatments ${ }^{*}$ & Total & $1,301.93$ & UHM \\
\hline \multicolumn{4}{|l|}{ USUAL } \\
\hline Diagnostic investigations and consutants. & Total & $1,684.47$ & UHM \\
\hline Surgical and other treatments & Total & 440.12 & UHM \\
\hline Hospitalization day university hospital & Day & 331.71 & $\mathrm{CLV}$ \\
\hline Hospitalization day elsewhere & Day & 235.97 & $\mathrm{CZN}$ \\
\hline Nursing home & Day & 135.23 & $\mathrm{CZV}$ \\
\hline Rehabilitation center & Day & 284.97 & CZV \\
\hline Old peoples home & Day & 62.17 & $C Z N$ \\
\hline Intermediate ward & Day & 135.23 & $\mathrm{CZN}$ \\
\hline Readmittance to hospital & Day & 235.97 & $\mathrm{CZN}$ \\
\hline \multicolumn{4}{|l|}{ Direcr health care: outpatient } \\
\hline Outpatient consult & Event & 79.41 & $\mathrm{CZN}$ \\
\hline General practitioner & Event & 16.59 & $\mathrm{CZV}$ \\
\hline Paramedical therapy $\$$ & Event & 18.30 & $\mathrm{CZV}$ \\
\hline Rehabilitation daycare treatment & Event & 50.37 & $\mathrm{CZV}$ \\
\hline Medications (prescribed and over the counterl) & dailly dose & per dnug & KNMP \\
\hline \multicolumn{4}{|l|}{ Direct non-health care: outpatient } \\
\hline Home help & hours as reported & 25.09 & $\mathrm{CZV}$ \\
\hline District nurse & hours as reported & 40.02 & $\mathrm{CZN}$ \\
\hline Domestic help & hours as reprorted & 22.83 & $\mathrm{CZV}$ \\
\hline Cleaner home caret & hours as reported & 8.53 & $\mathrm{CZN}$ \\
\hline Unpaid help from family or friends & hours as reported & 7.94 & $\mathrm{CZW}$ \\
\hline $\begin{array}{l}\text { Modilications at home, aids, clothing, travel } \\
\text { experises etc. }\end{array}$ & as reported & peritem & IRV \\
\hline Out of pocket expenses & as reported & peritem & patieni \\
\hline \multicolumn{4}{|l|}{ Indirect } \\
\hline Productivity losses & hours as reported. & 15.05 & CBS \\
\hline
\end{tabular}

* UHM=University Hospital Maastrich, $\mathrm{CZV}=$ Centraal orgaan Zorgverzekeringen (27), KNMP= Koninklijke Maatschappij ter bevordering der Phamacie (28). IRV=Instituut Revalidatie Voorzieningen (29), CBS= Centraal Bureau Statistieken (30); \&aboratory, radiology, nuclear mediche, cardiac pulmonary function testing, clinical neurophysiology, endoscopy, urology. internal medicine, neurology etc.: \& Rehabilitation, surgery, anesthesiology, physiotherapy, speech therapy; $\$$ Occupational therapy, physiotherapy, speech therapy, social work 
were converted to Euros against the rate of 1 Euro to 2.20371 Dutch Guilders, which was a fixed rate in the period 1999 to 2001 before the actual introduction of the Euro in 2002(25). In 1999, 1 Euro equals 0.892 US $\$$ when using Purchasing Power Parities (PPP are the rates of currency conversion that equalize the purchasing power of different curnencies by eliminating the differences in price levels between countries) (26).

\section{Direct health care costs}

For the base case analysis, the direct health care costs related to the treatment (e.g. utilization of the STEREO and USUAL treatment) were measured using the medical financial administration of the participating hospital. Other direct cost volumes were measured by means of interviews with the patient and/ or a close relative at three and six months follow-up. Questions in this interview concerned medical consumption, home help, medical aids and modifications at home, employment and income.

The calculations of the total costs per STEREO and USUAL intervention during the hospital stay were based on cost figures from the financial clepartment of the University Hospital Maastricht. If the patient died on the day of admission, this was counted as 1-day hospitalization.

Several Dutch studies $(31-34)$ have shown that stroke patients remain in hospital for a relatively long time due to non-medical reasons. These non-medical reasons are mostly caused by waiting for placement in a nursing home ( $28 \%$ ), or in a rehabilitation center $(5 \%)$, or waiting for home care facilities (3\%) (34). Some medical centers have therefore created a so-called intermediate ward, in which care is comparable to the care provided in nursing homes. As a result, a day in such an intemediate ward was valued equal to the nursing home price.

Other inpatient and outpatient costs were assessed on the basis of estimates derived from the Dutch national guidelines for cost measurement in health care (35). Allhough the costs of a general practitioner visit vary between a telephone-, surgery-and home consultation, these costs were not broken down into these three tariffs, but instead a llat rate of $€ 16.59$ was used.

Paramedical care was split into: Physiotherapy, occupational therapy, speech therapy, social work, and activity therapy. Supplementary costs like home help and modifications at home were taken as reported by the patients themselves. Home help was divided into professional home care (district nursing care, domestic help, home help, cleaner home carer), and informal care (help of family and/or friends). The category professional home care is a typical Dutch phenomenon; costs for it will rise according to 
the level of expertise needed. Other non-health care costs like modifications of the patient's house, aids and appliances, costs for clothing and travel expenses (to the general practitioner or consultants) were calculated as the patient reported them. In addition, loss of income due to out-of-pocket expenses was analyzed with data provided by the patient or spouse.

\section{Indirect costs}

Indirect cost calculation was based on the Human Capital Approach (HCA), which estimates the value of potential production lost during the entire period of absence from work referring to the national average gross hourly wage $(€ 15.05)$ for both sexes in 1999(30). In case of production losses due to mortality this period ranged up to the moment of retirement (age 65 years). In survivors, the assumption was made that, given the marked dependency in these patients, this period would also extend to the age of retirement. Cost-items, volumes and prices used in the base case analysis, are shown in table 1 . Some of the base case variables were measured in an alternative way in the sensitivity analysis, in order to assess the robustness of the baseline model.

\section{Effects}

The effectiveness of STEREO compared to USUAL therapy was measured in mortality, morbidity and quality of life during six months follow-up. Morbidity was measured with several scales; to measure stroke severity the Glasgow Coma Scale (GCS) and the Scandinavian Stroke Scale (36) (SSS, a neurological impairment scale also known as Stroke Severity Scale) were used. Functional outcome was measured using the Barthel Index (BI, a disability score) (37-39) and the modified Rankin Score (mRS) $(40,41)$. The mRS was adapted to include an extra grade for mortality, making it an instrument measuring functional health status and death $(40,41)$. Although mortality and morbidity are generally good clinical outcome measures in stroke, quality of life measurement is gaining popularity as a valid indicator of whether a medical treatment is beneficial (42). Quality of life in clinical practice is often defined as "the functional effect of an illness and its consequent therapy upon a patient, as perceived by the patient" (43). It is generally believed (43) that a quality of life instrument should incorporate four constructs: 1. physical and occupational function, 2. psychological state, 3. somatic interaction and 4 . somatic sensation. Besides the fact that quality of life measures give insight into the patient's well-being, another advantage is that these instruments can be used for a wide range of illnesses and different 
types of treatment. As a result inter-disease and inter-treatment comparison are possible, which are useful for resource allocation within economic evaluation.

In most quality of life instruments patients can describe their health status. In utility instruments this measurement is taken a step further: the patient is also asked to attribute a value to (changes in) his perceived quality of life. Values in this utility score range from zero (worst) to one hundred (optimal health status). In order to measure change in overall health-related quality of life the COOP/WONCA charts (44), the Short Form 36 (SF-36) (45-51) and the EuroQoL-5 Dimensions (EQ-5D) (52-56) were used. The COOP/WONCA is a user-friendly and easy-to-apply questionnaire, which includes the single-item dimensions Physical, Emotional, Daily Activities, Social Activities, Social Support, Pain and Overall Health. The COOP/WONCA charts were used as a 'hanger-on' instrument. The SF-36, which consists of 36 questions divided into 8 dimensions (physical functioning, physical pain, general health, vitality, social functioning, mental health, physical role functioning and emotional role functioning) was also used. Finally, in order to incorporate utility scores the EQ-5D was used. The EQ-5D contains a questionnaire, which assesses 5 dimensions of the overall health status (mobility, self care, usual activities, pain/discomfort and anxiety-depression), a question of health transition and a visual analogue scale (VAS). Both the SF-36 and the EQ-5D are acclaimed and widely used measures of health-related quality of life (HRQOL) providing descriptive information on HRQoL changes associated with health care interventions. In this form the SF-36 and the EQ-5D are not preference-based measures. In order to use them in economic evaluations it is necessary to attach relative valuations to the different health states. Brazier et al. revised the SF-36 into the SF-6D (6 instead of 8 dimensions) and had the health states evaluated by a representative sample of the UK general population $(n=611)$ using a standard gamble method. Further modeling resulted in a single index utility score ranging from 0 (=death) to 1 (perfect health) (57). The author (58) provided us with its algorithm and more detailed information. In the EQ-5D each dimension has three grades (no, some, and severe limitations) resulting in 243 possible sets of values each representing a health state. By means of a large-scale time-trade-off study, Dolan et al. had 42 of these health states valued by the general public in the United Kingdom $(n=3,395)(59)$. These valuation scores, ranging from - 0.549 (most undesirable state, worse than death) via 0 (death) to 1 (perfect state) have been validated for the Netherlands (60). More detailed information and the algorithm used to transform the EQ-5D scores into this single index measure, was provided by Dolan $(58,61-63)$. 


\section{Data andysis}

Analysis was performed according the 'Intention to treat' principle. After randomization, data from all patients were recorded and analyzed even in case of drop out or change of treatment. Besides descriptive statistics, the Mann Whitney U-test was used to compare the ordinal scales of the effect parameters (adapted mRS, COOP/WONCA, SF36, EQ-5D). Patients who were dead at the time of measurement were given the lowest score on the scale, in case of the SSS and the Barthel Index this was 0 and with the MRS this was 6 . Statistical significance expressed as $p<0.05$, is always measured two-tailed. Since the SICHPA trial extended over several years, only cost estimates from the year 1999 were used, in order to make data on costs comparable. Finally, a sensitivity analysis was performed to ensure the robustness of the analysis.

\section{RESULTS}

\section{Patient characteristics}

71 patients were included, 36 in the STEREO arm and 35 in the USUAL arm of the study. One patient from the USUAL group was not entered into the analysis because he had an arteriovenous malformation. There were no statistical differences in socio-demographic characteristics. Because the T1 measurements were similar to the end of follow-up T2 measurements, only the data from the latter were used. On base-line characteristics the STEREO group had mone cases of lobar ICH (67\% versus $41 \%, \mathrm{p}=0.03)$ and the ICH volume was on average larger in this group $(66 \mathrm{ml}$ versus $52 \mathrm{ml}, \mathrm{p}=0.03)$. The severuty of illness on admission was comparable with a mean. GCS score of 9.5 (median 9.5, range: 4-15) in the STEREO and 10 (median 9, range 6-14) in the USUAL group. SSS scores for the two groups were respectively: 13 (median 8, range: 0-50) and 16 (median 14, range: 0-41). For further details see Teeinstra et al. (23).

A limitation to follow-up was the high mortality of $57 \%$ at six months, and the fact that sometimes patients could not be interviewed due to ill health. Of the patients still alive at the end of follow-up, 27 patients were interviewed, two patients refused and one was incapable of being interviewed. 


\section{Direct costs}

Health care costs and volumes for both groups are given in tables 2 and 3 and depicted in fig 1.

Table 2. Volumes per treatment group

\begin{tabular}{|c|c|c|c|c|c|c|c|c|c|}
\hline \multirow[b]{2}{*}{ Vohume categories } & \multicolumn{3}{|c|}{ USUAL $(n=34)$} & \multicolumn{6}{|c|}{ STEREO $(n=36)$} \\
\hline & $n^{*}$ & mean & $\mathrm{SD}$ & $\min -\max$ & $n$ & mean & $\mathrm{SD}$ & mintr-max & Sig. \\
\hline \multicolumn{10}{|l|}{ Direct healh care: inpatient } \\
\hline Hospital & 34 & 38 & 47 & $1-180$ & 36 & 32 & 37 & $1-180$ & 0.791 \\
\hline Nursing home & 11 & 17 & 39 & $0-168$ & 7 & 23 & 50 & $0-155$ & 0.404 \\
\hline Rehabilitation center & 4 & 9 & 31 & $0-130$ & 5 & 9 & 28 & $0-146$ & 0.573 \\
\hline Old people's home & 1 & 4 & 23 & $0-135$ & 0 & 0 & 0 & $a-0$ & 0.303 \\
\hline Intermediate ward & 1 & 3 & 19 & $0-109$ & 1. & 4 & 26 & $0-156$ & 0.984 \\
\hline Readmittance to hospital & 1 & 1 & 7 & $0-42$ & 2 & 1 & 5 & $0-28$ & 0.615 \\
\hline Subtotal & 34 & 73 & 74 & $1-180$ & 36 & 69 & 74 & $1-180$ & 0.836 \\
\hline \multicolumn{10}{|c|}{ Dinect health care: outpatient } \\
\hline Ontpatient consult & 10 & 1 & 1 & $0-5$ & 12 & $\mathbb{1}$ & 2 & $0-7$ & 0.420 \\
\hline General practitioner & 9 & 1 & 2 & $0-7$ & 9 & 1 & 3 & $0-11$ & 0.731 \\
\hline Paramedical therapy & 4 & 3 & 10 & $0-43$ & 4 & 8 & 27 & $0-119$ & 0.295 \\
\hline Daycare treatment & 0 & 0 & 0 & $0 \sim 0$ & 2 & 2 & 8 & $0-39$ & 0.166 \\
\hline Medications & 4 & & & & 4 & & & & \\
\hline
\end{tabular}

Direct non-health care: outpatient

Aids and appliances. 10 travel expenses

Home help (hours:

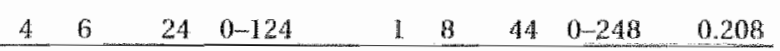

* $\mathrm{n}=$ number of patients. $\mathrm{SD}=$ Standard Deviation, min-max = minimum to maximum valuc, Sig: = statistical significance; expressed as $\mathrm{p}$-value (2-tailed)

Direct health outpatient care consumption was higher fat least twice as high) and therefore more costly in the STEREO group, but this contrast was not statistically significant. Direct non-health care costs were also greater (statistically non-significant however) in the STEREO group. This is due to the fact that the eight patients in this group received more home help (mean 44 hours compared to 6 in USUAL) and had on average more costs due to the need for aids and appliances, modifications of their house, and travel expenses. Modifications ranged from a heightened toilet seat to a complete specialized kitchen and major special adaptations of the patient's house. Overall outpatient costs were much higher in the STEREO group (€2,119) 


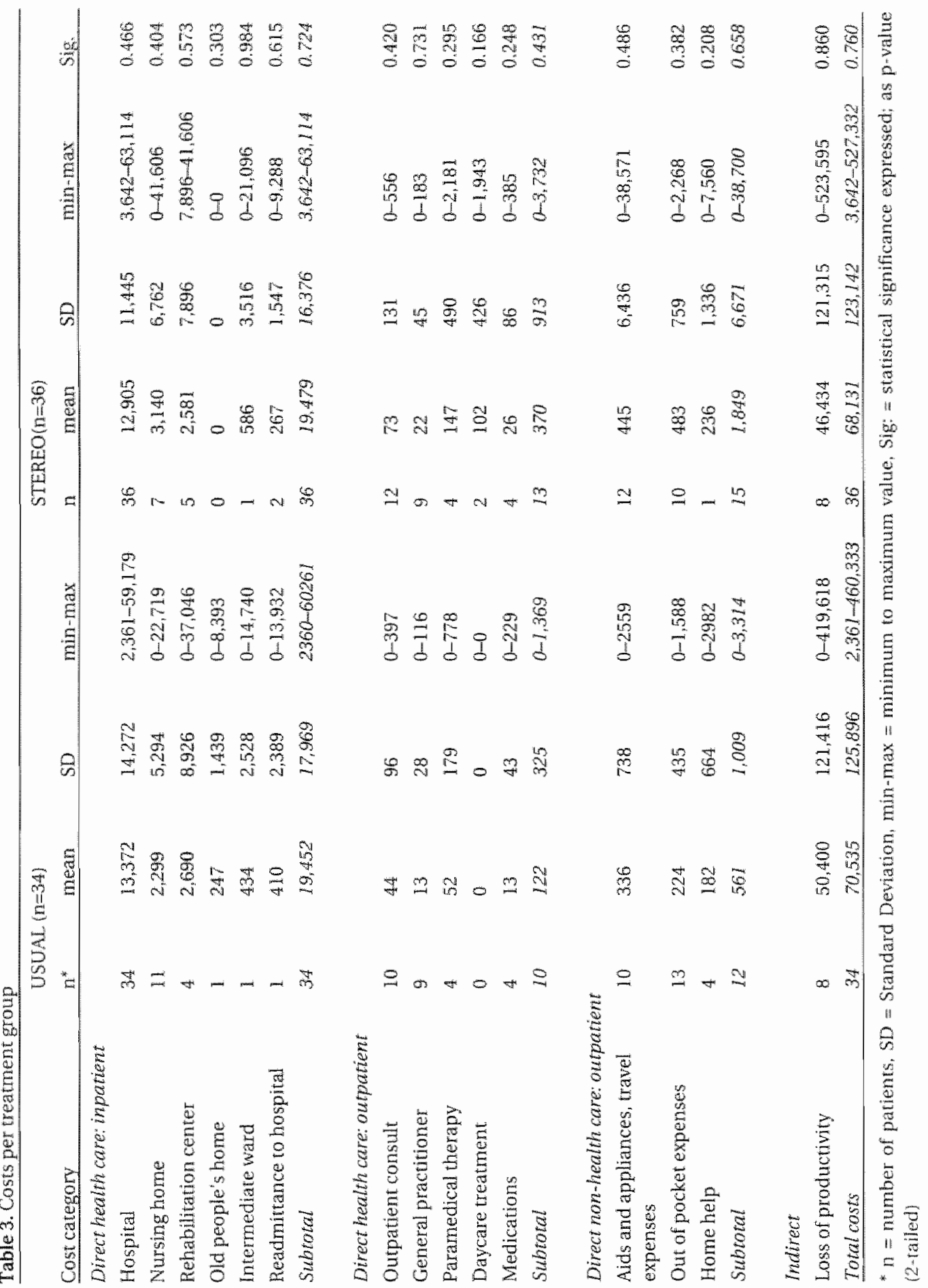


compared to the USUAL group $(€ 683)$ but this difference was not statistically significant. The expenses of one particular patient were markedly higher than those of the others ( $€ 38,700$ for adapting/rebuilding his home). This value, being an outlier, was mainly responsible for the abovementioned difference. When this figure was replaced by the average costs for this cost-item within his STEREO group the difference was reduced to $€ 244$. Direct non-health care costs due to out-of-pocket expenses were reported by 16 out of 26 patients. These extra costs mainly consisted of travel expenses $(n=5)$, in one case expenses due to moving to another home and other cases reported unspecified reasons. Three patients reported out of pocket expenses but did not specify the amount. Of the remaining 13 cases 8 patients in the USUAL group had a mean monthly income reduction of $€$ 112 (SD: $€ 217$, min: $€ 0-\max : € 794$ ), and seven in the STEREO group had a mean monthly reduction of $€ 241$ (SD: $€ 380$, min: $€ 0-\max : € 1,135$ ). This difference is not statistically significant $(p=0.382)$.

The overall outpatient costs for both groups were relatively low, because few patients had returned home by the time of measurement (180 days follow-up).

\section{Indirect costs}

The overall mean age at the time of inclusion in the study was 67.9 years. It was, therefore, unlikely that loss of productivity in this group would be an important factor. The retiring age in the Netherlands is generally 65 years of age. Twenty-two patients were younger than 65 years at the time of stroke occurrence. Of these 22, 11 had died during follow-up (5 patients in USUAL. and 6 in STEREO). Of the 11 patients who survived, 5 were already received a disability pension before their stroke ( 2 in USUAL and 3 in STEREO), one had retired early. The five remaining patients held no job at the end of follow-up, and given their state of dependence (according to their mRS scores) it was assumed that they were also not very likely to be employed again before retirement. Altogether there were 16 patients ( 8 in USUAL and 8 in STEREO) with loss of productivity until the age of 65 . The estimated indirect costs, based on the Human Capital Approach, were comparable for both groups $(€ 50,400$ in USUAL and $€ 46,434$ in STEREO, $p=0.860$ ). Figure I shows the costs for both groups. 


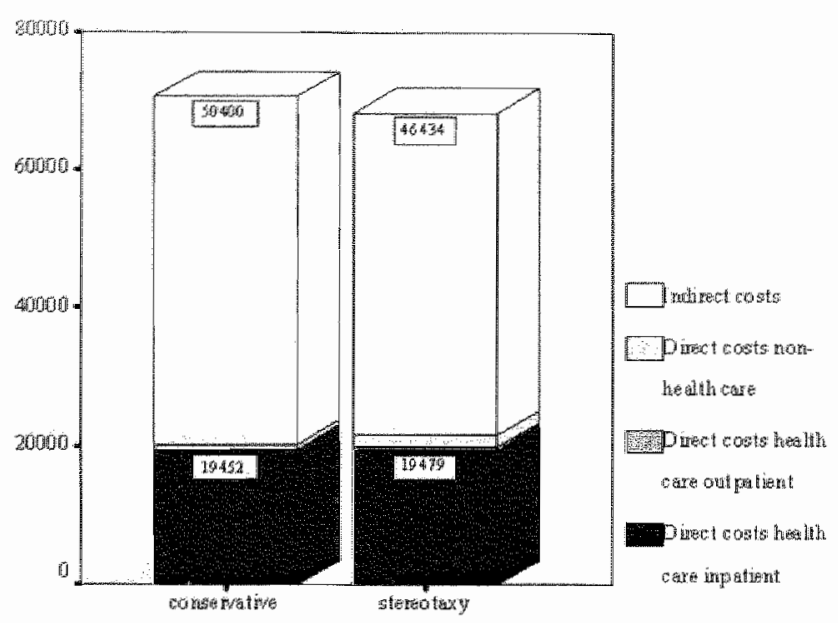

Figure 1. Average patient costs at 180 days in each treatment (euros)

\section{EFFECTMEASURES}

\section{Clinical outcome}

A detailed description of the primary outcome measure mortality can be found in Teernstra et al. (23), In the STEREO group ( $n=36), 20$ patients (56\%) and in the USUAL group ( $n=34), 20$ patients $(59 \%)$ had died before the end of follow-up at 180 days post-stroke. Table 4 shows functional outcome and neurological impairment for both groups. 34 patients in the USUAL group had a mean mRS score of almost 5 (severely dependent) compared to a mean score of 5 points in the STEREO group. No statistically significant differences were detected either, between mean SSS scores and Barthel index scores for the two groups (SSS: 15.7 and 17.9 out of 70 points and Barthel index: 3.6 and 3.8 points for each group, respectively).

Table 4. Scandinavian stroke: scale, barthel index, modified rankin score at 180 days post-stroke

\begin{tabular}{|c|c|c|c|c|c|c|c|c|c|}
\hline \multirow[b]{2}{*}{ Scale } & \multicolumn{4}{|c|}{ USUAL. } & \multicolumn{5}{|c|}{ STRREO } \\
\hline & $n^{*}$ & mean & $\mathrm{SD}$ & $\begin{array}{l}\text { min } \\
\text { max }\end{array}$ & n & mean & $\mathrm{SD}$ & $\begin{array}{l}\text { min- } \\
\text { max }\end{array}$ & Sig. \\
\hline Modified Rankin Scale & 34 & 4.9 & 1.8 & $0-6$ & 36 & 5.0 & 1.4 & $1-6$ & 0.937 \\
\hline Scandinavian Stroke Scale & 32 & 15.7 & 24.9 & $0-72$ & 36 & 17.9 & 24.9 & $0-70$ & 0.664 \\
\hline Barthel Index & 32 & 3.6 & 7.1 & $0-20$ & 36 & 38 & 7.2 & $0-20$ & 0.934 \\
\hline
\end{tabular}

* $\mathrm{n}=$ number of patient $\mathrm{s}, \mathrm{SD}=$ Standard Deviation, min max $=$ minimum to maximum value, Sig: = stastical significance expressed as p-value (2-tailed) 
Table 5. Quality of life: COOP/WONCA and RAND short form 36

\begin{tabular}{|c|c|c|c|c|c|c|c|c|}
\hline & & \multicolumn{3}{|c|}{ USUAI: $(n=11)$} & \multicolumn{4}{|c|}{ STEREO $(n=16)$} \\
\hline & & $n^{*}$ & Mean & $\mathrm{SD}$ & n & Mean & $\mathrm{SD}$ & Sig. \\
\hline \multicolumn{9}{|c|}{ COOPRWONCA Dimensions l (1-5) } \\
\hline \multicolumn{3}{|c|}{ Physical fitness } & 3.3 & 1.7 & & 4.0 & 1.3 & 0.286 \\
\hline \multicolumn{3}{|l|}{ Pain } & 2.1 & 1.2 & & 2.1 & 1.4 & 0.957 \\
\hline \multicolumn{3}{|l|}{ Mood } & 3.1 & 1.6 & & 2.7 & $\mathbb{1 . 3}$ & 0.457 \\
\hline \multicolumn{3}{|l|}{ Daily activities } & 3.5 & 1.6 & & 3.9 & 1.5 & 0.615 \\
\hline \multicolumn{3}{|l|}{ Social activities } & 2.6 & 1.7 & & 2.9 & 1.7 & 0.627 \\
\hline \multicolumn{3}{|l|}{ Change in health } & 3.4 & 1.4 & & 2.8 & 1.2 & 0.266 \\
\hline \multicolumn{3}{|l|}{ Overall health } & 3.8 & 1.3 & & 3.1 & 1.2 & 0.155 \\
\hline \multicolumn{9}{|c|}{ RAND 36 Dimensions $(0-100)$} \\
\hline \multicolumn{2}{|c|}{ Physical functioning } & 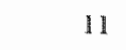 & 32.5 & 41.6 & 14 & 23.9 & 33.7 & 0.630 \\
\hline \multicolumn{2}{|l|}{ Social functioning } & 1.1 & 76.6 & 27.7 & 12 & 68.8 & 33.5 & 0.602 \\
\hline \multicolumn{2}{|c|}{ Role limitation (physical) } & 11 & 22.2 & 38.4 & 14 & 20.8 & 36.5 & 0.970 \\
\hline \multicolumn{2}{|c|}{ Role limitation (emotion) } & $\Lambda$ & 33.3 & 50.0 & 14 & 28.0 & 43.1 & 0.910 \\
\hline \multicolumn{2}{|l|}{ Mental health } & 11 & 63.7 & 13.8 & 14 & 66.4 & 25.4 & 0.241 \\
\hline \multicolumn{2}{|l|}{ Vitality } & 11 & 52.2 & 27.7 & 14 & 52.5 & 37.2 & 0.612 \\
\hline \multicolumn{2}{|l|}{ Pain } & 11 & 76.0 & 25.9 & 11 & 04.1 & 38.1 & 0.372 \\
\hline \multicolumn{2}{|l|}{ General health } & 11 & 55.6 & 23.4 & 10 & 69.5 & 19.5 & 0.246 \\
\hline \multirow[t]{2}{*}{ Heall th change } & & 11 & 30.6 & 34.9 & 10 & 30.0 & 32.9 & 1.000 \\
\hline & $\mathrm{n}$ & Mean & $\mathrm{SD}$ & $\begin{array}{l}\min - \\
\max \end{array}$ & Mean & $S D$ & $\begin{array}{l}\min \\
\max \end{array}$ & Sig \\
\hline SF 6D single index & 58 & 0.19 & 0.32 & $0-0.94$ & 0.22 & 0.32 & $0-0.89$ & 0.725 \\
\hline
\end{tabular}

* $\mathrm{n}=$ number of patients, $\mathrm{SD}=$ Standard Deviation, min-max $=$ minimum to maximum value, Sig: = statistical significance; expressed as p-value (2-tailed)

\section{Health-related Quality of Life}

11 patients in the USUAL and 16 patients in the STEREO group filled out the COOP/WONCA charts. None of the mean scores for individual dimensions between the two groups showed a statistically significant difference. The same patients had comparable results on the dimensions of the EuroQoL-5D. The mean health thermometer (VAS) score is somewhat lower in the STEREO group ( 31.1 compared to 39.3 in the USUAL group) but this difference is also statistically insignificant $(p=0.729)$. The mean computed EuroQoL-5D single index scores for both groups were: USUAL: 0.27 and STEREO: 0.13 . The difference in mean scores for the two groups on the dimensions of the SF-6D and the computed mean SF-6D single index scores 
Table 6. (quality of life: EuroQoL $5 \mathrm{D}$ dimensions, thermometer and single index

\begin{tabular}{|c|c|c|c|c|c|c|c|}
\hline & & & \multicolumn{2}{|c|}{ USUAL $(n=11)$} & \multicolumn{2}{|c|}{ STEREO $(n=16)$} & \multirow[b]{2}{*}{ Sig } \\
\hline & & & $n^{*}$ & percent & $\mathrm{n}$ & percent & \\
\hline \multicolumn{8}{|c|}{ EuroQol-5D Dimersions } \\
\hline \multirow[t]{3}{*}{ Mobility } & \multicolumn{2}{|c|}{ no problems } & 3 & 27 & 3 & 19 & nis. \\
\hline & \multicolumn{2}{|c|}{ some problems } & 3 & 27 & 5 & 31 & ns. \\
\hline & \multicolumn{2}{|c|}{ confined to bed } & 5 & 45 & 8 & 50 & mas. \\
\hline \multirow[t]{3}{*}{ Sell care } & \multicolumn{2}{|c|}{ no problems } & 4 & 36 & 3 & 19 & nas. \\
\hline & \multicolumn{2}{|c|}{ problems } & 2 & 18 & 5 & 31 & ns. \\
\hline & \multicolumn{2}{|c|}{ unable to } & 5 & 45 & 8 & 50 & ns. \\
\hline \multirow[t]{3}{*}{ Usual activities. } & \multicolumn{2}{|c|}{ no problems } & 2 & 18 & 2 & 13 & ms. \\
\hline & \multicolumn{2}{|c|}{ some problems } & 2 & 18 & 2 & 13 & nis. \\
\hline & \multicolumn{2}{|c|}{ unable to } & 7 & 64 & 12 & 75 & ns. \\
\hline \multirow[t]{3}{*}{ Pain/Discomfort } & \multicolumn{2}{|l|}{ none } & 8 & 73 & 5 & 31 & ns. \\
\hline & \multicolumn{2}{|c|}{ moderate } & 2 & 18 & 9 & 56 & ns. \\
\hline & \multicolumn{2}{|c|}{ extreme } & 1 & 9 & 2 & 13 & ns. \\
\hline \multirow[t]{4}{*}{ Anxiety-depression } & \multirow{3}{*}{\multicolumn{2}{|c|}{$\begin{array}{l}\text { none } \\
\text { moderate } \\
\text { extreme }\end{array}$}} & 5 & 45 & 6 & 38 & ns. \\
\hline & & & 4 & 36 & 6 & 38 & ns. \\
\hline & & & 2 & 18 & 4 & 25 & ns. \\
\hline & Mean & SD & $\begin{array}{l}\min - \\
\max \end{array}$ & Mean & $\mathrm{SD}$ & $\min -\max$ & Sig \\
\hline Heal th thermometer & 39.3 & 31.1 & $2-80$ & 43.6 & 31.1 & $2-90$ & 0.729 \\
\hline EQ-5D Single index & 0.27 & 0.47 & $-0.36-1.0$ & 0.13 & 0.46 & $-0.43-1.0$ & 0.348 \\
\hline
\end{tabular}

" $\mathrm{n}=$ number of patients, $\mathrm{SD}=$ Standard Deviation, min $\cdot \mathrm{max}=$ minimum to maximum value, Sig: = statistical significance expressed as $\mathrm{p}$-value (2-tailed)

(USUAL: 0.19 and STEREO: 0.22) was also statistically insignificant. Results are shown in tables 5 and 6.

Since there were no data available on health-related quality of life before stroke, quality adjusted life years could not be calculated. Consequently, and since no statistically significant differences were found either in costs or in effectiveness, a cost-effectiveness ratio could not be computed.

\section{Sensitivity anallysis}

In order to calculate costs, several assumptions were made in our analysis. To check for the robustness of these assumptions they were replaced by alternatives, so their impact on changing the results could be analyzed. Firstly, we counted hospital stay in the AMCH as in a general hospital $(€ 236$ ), but the neurosurgical service of the $\mathrm{AMCH}$, which is in fact a general 
hospital, is similar to that of a university hospital. Because it could be argued that this is unfair, we also calculated total costs with the university hospital tariff ( $€ 332$ ) for this center. This meant an $€ 1275$ and $€ 988$ cost increase for USUAL and STEREO, respectively.

Secondly, we estimated the costs of an intermediate ward as being the same as in a nursing home. Intermediate ward is a form of hospitalization care in which the patient is still present in the hospital but no longer in need of medical treatment and actually waiting for a vacancy in a nursing home. We changed the tariff for nursing home to the one for general hospital stay ( $€ 236$ ), resulting in a total cost increase of $€ 323$ in the USUAL and $€ 437 \mathrm{in}$ the STEREO group.

Thirdly, we used a single flat tariff for all GP consultations $(€ 16.39)$, but this could have been unfair because GP's make house calls ( $€ 26.14)$ as well as doing consultations at their surgery $(€ 17.34)$ or more simple consultations by telephone $(€ 8.71$ ). From the number of each consultation-category (as reported by the patient) we calculated separate costs, and the sum of these was used as an alternative for the flat rate. It barely made any difference ( $€ 5$ increase) in the USUAL group or in the STEREO group ( $€ 12$ increase).

Fourthly, we estimated the indirect costs using the Human Capital Approach, a method that is controversial in cost-effectiveness analysis, as it is known to overestimate costs because it does not take into account the fact that human labor can in due course be replaced. It takes on more of a patient-perspective rather than a societal one; it implicitly assumes that labor markets are in equilibrium with no or little unemployment (that is, a worker cannot be replaced). Another method that does allow for worker replacement is the Friction Cost Method (FCM). It modifies the HC approach by allowing for worker replacement by other workers or by those in the unemployed pool. The time needed to fill in the vacancy ('friction time') can be estimated for a particular year. This friction period specifies the actual period of indirect costs. In 1998, it accounted for 123 days. These friction costs for the complete friction period are age- and sex-related: for men aged 45 to $49: € 18,1.06,50$ to $54: € 17,607,55$ to $59: € 17,198$ and 60 to 64: $€ 17,062$, and respectively for women in these age groups: $€ 9,439$, $€ 8,940, € 8,803$ and $€ 8,259$. We estimated friction costs based on these figures. Using the FCM, indirect costs were reduced drastically compared to the HC approach (USUAL: from $€ 50,400$ to $€ 3,042$ and STEREO: from $€ 46,433$ to $€ 3,369$ ). The reason for this large costs reduction is that the $\mathrm{HC}$ approach concerned the period upto retirement of the patient instead of the 123 days used in the FCM. The differences in indirect-or total costs between the groups, however, remained statistically insignificant. 
Fifthly, as an alternative we analyzed costs only for the 14 USUAL and 16 STEREO patients that survived after follow-up. Mean overall costs for each group almost doubled (USUALto $€ 121,250$ and STEREO to $€ 125,648$ ) but differences remained statistically insignificant $(\mathrm{p}=0.759)$. This increase is unsurprising given the high mortality rate.

Sixthly, outcome parameters were evaluated without including patients who had died. In the baseline analysis, the worst possible outcome on the various scales was assigned to the patients who had died ( 0 on the 70 -point SSS, 0 on the 20-point $B I$ and 6 on the mRS that normally ranges from 0 to 5 ). Aside from the expected improvement in scores in both groups, the differences between the groups did not alter and remained statistically insignificant (USUAL versus STEREO mean scores: mRS: 3.29, SD: 1.82 to 3.75, SD: $1.34, p=0.541$, SSS: $42.1, \mathrm{SD}: 23.0$ to $40.3, \mathrm{SD} 21.9, \mathrm{p}=0.693$ and Bl: $9.5, \mathrm{SD}: 9.1$ to $8.6, \mathrm{SD} 8.8, \mathrm{p}=0.464$ ).

In none of these calculations with alternative assumptions, was a statistically significant difference between the treatment groups found. As in the baseline analysis, the costs of the STEREO group were always slightly higher than those in the USUAL group. This sensitivity analysis lends support to the robustness of the baseline analysis.

\section{DISCUSSION}

The primary result of this economic evaluation study is that the total costs from a societal perspective for the investigated experimental intervention (STEREO) were almost equal to that of usual conservative treatment (USUAL). The mean total costs were only $€ 2,404(=4.8 \%$ ) less at 180 days follow-up, in patients receiving the experimental STEREO trearment, a statistically insignificant difference. None of the 16 cost subcategories including indirect costs, showed a significant difference between the groups.

A secondary result is that the outcome parameters were similar for both groups. The mortality rate at the end of follow-up was $59 \%$ ( 20 of 34 patients) in the USUAL group and $56 \%$ (20 out of 36 patients) in the STEREO group. Functional outcome and disability, measured with the mRS, SSS and BI, did not show statistically significant differences between the two groups. Nor was health-related Quality of Life, measured with COOP/WONCA charts, SF-36 and EuroQoL-5D, statistically different for either group. A cost-effectiveness/utility ratio was not computed because neither the costs nor the values/utilities differed between groups, and moreover a baseline utility 
assessment, which is required for a quality adjusted life years (QALY) analysis, was not available.

The sensitivity analysis showed highly robust outcomes with respect to the major costs and outcomes. The parameter that mainly influenced the base-case results was indirect costs. The dramatic increase in overall costs, resulting from changing the Human Capital approach with the Time Friction method was equal for both groups, therefore it did not lead to a change in the difference in overall costs between the two groups. Overestimation of costs resulting from the application of the commonly used Human capital approach is well known. This drawback that has led this method to be criticized, has also resulted in an increased use of the Friction Cost Method, which many authors believe to be a more accurate estimation from a societal perspective.

As in most other economical evaluations, the distribution of costs was skewed (asymmetrical) in our trial. However, we did not apply log transformation to achieve a more normal distribution, nor did we use median instead of mean values to compare for costs. We used a non-parametric test (Mann-Whitney $U$-test) to account for the skewed costs distributions. The main reason for this approach is that the mean is the most informative measure as it can be used to calculate the cost in all treated patients, a requirement in health care policy decisions. Other measures (like median or geometric mean) may result in misleading conclusions (64).

Given the results of a logistic regression analysis, which detected a trend towards reduced mortality (OR: $0.23,95 \% \mathrm{Cl} 0.05-1.2$, more details are provided in the original publication(23)), the most important reason for the absence of significant costs or effectiveness differences is the small trial size,. A power calculation, prior to the trial, estimated the need for 75 or more patients in each trial arm, based on the assumption of a $35 \%$ drop in mortality rate in the STEREO group. With less than half of the required trial population size included within a period of more than three years (71 patients), the patient accrual rate was definitely lacking behind Several, mostly practical, reasons for this are discussed in the original publication (23). Because of the slow inclusion and an interim analysis showing no benefits of the STEREO treatment, financial funding was withdrawn, resulting in a premature conclusion of the trial, without the required number of patients being included.

Apart from the general pitfalls in neuroepidemiological research (65), performing outcome measurement in the SICHPA-trial involved some additional problems.

Firstly, stroke has an acute onset. Data on the quality-of-life before stroke and before starting the treatment are therefore not available. 
Secondly, another point that may especially influence the quality of life measurement is that stroke patients, like other chronically ill patients, have a remarkable capacity to adapt to their poor health status. Both problems make it difficult to measure the improvement caused by (acute) stroke interventions. This may be solved by using a retrospective pretest or so-called 'then-test.' In the 'then-test,' stroke patients are asked to provide a judgment about the health care status prior to stroke.

Thirdly, a large group of the ICH patients die, which may lead to nonrandom missing values: i.e. the severely disabled ICH patients are excluded from follow-up. In economic evaluation studies, it is still unclear how one can best value the costs and HRQoL aspects in these patient groups.

Fourthly, many stroke survivors have cognitive and communicative disorders, so that self-reported information on a patient's quality of life cannot always be obtained. One solution is to use proxy measurements to avoid this group of patients being excluded from the study.

Fifthly, the instruments used in economic evaluation research are usually not very sensitive to small changes in health status. Therefore, the effects of stroke interventions may remain undetected with the crude tools of economic evaluation. The HRQoL instruments we used were generic ones, which can be applied to a broad spectrum of disease/intervention studies and have the advantage that they can be transformed into preference-based utilities. The information they provide can be interpreted on a societal level. The limitation of these generic instruments is that due to their aspecificity they lack sensitivity in detecting disease-specific changes in HRQOL. This means that, on a patient level, meaningful changes in HRQOL can be overlooked. For stroke such a disease-specific instrument is, for example, the Stroke-specific quality of life (SSQOL) (66).

Sixthly, as disease not only has an impact on the patient but also on close relatives of the patient, as their primary care givers (67), an assessment of changes in their HRQoL should be included in a study.

Seventhly, the distribution of baseline parameters is not equal in the SICHPA trial population. Patients in the STEREO group had lobar ICH'S significantly more often, and the mean volume was larger in this group. However, when these differences were statistically corrected for in a logistic regression analysis, the treatment effect remained insignificant (Odds Ratio (OR) of 0.23, Confidence Interval (CI) 0.05-1.20, $\mathrm{p}=0.08$ ) (23).

Eighthly, the appropriateness of the length of the follow-up period of 180 days was questionable. The rehabilitation of stroke patients more often than not is extended over a lengthy period that frequently exceeds the period of 180 days. This means that the (functional) outcome, health related quality of 
life and costs measured at this point, did not reflect a stable endpoint in some of the surviving patients.

In conclusion, costs and clinical outcome of stereotactic aspiration of spontaneous intracerebral hematoma with the use of urokinase were similar compared to the usuall conservative treatment. The main reason for not detecting significant differences was the small size of the SICHPA trial. It is recommended that in future larger trials, besides generic, also diseasespecific instruments be used in order to analyze changes in quality of life both in patients and in their close relatives. 


\section{REFERENCES:}

1. Reitsma JB, Konings-Dalstra JAA. Hart-en vaatziekren in Nederland 1999, cijfers over ziekte en sterfe. The Hague: Nederlandse Hartstichting; 1999.

2. Bogousslavsky I. Kaste M, Skyhoj Olsen T, Hacke W, Orgogozo JM. Risk factors and stroke prevention. European Stroke Initiative (EUSD). Cerebrovasc Dis 2000;10 Suppl $3: 12-21$.

3. de Haan R, Limburg M, van der Meulen I, Jacobs HM, Aaronson NK. Quality of life after stroke. Impact of stroke type and lesion location. Stroke 1995;26(3):402-8.

4. Payne KA, Huybrechts KF, Caro J, Green TJC, Kittich WS. Long term cost-of-illness in stroke: an international review. Pharmacoeconomics 2002;20(12):813-25.

5. Evers SM, Goossens ME, Ament AJ, Maarse JA. Economic evaluation in stroke research. An introduction. Cerebrovasc Dis 2001;11 (2):82-91.

6. Voeker JL, Kaufman HH. Intraparenchymal hemorrhage. New Horiz 1997;5(4): $342-51$.

7. Broderick JP, Brott 'T, Tomsick T, Miller R, Huster G. Intracerebral hemorrhage more than twice as common as subarachnoid hemorthage. Joumal of neurosurgery $1993 ; 78(2): 188-91$.

8. Sacco RL, Boden Albala B, Gan R, Chen X, Kargman DE, Shea S, Pajk MC, Hauser WA. Stroke incidence among white, black, and Hispanic residents of an urban community: the Northern Manhatian Stroke Study. Am J Epidemiol 1998;147(3):259-68.

9. Jorgensen HS, Nakayama $H$, Raaschou HO, Olsen TS. Intracerebral hemornage versus infarction: stroke severity, risk factors, and prognosis. Ann Neuroll 1995;38(1): $45-50$.

10. Ojemann RG, Heros RC. Spontaneous brain hemorrhage. Stroke 1983;14(4):468-75.

11. Karnik R, Valentin A, Ammerer HP, Hochfelner A, Donath P, Slany J. Outcome in patients with intracerebral hemorrhage: predictors of survival. Wien Klin Wochenschr 2000; $112(4): 169-73$.

12. Sacco RL, Wolf PA, Kannel WB, McNamara PM. Survival and recurrence following stroke. The Framingham study. Stroke 1982;13(3):290-5.

13. Porsdal V, Boysen $\mathrm{G}$. Direct costs during the first year after intracerebral hemorrhage. Eur J Neuroll 1999;6(4):449-454.

14. Taylor TN, Davis PH, Torner JC, Holmes J, Meyer MW, Jacobson MF. Lifetime cost of stroke in the United States. Stroke 1996;27(9):1459-66.

15. Meerding W], Bonneux $L_{\text {w }}$ Polder II, Koopmanschap MA, wan der Maas PJ. Demographic and epidemiological determimants of healthcare costs in Netherlands: cost of illness study. Bmj 1998;317(7151):11.1-5.

16. Polder IJ, Meerding WJ, Koopmanschap MA, Bonnewx $L$, van der Maas PJ. The cost of sickness in the Netherlands in 1994; the main determinants were adwanced age and disabling conditions. Ned Tijdschr Geneeskd 1998;142(28):1607-11.

17. Loddler I. Bouter LM. Future numbers of patients with a cerebrovascular accident in The Netherlands. Ned Tijdschr Geneeskd 1992;136(9):425-8.

18. Struijs JN, van Genugten MLL, Evers SMAA, Jager JC. Future prevalence and costs of stroke in the Netherlands. In: 16th Annual Meeting of the International Society of Technology Assessment in Heald Care; 2000; The Hague, The Netherlands; 2000. p. 99. 
19. Struijs $\mathrm{NN}_{*}$ van Genugten MLL, Evers SMAA, Ament AJHA, Jager IC. Scenario-onderzoek naar het zorggebruik en de kosten van de zorg van CVA patiènten in Nederland tot en met het jaar 2015. Bilthoven: RIVM rapport S/280751001/2001; 2001 .

20. Evers SM, Ament AJ, Blaauw G. Economic evaluation in stroke research : a systematic review. Stroke 2000;31(5):1046-53.

21. Drummond MF, O'Brien B, Stoddart GL, Torrance GW. Methods for economic evalu* ation of health care programmes. Second edition ed. Oxford: Oxford University Press; 1997.

22. Ament A, Evers $S_{*}$ Baltussen R. The usefulness of ratios for allocation decisions: the case of stroke. Cerebrovasc Dis 2000;10(4):283-8.

23. Teernstra OPM, Evers SMAA, Lodder J, Leffers P, Franke CL, Blaauw G. Stereotactic treatment of Intracerebral Hematoma by means of a Plasminogen Activator: $A$ multicenter randomized controlled trial (SICHPA). Stroke accepted 2002.

24. Gold MR, Siegel JE, Russell LB, Weinstein MC. Cost-effectiveness in heald and medicine. New York/Oxford: Oxford University Press; 1996.

25. DNB. De Nederlandsche Bank, Statistieken, website. In: http:/fwww.statistics.dnb.n.l/; 2002.

26. OECD. Organisation for Economic Co-operation and Development, website. In: http: //Www.oecd.org; 2002.

27. CVZ. College Voor Zorgverzekeringen, website. Im: http://www.cvz.nI/; 2002 .

28. KNMP. Koninklijke Nederlandse Maatschappij ter bevordering der Pharmacie, website. In: http://www.knmp.nl/; 2002.

29. IRV . Instituut Revalidatie Voorzieningen, Hoensbroek, Personal communication. In; 1999.

30. CBS. Centraal Bureau voor Statistieken, website. In: http://www.statline.cbs.nl/; 2002.

31. Evers $S_{\text {, Voss }} \mathrm{G}$, Nieman F, Ament A, Groot T, Lodder J, Boreas A, Blaauw G. Predicting the cost of hospital stay for stroke patients: the use of diagnosis related groups. Health Policy 2002;61(1):21-42.

32. Hermans $\mathrm{E}$. In het verkeerde bed; het zorgtraject van een cohort CVA-patiènten na ziekenhuisopname. Maastricht: Universiteit Maastricht; 2000 [Thesis].

33. Van Suaten A. Quality of hospital care and health outcomes after stroke. Amsterdam: University of Amsterdam; 2000 |Thesis!.

34. van Straten $A$, van der Meulen JH, van den Bos GA, Limburg M. Length of hospital stay and discharge delays in stroke patients. Stroke 1997;28(1):137-40.

35. Oostenbrink J, Koopmanschap M, Rutten F. Handleiding voor kostenonderzoek, methoden en richtlijnprijzen voor economische evaluaties in de gezondheidszorg. Amstelveen: College voor zorgverzekeringen; 2000.

36. de Haan $\mathbb{R}$, Horn $\mathbb{I}$, Limburg $M$, van der Meulen J, Bossuyt $P$. $\Lambda$ comparison of five stroke scalles with measures of disability, handicap, and quality of life. Stroke $1993 ; 24(8): 1178-81$.

37. Mahoney F, Barthel D. Functional evaluation: The Barthel Index. Maryland State Med I 1965;14(3):61-65.

38. Collin C, Wade DT, Davies $S$, Home V. The Barthel ADL Index: a reliability study. Int Disabil Stud 1988;10(2):61-3.

39. Wade DT, Collin C. The Barthel ADL Index: a standard measure of physical disability? Int Disabil Stud 1988;10(2):64-7. 
40. de Han $R$, Limburg $M$, Bossuyt $P$, van der Meulen J, Aaronson $N$. The clinical meaning of Rankin 'handicap' grades after stroke. Stroke 1995;26(11):2027-30.

41. Rankin I. Cerebral vascular accidents in patients ower the age of 60: II. Prognosis. Scor Med) 1957;2:200-215.

42. Spilker B. Quality of life and pharmacoeconomics in clinical trials. Philadelphia: Lippincott Will iams \& Wilkins; 1996.

43. Schipper $H$, Cinch J, Powell V. Definitions and conceptual issues. In: Spilker $B$. editor. Quality of life and pharmacoeconomics in clinical trials. Philadelphia: Lippincott Williams \& Wilkins; 1996.

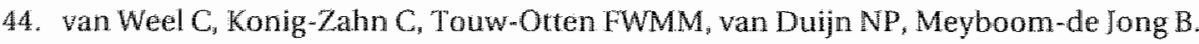
Measuring functional health status with COOP/WONCA charts. Gromingen: Noordelijk Centinm voor Gezondheidswraagstukken/ World Organization of Family Doctors (WONCA), European Research Group on Health Outcomes (ERGHO), Northern Centre for Health Care Research (NCH); 1995.

45. Brazier JE, Harper $\mathbb{R}$, Jones NM, O'Cathain A, Thomas KJ, Usherwood $T$, Westlake L. Validating the $\mathrm{SF}-36$ health survey questionnaire: new outcome measure for primary care. $B \mathrm{~mm} 1992 ; 305(6846): 160-4$.

46. Anderson C, Laubscher S, Burns R. Validation of the Short Form 36 (SF-36) health survey questionnaire among stroke patients. Stroke 1996;27(10):1812-6.

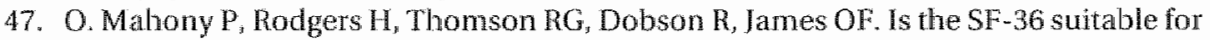
assessing health status of older stroke patients? [see comments]. Age Ageing $1998 ; 27(1): 19-22$.

43. Hobson $\mathrm{P}$, Bhowmick B, Meara I. Use of the SF-36 questionnaire in cerebrovascular disease Stroke 1997;28(2);464-5.

49. Ware JE, Ir., Sherbourne CD. The MOS 36-item short-form health survey (SF-36). I. Conceptual framework and item selection. Med Care 1992;30(6):473-83.

50. van der Zee KI, Sanderman R. Het meten wan de algemene gezondheidstoestand met de RAND-36. Groningen: Rijksuniversiteit Groningen: Noordelijk Centrum woor Gezondheidsvraagstukken; 1993.

51. SF-36. SF-36, website. [n: http://www.sf-36.com; 2002 .

52. Dorman PI, Waddell $F$, Slattery J, Dennis M, Sandercock $\mathbb{P}$. Is the EuroQoL a valid mocauro of hoalth - - rolatod quality of lifo aftor atroko? Stroko 1097;28(10);1076 92.

53. EuroQoL Group. A new facility for the measurement of the heath-related Quality of Life. Health Policy 1990(16):199-208.

54. EuroQol. Group. Not a quick fix. The EuroQoL Group. Health Serv J 1991;101 $(5279): 29$,

55. EuroqoL Group. EQ-5D User Guide. Rotterdam: Erasmus Universiteit Rotterdam, Centrum voon Gezondsheidsbeleid en Recht; 1995.

56. EuroQol Group. EuroQoL Group, website. In; www.euroQoL.org; 2002.

57. Braziter I, Roberts J Deverill $M$. The estimation of a preference-based measure of health from the $S F-36$. J Health Econ $2002 ; 21(2): 271-92$.

58. Dolan P. Single-index EuroQoL 5D, personal communication. In; 2002.

59. Dolan $P$, Gudex $C$, Kind $P$ 。 Williams $A$. The time trade-off method: results from a general population study. Health Econ 1996;5(2):141-54.

60. Busschbach J, McDomnell J, Essink-Bot ML, van Hout BA. Estimating parametric relationships between health description and health valuation with an application to the EuroQoL EQ-5D. I Health Econ 1999;18(5):551-71. 
61. Dolan P. Modeling valuations for EuroQol health states. Med Care 1997;35(11): 1095-108.

62. Dolan P, Gudex C, Kind P. Williams A. A social tariffs for EuroQoL: Results from a UK general population survey. York: The University of York Centre for heatch economics, york health economics consortium, NHS centre for reviews \& dissemination; Discussion paper 138; 1995.

63. Dolan P, Roberts J. Modelling valuations for Eq-5d health status: an alternative model using differences in valuations. Med Care 2002:40[5):442-6.

64. Thompson $\mathrm{SG}$, Barber $\mathrm{JA}$. How should cost data in pragmatic randomised trials be analysed? Bmj 2000;320(7243):1197-200.

65. Anderson DW, Rocca WA, Rosário. Pitfalls in Neuroepidemiologic Research. Neuroepidemiology 1998;17:55-62.

66. Williams LS, Weinberger M, Harris LE, Clark DO, Biller J. Development of a strokespecific quality of life scale. Stroke 1999;30(7):1362-9.

67. Williams AM. Caregivers of persons with stroke: their physical and emotional wellbeing. Qual Life Res 1993;2(3):213-20. 



\section{Meta Analyses in treatment of spontaneous supratentorial intracerebral hematoma}

O.P.M.Teernstrail, A.G.H. Kessels ${ }^{2}$ and S.M.A.A. Evers 1,3

Dept of Neurosurgery 1 , Uniwersity Hospital Maastricht and Atrium Medical Center Heerlen, Dept of Clinical Epidemiology and Medical Technology Assessment ${ }^{2}$. Dept of Health Organization Policy and Economics ${ }^{3}$ University of Maastricht, "The Netherlands

Submitted 


\section{ABSTRACT}

Introduction. Optimal treatment in spontaneous supratentorial intracerebral hemorrhage (ICH) is to this date still a matter of debate. There are many case reports and non-randomized studies, but only a few randomized controlled trials (RCT) investigating the role of surgery in ICH. None of these RCTs shows surgery to be beneficial over conservative treatment alone, in terms of reduced death and dependency. Systematic reviews that pooled these RCTs were also inconclusive. The systematic review in this paper updates previous meta-analyses, and presents an alternative manner of reviewing. Instead of the conventionally used generic criteria, disease specific methodological criteria were employed to evaluate studies. The resulting selection of studles was compared to that of previous systematic reviews.

Methods. All RCT's and quasi-RCTs (Q-RCT) published in English were identified with a systematic literature search. Their applicability was evaluated with disease specific criteria. With a preconceived list of disease specific methodological criteria, remaining studies were then evaluated on comparability between intervention and control group concerning prognostic factors, co-interventions and effect measurement. The resulting selection of studies was compared to those of two earlier systematic reviews. In a base case meta-analysis selected studies were statistically pooled, studies in which doubt existed about applicability or methodological quality were entered separately. An intervention specific subgroup analysis was done (stereotactic versus craniotomy evacuation).

Results. 7 RCTs and 1 Q-RCI were identified with the systematic literature search. Reservations on applicability existed in one RCT dating from a pre-CT era. In the ensuing methodological evaluation, this RCT and another (with a good methodological design but unfortunately not leading to good comparability in prognostic factors between trial groups) were marked as doubtful and were entered separately in the meta-analysis. Apart from the inclusion of two new studies, our selection differed from the two previous systematic reviews mainly in respect to the RCT that was excluded from base-case analysis because of our methodological evaluation; this resulted in a different conclusion. The six remaining studies, pooled in the base-case meta-analysis, showed a statistically significant reduction in the odds of death (OR: 0.48,95\% CI: 0.27-0.84), and a trend toward improved survival and independency (OR: 0.63, 95\%Cl: 0.36-1.08) for surgery. Subgroup-analysis demonstrated a statistically significant effect of stereotactic surgery in reducing the chance of death (OR: $0.29,95 \% \mathrm{Cl}: 0.14-0.59$ ) and death and dependency (OR: $0.48,95 \%$ CI: $0.24-0.96$ ). 
Discussion. Our disease specific methodological evaluation focusing on the achieved comparability between intervention and control group in a (Q-)RCT, led 1 RCT to be excluded from base case meta-analysis that was included in two previously conducted systematic reviews. Separate inclusion of this RCT in the meta-analysis reduced the significant effect found in the base-case meta-analysis. This demonstrates that the manner in which studies are methodologically evaluated in a systematic review has a great impact on its conclusions. This meta-analysis is the first to report a clear and significant beneficial effect of stereotactic surgery in ICH with respect to mortality and dependency. New RCTs specifically on stereotactic treatment of ICH are therefore warranted to consolidate this finding. In future RCTs improved concealment, especially in effect-measurement is recommended. Based on our results, we feel that achieved comparability of prognostic factors, co-interventions and effect measurements between the trial groups in a RCT, and also the use of disease specific criteria are important issues to be considered in future systematic reviews.

\section{INTRODUCTION}

With a worldwide incidence of 10 to 20 per $100,000(1,2)$, primary intracerebral hemorrhage accounts for 10 to 15 percent of all cases of stroke (3-5). It is twice as common as subarachnoid hemorrhage (3). It has a high mortality rate of $23 \%-58 \%$ at six months, which is twice that of ischemic stroke, and is often leading to severe disability $(3,6-11)$. Despite these devastating characteristics there is no consensus about optimal treatment: surgical or conservative. Up to now clinical practice is guided by subjective believes rather than evidence-based medicine (12). In some countries surgery is used very modestly but in others like Japan and Germany reports indicate that more than half of the patients are treated surgically (13).

Evaluation of efficacy of surgery in primary supratentorial intracerebral hematoma (ICH) in the form of a randomized controlled trial (RCT) has only been performed in a few instances $(3,14-21)$. The first RCT on this subject, performed by McKissock et al in 1961 is the largest to date (21), all others are rather small and remain inconclusive with exception to the RCT by Auer et al. (14). In the 100 patients he analyzed he found (endoscopic) surgery to be associated with a reduction of mortality.

Several descriptive reviews have been published but their recommendaw tions are conflicting $(5,22-26)$. Systematic reviews or meta analyses are even more sparse (27-30), the most recent being the study of Fernandes et al. in 
2000 (30). None of them was able to demonstrate a significant treatment effect of either surgery or conservative therapy in $\mathrm{ICH}$.

An important objective of systematic reviews is to provide an empirical basis for clinical decision-making. In the end, the conclusion of a systematic review is closely related to the quality of both the individual RCTs that were included and the review process itself. Quality of a RCT is sometimes referred to as 'the likelihood of the trial design to generate unbiased results' (31). The main goal of a RCT is to unambiguously determine the efficacy of an intervention. In order to achieve this, different methodological measures are employed to ensure maximum comparability between intervention and control group with respect to prognostic factors, co-interventions and effect measurement. Most systematic reviews use predefined generic methodological criteria lists to check for these measures (32). This reviewing process results in a 'quality score' of the study design, on which inclusion of the study into the meta-analysis is based.

A potential weakness of this approach is that, while checking only for a methodologically adequate design of a study, it disregards whether this design results in actual good comparability of the trial groups. Due to bad luck, a RCT on surgery in ICH with an excellent methodological design, still can have unbalanced trial groups for significant prognostic factors like hematoma volume etc. . Despite that a conclusion in such a trial probably would be biased, most conventional systematic reviews would include it on account of its good design. A second possible disadvantage is related to use of generic methodological criteria lists. Depending on the disease and the intervention that is of interest, some of the methodological criteria in the generic list may not be relevant. When for example the effect of an experimental treatment on mortality is studied in a disease with a clear natural course, like in metastasized melanoma (certain death within a year), a control group would be unnecessary. A disease specific criteria list would result in a more fair inclusion and assessment such a study, whereas most generic criteria lists would exclude this study.

In order to test these views we carried out a systematic review on surgery for spontaneous $I \mathrm{CH}$. A disease specific applicability criteria list was constructed to verify that the studies selected by our literature search were appropriate and comparable. A disease specific methodological criteria list was used to further evaluate a study for comparability between intervention group and control group with respect to prognostic factors, co-interventions and effect-measurements. This list can be found in the appendix. The results of our systematic review (on inclusion of studies) were compared to those of two other systematic reviews that used generic criteria lists: 
Fernandes et al.(30) and Prasad et al. $(28,29)$. In addition, this meta-analysis updates the results of these by including new trials.

\section{METHODS}

\section{Literature search}

Literature selection was performed by searching the MEDLINE and EMBASE-Excerpta Medica databases from 1966 to November 2002, using a search strategy recommended by the Cochrane Group (33) with medical subject heading (MESH) terms: intracerebral hematoma, intracerebral hemorrhage, surgery (combined with each of the former MESH terms). In all the articles that were found reference lists were screened for relevant publications. Only RCTs and quasi-randomized controlled trials (i.e. unconcealed treatment allocation, e.g. by matching) in the English language were selected. A recent report (34) suggests that disregarding of non-English publications is not likely to bias the conclusions of a meta-analysis.

\section{Applicability evaluation}

Two of the authors (SE and OT) independently used an applicability criteria list (see appendix) that was constructed in advance, to verify that a study measured similar effects of similar interventions on similar patients compared to the other studies. Subjects on this list were: inclusion criteria (age $>15$ years, altered level of consciousness, anticoagulant use, CT-scan showing ICH volume $>10 \mathrm{ml}$., and treatment within 72 hours), intervention (all kinds of surgical methods were allowed, conservative medical treatment in a control group), effect parameters (mortality, functional outcome and number of measurements during follow-up), analysis of side effects and sufficient follow-up period ( $>2$ months). If a study was found not to be sufficiently in accordance with these criteria, it was dropped from the review procedure.

\section{Methodological evaluation}

A previously designed disease specific methodological criteria list (see appendix) was used by the 2 reviewers to check for comparability of treatment groups for prognostic factors, co-interventions and effect measurement. A balanced distribution over both treatment groups of recognized prognostic factors was judged very important, as it reflects a successful allo- 
cation procedure and reduces possible confounding. Prognostic factors that were checked were: age, level of consciousness (Glasgow Coma Scale; GCS), ICH size and the presence of intraventricular blood (IVH) (35-40). A good description of baseline characteristics was important to enable assessment of prognostic factor distribution. Data were extracted from the studies concerning the use of pre-stratification, randomization (procedure, blinding), size of trial groups (more than 50 patients in each group), and percentage dropouts. These were however of less importance compared to a balanced distribution of prognostic factors over both trial-groups. Comparability of co-interventions was evaluated by checking for blinding of the patient and/or attending medical personnel. Any simultaneous treatments other than the intervention had to be regimented or at least described. Evaluation of comparability of effect measurement was done by assessment of concealment of the evaluator.

The performance on the three main methodological issues (comparability of groups for prognostic factors, co-interventions and effect measurements) was graded as excellent $(++)$, good $(+)$, doubtful $( \pm)$ or poor $(-)$ or unclear (?). When doubt existed concerning comparability of prognostic factors between study groups, the use of multivariate testing to compensate for possible confounding, could lead to inclusion of the particular study. Together the grades on the three main methodological issues determined if the study was included in the base-case meta-analysis (BC). If still doubt existed concerning the methodological quality of a study, it was separately included in the meta-analysis (S). The results on inclusion of studies were compared to those of Prasad et al. $(28,29)$ and Fernandes et al. $(30)$.

\section{Meta-analysis}

Data of all the studies with sufficient methodological quality were statistically pooled in a base case meta-analysis. Statistical pooling was done by weighting the natural $\log$ of the Odds Ratio (OR) with its inverse variance. The effect of an intervention was expressed as an OR with a $95 \%$ confidence interval (95\%Cl). Separate statistical pooling was conducted including studies in which doubt existed about methodological performance. Stereotactic, minimally invasive surgery differs from conventional open craniotomy (less collateral damage to the brain) and is assumed by many to result in a more favorable outcome. Therefore, given a statistically significant treatment effect of the pooled studies, a subgroup analysis was to be performed with only studies that used craniotomy and with studies that used stereotactic surgery. 


\section{RESULTS}

With the literature search 7 RCTs $(14,15,17-21)$ were identified, and one Q-RCT (4l). With most of these studies extensively described in previous meta analyses(28-30) the reader is referred to table $\mathbb{1}$ for an overview containing the most important characteristics. The two new studies, Tan et all (41) and Teernstra et al.(20) are described in more detail.

The applicability of the studies was determined by evaluation with disease specific criteria. A point of discussion was the variance in interventions that was found. Auer et al.(14) used stereotactically guided endoscopic evacuation, Teernstra et al.(20) used stereotactic aspiration with urokinase, Zuccarello et al.(19) used both craniotomy (5 patients) and stereotactic aspiration (with urokinase, 4 patients), and all the rest used craniotomy evacuations. From a practical point of view, it was agreed to allow for all methods in the base case meta-analysis, but to do a subgroup analysis in a later stage. In the study of Batjer et al.(15) one surgical and two medical treatment groups existed, one of these had additional intracranial pressure (ICP) monitoring, in the analysis the two medical groups were combined to one.

Although the trial of McKissock et al. (21) is a methodologically excellent conducted study, it dates from a pre CT-era, and there was doubt whether it should be included in the meta-analysis. The absence of CT-scanning results in a significant diagnostic error rate. The study mentions 82 patients with JCH who were not included in the trial, in 18 cases the reason being a clinical presentation not suspect for ICH. Furthermore, the author reports a high diagnostical error rate of $4 \%$ in surgical patients, and in $5.5 \%$ in conservatively treated patients. Without the diagnostic capabilities of CT-scanning, there could easily have been more patients with a wrong diagnosis, especially in the conservative group. All this leads to uncertainty about accurate patient inclusion in this study.

All studies measured mortality and functional outcome falthough not with uniform instruments, see methods section) and had an adequate follow-up period, 8 with 6 months or more and one with 3 months post-stroke (19). Because of its relevance to clinical practice, a composite outcome of death and dependency was included (next to mortality alone). The outcome parameter death or case fatality was extracted from the studies without difficulty, but death and dependency was less uniformly defined and had to be reclassified (in: death, dependent, independent). Table 2 presents a summary of this reclassification.

In 1 study (20) inter-group differences in side-effects were statistically analyzed, 4 studies $(14,17,19,41)$ described side effects per group (mostly concerning rebleeding), in $3(15,18,21)$ no side-effects were mentioned. 


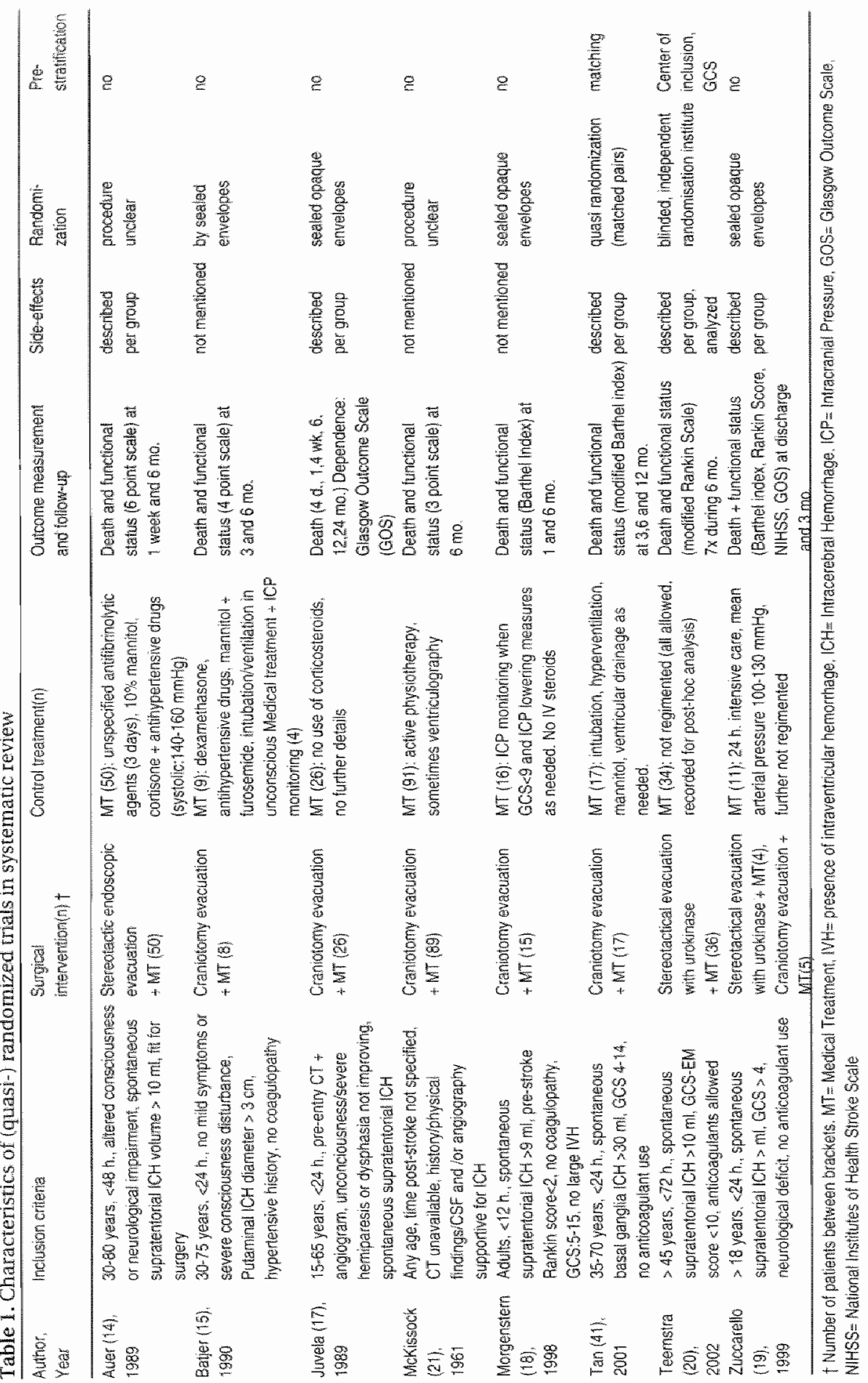




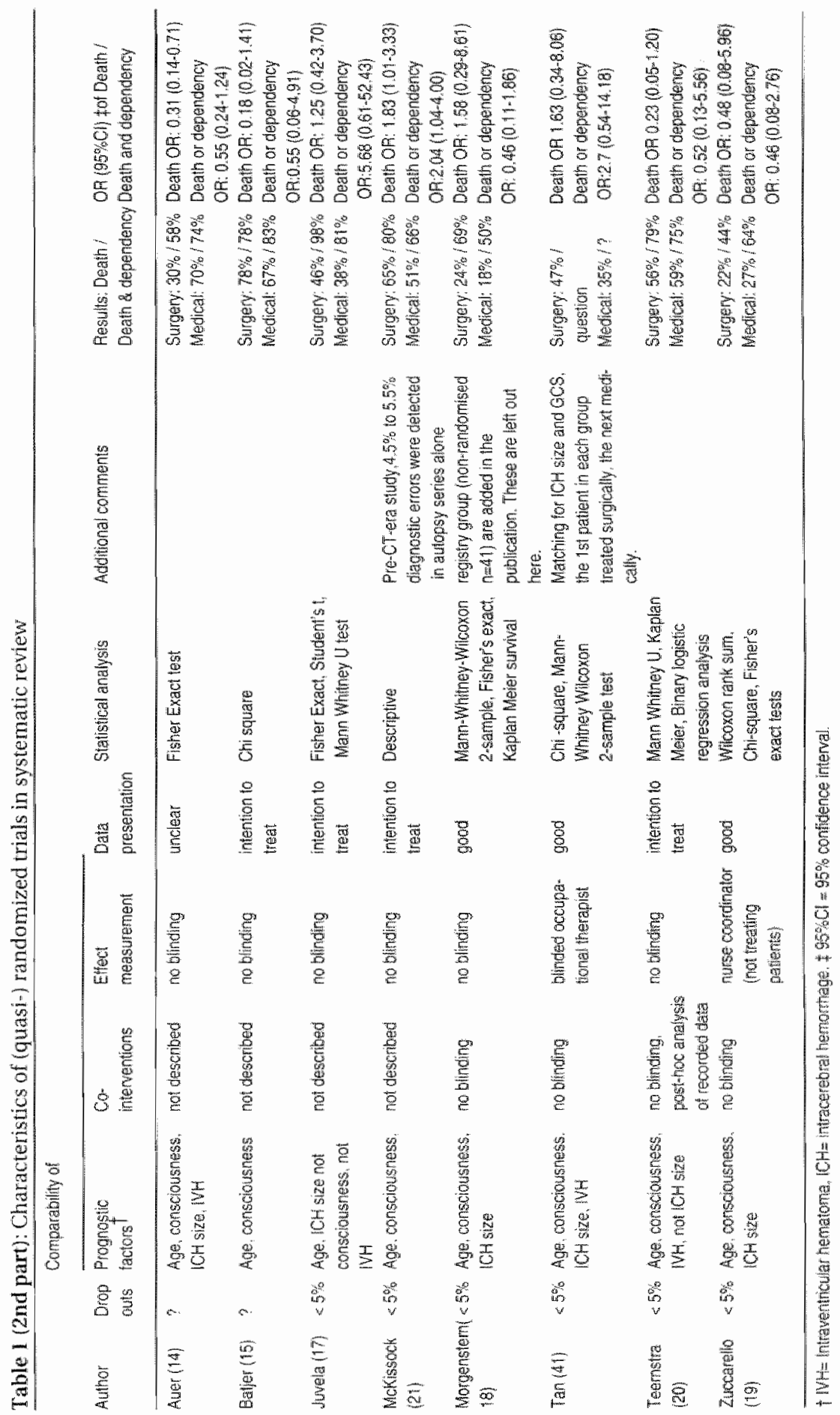


Table 2. Reclassification into death \& dependency

\begin{tabular}{|c|c|c|c|}
\hline Author & Used Scalle & Death & Dependency \\
\hline Auer(14) & own 6-point scale & grade $6=$ death & $\begin{array}{l}\text { grade } 5=\text { conscious patient, } \\
\text { totally dependent on others } \\
\text { for activities of the day }\end{array}$ \\
\hline Batjer(15) & own 4 point scale & level $\mathrm{L}=$ death & $\begin{array}{l}\text { level } 2=\text { dependent at home } \\
\text { or institution }\end{array}$ \\
\hline luvela(17) & Glasgow Outcome Scale & grade $1=$ death & $\begin{array}{l}\text { grade } 2 \& 3=\text { dependent or } \\
\text { severely disabled }\end{array}$ \\
\hline Mckissock(21) & own scale & 'death'-group & "rotal disability" -group \\
\hline Morgenstern (18) & Barthel index & death & score $<61$ \\
\hline $\operatorname{Tan}(41)$ & Barthel index & death & score $<61$ \\
\hline Teernstra(20) & modified Rankin Scale & grade $6=$ death & $\begin{array}{l}\text { grade } 4 \& 5=\text { (moderately) } \\
\text { severe handicap }\end{array}$ \\
\hline Zuccarello(19) & Glasgow Outcome Scale & grade $1=$ death & $\begin{array}{l}\text { grade } 2 \& 3=\text { dependent or } \\
\text { severely disabled }\end{array}$ \\
\hline
\end{tabular}

Applicability was judged to be sufficient in all studies with some reservations concerning the trial of McKissock et al.(21), we decided to include it separately in the meta-analysis.

\section{Methodological evaluation}

We focused not so much on the methodological measures themselves, but rather on grading their effectiveness in achieving comparability of trial groups regarding prognostic factors, co-interventions and effect measurement.

In the study of Auer et al.(14) the randomization procedure, which is only referred to in the abstract of the publication, is unclear, but the study had a similar distribution of all checked prognostic factors (see table 3 ). Comparability of ICH size and the presence of IVH in the study of Batjer et al.(15) was unrevealed.

Juvela et al.(17) found statistically significant differences between the trial groups for level of consciousness and the presence IVH. No multivariate analysis was used to correct for possible confounding. Therefore, the study was excluded from the base case meta-analysis and entered separately.

In Mckissock et al.(21) there were, due to the absence of CT-scanning, no data on ICH size and IVT, after randomization, in $40 \%$ of surgical patients ventriculography was needed to localize the hematoma. Craniotomy was only carried out if the lesion was accessible (hematomas confined to the region of the thalamus or the basal ganglia were not operated). According to 
Table 3. Methodological grading and inclusion in meta-analysis

\begin{tabular}{|c|c|c|c|c|c|c|}
\hline \multirow[b]{2}{*}{ Authors } & \multicolumn{4}{|c|}{ Reviewers appraisal on } & \multirow{2}{*}{$\begin{array}{l}\text { Prasad } \\
(28) \\
\text { Inclusion }\end{array}$} & \multirow{2}{*}{$\begin{array}{l}\text { Fernandes } \\
\text { (30) } \\
\text { Inclusion }\end{array}$} \\
\hline & $\begin{array}{l}\text { Prognostic } \\
\text { factors }\end{array}$ & $\begin{array}{l}\text { Co-inter- } \\
\text { ventions }\end{array}$ & $\begin{array}{l}\text { Effect measu- } \\
\text { rement }\end{array}$ & Inclusion & & \\
\hline Aner $(14)^{\stackrel{*}{\prime}}$ & $4+$ & - & - & $B C^{4}$ & $s$ & $\mathrm{BC}$ \\
\hline Batjer (15) & 4 & м & " & $\mathrm{BC}$ & $\mathrm{BC}$ & $\mathrm{BC}$ \\
\hline Juvela $(17)$ & \pm & - & $=$ & $S^{\mathrm{s}}$ & $\mathrm{BC}$ & $B C$ \\
\hline Mckissock (21) & \pm & - & - & $S$ & $S$ & $S$ \\
\hline Morgenstern (18) & + & \pm & - & $\mathrm{BC}$ & . & $B C$ \\
\hline $\operatorname{Tan}(11)$ & $*+$ & + & + & $B C$ & . & . \\
\hline Teemstra $(20)^{\dagger}$ & + & \pm & - & $\mathrm{BC}$ & . & . \\
\hline Zuccarello $(19)^{\dagger}$ & + & + & \pm & $B C$ & & $B C$ \\
\hline
\end{tabular}

* Study unavailable at time of meta-analysis; $\uparrow$ A subgroup analysis/pooling is done with: Auer et al, Teernstra et al. and the 4 stereotactically treated patients from Zuccarello ef al.; $\#$ BC: included in the Base-case meta-analysis: $\$ S$ : separately included in base-case meta-analysis

the intention to treat principle, this unquantified proportion of patients that did not receive their allocated treatment remained in the surgical group. The study of McKissock et al. (21) was not included in the base case meta-analysis, but analyzed separately, for reasons of uncertainty concerning both applicability and comparability of treatment groups. All the above mentioned studies $(14,15,17,21)$ did not explicitly report on co-interventions.

The study of Tan et al. (41) is the only quasi-randomized trial in this review. In his prospective trial, he used a non-blinded allocation method matching consecutive patients for ICH size and Glasgow Coma score (GCS) on admission. In each group the first patient was then treated surgically and the next medically. Inclusion criteria were: age between 35 and 70 years, spontaneous basal ganglia hemorrhage, ICH volume of more than $30 \mathrm{~mL}$, GCS between 3 and 15, no bleeding disorders or anticoagulant use, no organ failure or active malignant disease or previous strokes. Surgical intervention consisted of a craniotomy and a microsurgical evacuation of the ICH within 24 hours post-stroke. Medical treatment (also in surgical group) consisted of intubation with hyperventilation and use of mannitol if necessary and ventricular drainage in case of hydrocephalus. There was no cross-over. Blinded assessment of functional status (modified BI) was obtained by telephone or home-visits at 3,6 and 12 months post-stroke. He included 17 patients in each treatment arm, the baseline characteristics matched closely with no statistically differences between groups, concerning age, sex, hypertension, ICH size, GCS, and the presence of intraventricular blood (IVH). Co-interventions like ventricular drainage occurred equally for both groups ( $11.7 \%$ in surgical and $17.6 \%$ in conservative group). Eight $(41.2 \%)$ patients 
had died in the surgical arm, and six $(35.3 \%)$ in the conservative arm at 6 months. The or for mortality was 1.63 (95\% CI: 0.34-8.06). Poor functional outcome defined as a modified BI score $<61$ or death was also statistically insignificant at 6 months with an OR of $2.7(95 \% \mathrm{CI}: 0.54-14.18)$. Because of a very good comparability of both intervention and control group concerning prognostic factors, co-interventions and effect-measurement (blinded), this study was included in the meta-analysis.

Teemstra et al.(20) reported on the SICHPA trial in which, by blinded randomization 36 patients were allocated to a surgical group (stereotactic aspiration with urokinase use) and 34 in a conservative treatment group. Admission criteria were: age $>45$ years, spontaneous supratentorial $\mathrm{ICH}$, Glasgow EM score ranging from 2 to 10 , ICH volume $>10 \mathrm{cc}$, treatment within 72 hours. The follow-up was 6 months, effect measurement (mortality, Barthel index, modified Rankin Scale, different quality of life scales) was not blinded. Co-interventions (not blinded) were recorded and post-hoc analysis showed a significant higher rate of mechanical ventilation and use of low-molecular weight heparins in the surgical group. A total of 7 clear protocol violations occurred: 5 patients did not receive stereotactic treatment, 1 had a craniotomy instead, and 1 patient in the conservative group had a craniotomy. In compliance with the intention to treat principle all patients were analyzed according to their allocated groups. Statistically significant differences between the trial groups concerned frequency of lobar ICHs (67\% in surgical and $41 \%$ in conservative group) and the ICH size (66 $\mathrm{ml}$ versus $52 \mathrm{ml}$ respectively). However, using logistic regression analysis, possible confounding was corrected for. The OR for mortality is 0.23 (95\% CI: $0.05-1.20)$ and for death and dependency $0.52(0.13-5.56)$. With one of the checked prognostic factors being unbalanced, but with adequate compensation of this possible bias with multivariate analysis, the study was included in the baseline meta-analysis.

The feasibility study of Zuccarello et al.(19) showed good comparability for prognostic factors, although on one (presence of IVH) no data are provided. Co-interventions (not blinded) were described per group in a detailed manner. A nurse coordinator, not involved in the treatment of patients, performed effect measurement at 3 months follow-up. We were unsure whether to consider this blinded effect measurement. This trial was included in the meta-analysis. Concealment of the outcome evaluator was absent in all trials except for the one of Tan et al.(41) and possibly the one of Zuccarello et al.(19). No study reported blinded co-interventions.

In 2 studies $(17,21)$ it was decided to perform a separate analysis in order to determine their effect on the results of the base case meta-analysis. Aside from studies not included, due to unavailability at the time, our results 
differed from those of Prasad et al. $(28,29)$ firstly, in not excluding Auer et al.(14) from the baseline meta-analysis (although we additionally did perform a subgroup analysis with it) and secondly, in excluding Juvela et al.(17) from it. Our selection was different to that of Fernandes et al. in that the study of Chen et al.(16) was not included (non-English publication) and the exclusion of the trial of Juvela et al.(17) from our base case meta-analysis. An "update" was done in the sense that the quasi randomized trail of Tan et al.(41), and our own RCT (20) were included.

\section{Statistical pooling}

Figure 1 shows the ORs for the different studies and their pooled ORs for mortality, figure 2 is similar except for the outcome is here death and dependency. The only study showing a significant reduction of the odds of death (OR: $0.31,95 \% \mathrm{CI}: 0.14-0.71$ ) at 6 months post-stroke was that of Auer et al.(14). The study of McKissock et al.(21) on the contrary showed an opposite effect (OR 1.83, 95\% CI: 1.01-3.7). The base case (BC) statistical pooling

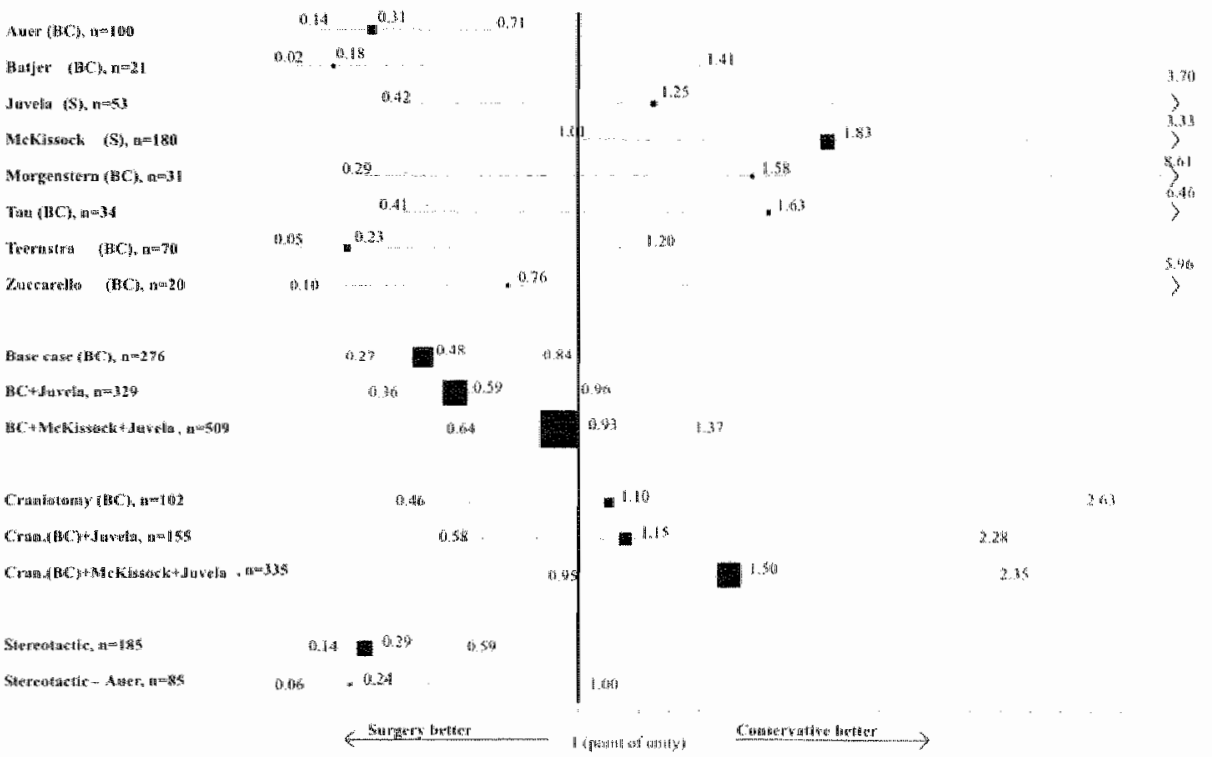

Figure 1. Meta-analysis of (quasi-) RCTs of surgery in ich: mortality

$\mathrm{BC}=$ Base case meta-analysis, $\mathrm{S}=$ separate inclusion in meta-analysis, $\mathrm{n}=$ total number of patients. * The upper 8 lines represent the single studies (Jower limit of $95 \%$ confidence interval to odds ratio to upper limit confidence interval). "The number of patients is given berween brackets and is also reflected in the size of the quadrant indicating the OR. * An OR with its $95 \%$ $\mathrm{Cr}$ below the level of unity (1) indicates a significantly reduced probability of death. 


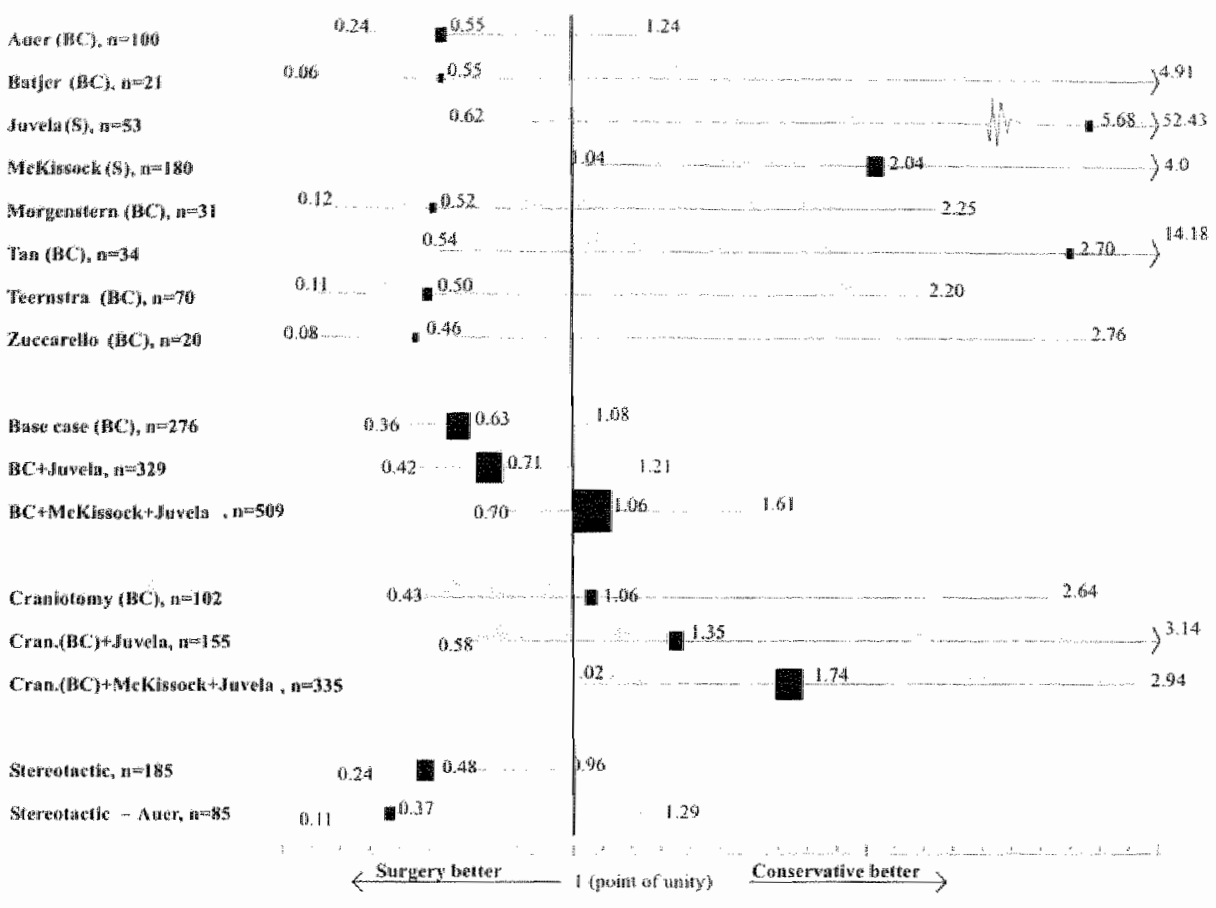

Fugure 2. meta-analysis of (quasi-) rots of surgery in ich: death \& dependency

* $\mathrm{BC}=$ Base case meta-analysis, $\mathrm{S}=$ separate inclusion in meta-amalysis, $\mathrm{n}=$ total number of patients; * The upper 8 lines represent the single studies (lower limit of $95 \%$ confidence interval to odds ratio to upper limit confidence interval): * The number of patients is given between brackers and is allso reflected in the size of the quadrant indicating the $\mathrm{OR}_{0}^{*}$. An OR with its $95 \% \mathrm{Cl}$ below the level of unity (1) indicates a significantly reduced probability of death \& dependency.

demonstrated a statistically significant effect of surgery in lowering the probability of death (OR: $0.48,95 \% \mathrm{CI}: 0.27-0.84$ ). This effect remained when in a separate pooling the study of Juvela et al.(17) was added, but disappeared in combination with the study of McKissock et al.(21). When the outcome reflected death and dependency however, this effect was not seen, with an OR of 0.63 (95\% Cl: $0.36-1.08$ ) it could be described as a mere trend towards improved survival (which disappeared altogether when the studies of Juvela (17) or McKissock (21) were added).

Auer et al.(14), Teernstra et al.(20) and Zucarello et al.(19) (in 4 out of 9 surgical patients) used stereotactic surgery. Subgroup analysis showed a clear and significant effect of stereotactic surgery (with and without the study of Auer et al.(14)) in reduction of chances of death (OR: $0.29,95 \% \mathrm{Cl}$ : $0.14-0.59)$, in contrast to the subgroup with craniotomies, which indicated no significant effect. Stereotactic surgery was also found to reduce the 
chances of death and dependency (OR: $0.48,95 \% \mathrm{CI}: 0.24-0.96$ ), but when the study of Auer et al.(14) was left out this effect did not persist. The subgroup of studies with craniotomies did not indicate such an effect, on the contrary when both studies of McKissock (21) and Juvela (17) were added, patients who were treated conservatively in the control group were significantly better off.

\section{DISCUSSION}

With a preconceived disease-specific criteria list (for applicability and methodological quality) two reviewers independently selected 5 RCTs $(14,15$, 18-20) and one Q-RCT (41). All of them had good comparability for prognostic factors, co-interventions and effect measurement. In contrast to earlier meta-analyses (28-30) the trials of McKissock et al.(21) and Juvela et al.(17) were not included in our base-case meta-analysis. In this meta-analysis the selected studies showed a statistically significant effect in reducing the odds of death (OR: $0.48,95 \% \mathrm{CI}: 0.27-0.84$ ), and a trend toward improved survival and independency (OR: $0.63,95 \% \mathrm{CI}: 0.36-1.08$ ). Subgroup-analysis demonstrated a statistically significant effect of stereotactic surgery in reducing the chance of death (OR: $0.29,95 \% \mathrm{CI}: 0.14-0.59$ ) and death and dependency (OR: $0.48,95 \% \mathrm{CI}: 0.24-0.96$ ).

Evidence based medicine relies on the results of large conclusive and methodologically well-conducted trials. In the absence of such trials, results of systematic reviews or meta-analyses are of particular value. However, no matter how systematic the reviewing, a subjective element remains. This is demonstrated by the variance in the studies that are selected by using different review strategies (42), or even because of different reviewers. The reliability and validity often associated with systematic reviews may be overestimated. One of the criticisms is that checking whether a study has complied with generic methodological criteria, does in itself not guarantee a good comparabillity of intervention and control group. By not just checking methodological criteria, but also by judging this actually achieved comparability, this systematic review included a different set of trials than two previous ones (28-30).

The main difference is the exclusion of the trial of Juvela et al.(17). This is a methodollogically well-constructed trial, which observes most of established methodological standards, but unfortunately, this did not result in balanced trial-groups. With an unequal distribution of more than two important prognostic variables, its results are prone to bias, and regrettably, no multivariate analysis was done to correct for possible confounding. 
The importance of not just checking for implementation of methodological standards but also evaluating if these result in comparable treatment groups, especially in small trials, was also demonstrated in evaluation of the RCT of Teernstra et al.(20). Despite a concealed randomization procedure, the intervention group had a significantly higher frequency of lobar ICHs, ICH size was also significantly larger in this group. Patients with larger ICHs have a worse prognosis. A logistic regression analysis was used to correct for this possible confounding, resulting in an OR of 0.23 (95\% CI: $0.05-1.20$ ) instead of an uncorrected (probably biased) OR of 0.88 (95\% CI: 0.34-2.26).

Like in the meta-analyses of Prasad et al. $(28,29)$ and Fernandes et al. (30) the trial of McKissock et al.(21) was not included in the base case meta-analysis. Although this trial is the oldest it is also still the largest of its kind, and many clinicians were influenced by its conclusions (craniotomy has no advantage over conservative treatment alone), it has serious imperfections that are related to its pre-CT-era date, which should prevent it from being included in modern-day meta-analyses.

The majority of the trials that were evaluated were comparable but lacked uniformity in effect measurement, whereas functional outcome was concerned. The use of a disease specific validated scale like for example the modified Rankin Scale $(43,44)$ in stroke patients, is advisable in order to better compare results of different trials.

A problem in systematic reviewing is that reports on RCTs not always mention all relevant aspects. Side effects are as important as the investigated effects of an intervention when deciding on its usefulness in daily clinical practice. In three out of eight studies, nothing was mentioned about these. Blinding of effect-measurement in some form was observed twice in all of the eight trials, this is probably due to difficulties in obscuring a surgical treatment to an evaluator. Co-interventions, when described were in none of these trials blinded, possible this also has to do with the fact that in a surgical trial this is hard to realize (45). Unconcealed effect measurement however, can lead to serious bias, and every effort should be made to avoid it $(31,46)$.

In comparing the results of our systematic review to those of two previous reviews we found several differences. In his meta-analysis Prasad et al. $(28,29)$ did a separate analysis of the study of Auer et al.(14), being the only study with stereotactic endoscopic evacuation as intervention. He concluded its effect to be insignificant. In our subgroup meta-analysis we pooled all patients from three studies with stereotactic surgery, which resulted in a significant effect by this intervention in reducing chances for death and death and dependency. The effect was reduced by removing the study of Auer et al., but still remained significant in relation to mortality. The 
subgroup with craniotomies on the other hand tended (insignificantly) to favor the conservative control group. This reinforces the believe that stereotactic surgery in ICH is an intervention of a different kind compared to open craniotomy. At least one large multicenter, randomized controlled trial is currently underway evaluating surgery in spontaneous ICH. This trial called the ISTICH trial (International Surgical Trial in Intracerebral Hemorrhage) will end in springtime 2003, having included over 1200 patients (47). The subgroup of stereotactically treated patients in this trial could be added to existing stereotactic trials, possibly providing further proof concerning the efficacy of this method.

In conclusion, our results suggest that stereotactic surgery is a more promising treatment than open craniotomy with respect to improved (functional) outcome in patients with spontaneous ICH. Further research is therefore warranted to better ascertain its efficacy. Concealment of effect measurement and co-interventions, and extra vigilance with respect to trial-group comparability (including the application of multivariate testing) are points, which deserve increased attention in future research. Based on our results, we feel that achieved comparability of prognostic factors, co-interventions and effect measurements between the trial groups in a $\mathrm{RCT}$, and also the use of disease specific criteria are important issues to be considered in future systematic reviews. 


\section{REFERENCES}

1. Furlan A, Whisnant JP, Elveback $L R$. The decreasing incidence of primary intracerebral hemomhage: a population study. Ann. Neurol. 1979:5(4):367-73.

2. Broderick $\mathbb{J}$, Brott $T$, Tomsick $T$, Huster $G$, Miller $R$. The risk of subarachnoid and intracerebral hemorrhages in blacks as compared with whites. The New England joumal of medicine $1992 ; 326$ (11):733-6.

3. Broderick JP, Brott T, Tomsick T, Miller R, Huster G. Intracerebral hemorrhage mone than twice as common as subarachnoid hemorrhage. I. Neurosurg. 1993;78(2): $188-91$.

4. Sacco RL, Boden-Albala B, Gan R, Chen X, Kargman DE, Shea S, Paik MC, Hauser WA. Stroke incidence among white, black, and Hispanic residents of an urban community: the Northern Manhattan Stroke Study. Am. J. Epidemiol. 1998;147(3):259-68.

5. Voelker IL, Kaufman HH. Intraparenchymal hemorrhage. New Horiz. 1997;5(4): $342-51$.

6. Tuhrim $S$, Horowitz DR, Sachel $M$, Godbold $J H$. Validation and comparison of models predicting survival following intracerebral hemorrhage. Crit. Care Med. $1995 ; 23(5): 950-4$

7. Sacco RL, Wolf PA, Kannel WB. McNamara PM. Survival and recurrence following stroke. The Framingham study. Stroke 1982;13(3):290-5.

8. Ojemann RG. Spontaneotss brain hemorrhage: what treatment should we recommend? Stroke 1983;14(4):467.

9. I.isk DR, Pasteur W, Rhoades H, Putnam RD, Grotta JC. Early presentation of hemispheric intracerebral hemorrhage: prediction of outcome and guidelines for treatment allocation. Neurology 1994;44(1):133-9.

10. Kamik R, Valentin A, Ammerer HP. Hochfelner A, Donath P, Slany J. Outcome in patients with intracerebral hemorrhage: predictors of survival. Wien. Klin. Wochenschr. 2000;112(4):169-73.

11. Jorgensen HS, Nakayama $\mathrm{H}$, Raaschou $\mathrm{HO}$, Olsen TS. Intracerebral hemorrhage versus infarction: stroke severity, risk factors, and prognosis. Ann. Neurol. $1995 \cdot 38(1): 45-50$.

12. Fernandes HM, Mendelow AD. Spontaneous intracerebral haemorthage: a surgical dilemma. Bi. I. Neurosurg. 1999;13(4):389-94.

13. Kaufman HH. Intracerebral Hematomas. New York: Raven Press, Ltd.; 1992.

14. Auer LM. Ultrasound stereotaxic endoscopy in neurosurgery. Acta Neurochir. Suppl. (Wien). 1992,54:34-41.

15. Batjer HH, Reisch IS, Alen BC, Plaizier LJ, Su Cl. Failure of surgery to improve outcome in hypertensive putaminal hemorthage. A prospective randomized trial. Arch. Neurol. 1990;47(10):1103-6.

16. Chen XG, Yang $\mathrm{H}$, Czherig Z. A prospective randomised trial of surgical and conservative treatment of hypertensive intracranial haemorraghe. Acta Acad Med Shanghai (Chin) 1992; 19:237-240.

17. Juvela $S$, Heiskanen $O$, Poranen $A$, Valtonen $S$, Kumme "T, Kaste $M$, Troupp H. The treatment of spontaneous intracerebral hemorrhage. A prospective randomized trial of surgical and conservative treatment. I. Neurosurg. 1989;70(5):755-8. 
18. Morgenstern LB, Frankowski RF, Shedden P, Pasteur W, Grotta IC. Surgical treatment for intracerebral hemorrhage (SICH): a single- center, randomized clinical trial. Neurology 1998;51(5):1359-63.

19. Zuccarello M, Brott T, Derex $\mathbb{L}_{\text {, Kothari }}$, Sauerbeck L, Tew J, Van Loveren H, Yeh HS, Tomsick T, Pancioli A, Khoury I, Broderick I. Early surgical treatment for supratentorial intracerebral hemorrhage: a randomized feasibility study. Stroke $1999 ; 30(9): 1833-9$.

20. Teernstra OPM, Evers SMA, Lodder J, Leffers P, Franke CL, Blaaw G. Stereotactic treatment of Intracerebral Fematoma by means of a plasminogen Activator: $A$ multicenter randomized controlled trial (SICHPA). Stroke accepted 2002.

21. Mckissock W, Richardson A, Taylor J. Primary intracenebral haemorrhage: a controlled trial of surgical and conservative treatment in 180 unselected cases. l.ancet 1961;2:221-6.

22. Unwin $D H$, Batjer $H H$, Greenlee $R G$, Ir. Management controversy. Medical versus surgical therapy for spontaneous intracerebral hemowrhage. Neurosurg. Clin. N. Am. $1992 ; 3(3): 533-7$.

23. Kopitnik TA, Jr., Kaufman HH. The future. prospects of inmovative treatment of intracerebral hemorrhage. Neurosurg. Clin. N. Am. 1992:3(3):703-7.

24. Feldmann E. Intracerebral hemorrhage. Stroke 1991;22:684-91.

25. Qureshi AI, Tuhrim S, Broderick JP, Batjer HH, Hondo H, Hanley DF. Spontaneous intracerebral hemormage. N. Engl. J. Med. 2001;344(19):1450-60.

26. Broderick JP. Adams HP, Jr, Barsan W, Feinberg W, Feldmann E, Grotta J, Kase C, Krieger D, Mayberg M, Tilley B, Zabramski JM. Zuccarello M. Guidelines for the management of spontaneous intracerebral hemorrhage: $A$ statement for healthcare professionals from a special writing group of the Stroke Council, American Heart Association. Stroke 1999;30(4):905-15.

27. Saver JL. Surgery for primary intracerebral themorrhage: meta-analysis of CT-era studies. Stroke 1998;29(7):1477-8.

28. Prasad K, Browman G, Srivastava A, Menon G. Surgery in primary supratentorial intracerebral hematoma: a meta- analysis of randomized trials. Acta Neurol. Scand. 1997;95(2):103-10.

29. Prasad K, Shrivastava A. Surgery for primary supratentorial intracerebral haemorrhage. Cochrane Database Syst Rev 2000;2.

30. Fermandes HM, Gregson B. Siddique S, Mendelow AD. Sungery in intracerebral hemorhage. The uncertainty continues. Stroke 2000,31(10):25 II 1 -6.

31. Jadad AR, Moore RA, Carroll D, Jenkinson C, Reynolds DI, Gavaghan DJ, McQuay HJ. Assessing the quality of reports of randomized clinical trials: is blinding necessary? Control Clin. Trials 1996;17(1):1-12.

32. Moher D, Jadad AR, Nichol G, Penman M, Tugwell P, Walsh S. Assessing the quality of randomized controlled trials: an annotated bibliography of scales and checklists. Control Clin. Trials 1995;16(1):62-73.

33. Clarke M. Oxman AD. Locating and selecting studies, In: Clarke M, Oxman AD, editors. Cochrane reviewers handbook 4.1.5 Iupdated April 20021. Oxford: Updated software. Updated quarterly.; 2002.

34. Moher D, Pham B, Klassen TP, Schulz KF, Berlin IA, fadad AR, Liberati A. What contributions do languages other than English make on the results of meta-analyses? 1 . Clin. Epidemiol. 2000;53(9):964-72. 
35. Tuhrim S, Horowiz DR, Sacher M, Godbold HH. Volume of ventricular blood is an important determinant of outcome in supratentorial intracerebral hemorrhage. Crit. Care Med. 1999;27(3):617-21.

36. Bolander HG, Kourtopoulos H, Liliequist B, Wittboldi S. Treatment of spontaneous intracerebral haemorthage. A retrospective analysis of 74 consecutive cases with special reference to computertomographic data. Acta Neurochir 1983;67 (1-2):19-28.

37. Fieschi $C$, Carolei $A$, Fiorelli M, Argentino C, Bozzao L, Fazio C, Salvetti M, Bastianello S. Changing prognosis of primary intracerebral hemorrhage: results of a clinical and computed tomographic follow-up study of 104 patients. Stroke 1988;19(2):192-5.

38. Franke CL, van Swieten JC, Algra A, van Gijn J. Prognostic factors in patients with intracerebral haematoma. I. Neurol. Neurosurg. Psychiatry 1992;55(8):653-7.

39. Mitra D, Das SK, Ganguly PK, Roy TN, Maity B, Munshi AK. Prognostic factors in intracerebral haemorrhage. J. Assoc. Physicians India 1995;43(9):602-4.

40. Poungvarin $N$, Viriyavejakul A. Spontaneous supratentorial intracerebral haemorrhage: arognostic study. J. Med. Assoc. Thai. 1990; 73(4) 206-11.

4.1. Tan SH, Ng PY, Yeo TT, Wong $\mathrm{SH}$, Ong PL, Venketasubramanian N. Hypertensive basal ganglia hemorrhage: a prospective study comparing surgical and nonsurgical management. Surg. Neurol. 2001;56(5):287-92; discussion 292-3.

42. Jadad AR, Cook DJ, Jones A, Klassen TP, Tugwell P, Moher M, Moher D. Methodology and reports of systematic reviews and meta-analyses: a comparison of Cochrane reviews with articles published in paper-based journals. IAMA 1998;280(3):278-80.

43. Rankin J. Cerebral vascular accidents in patients over the age of 60: II. Prognosis. Scot Med J 1957:2:200-215.

44. de Haan R, Limburg $M$, Bossuyt P, wan der Meulen J, Aaronson $N$. The clinical meaning of Rankin 'handicap' grades after stroke. Stroke 1995;26(11):2027-30.

45. Hall JC, Hall JL. Randomization in surgical trials. Surgery 2002;132(3):513-8.

46. Schulz KF, Chalmers I, Hayes RJ, Altman DG. Empirical evidence of bias. Dimensions of methodological quality associated with estimates of treatment effects in controlled. trials. JAMA 1995;273(5):408-12.

47. Mendelow AD. Progress of ISTICH. Personal communication. Newcastle upon Tyne; 2002. 
GENWRAN DISCUSGION 
Spontaneous intracerebral hematoma (ICH) is a common disorder with a high mortality rate often resulting in severe neurological impairment and reduced quality of life in survivors. With the arrival of computed tomography scanning, diagnosis of ICH is fairly advanced nowadays. Which treatment should be given is, however, still very much open to debate. ICH volume reduction may improve outcome, but surgery, consisting of an open craniotomy and subsequent ICH clot removal from the brain, a fast and effective way of reducing ICH volume, did not show improved outcome when compared to conservative treatment alone. This apparent contradiction was explained by collateral damage inflicted on brain tissue during open surgery. Over the last decade, a new minimally invasive neurosurgical treatment has become popular. A stereotactically placed catheter is used to liquefy the blood clot and to aspirate it. Despite its increasing popularity, evidence regarding its efficacy is still lacking. To establish its clinical value, a multicenter, randomized clinical trial was conducted in The Netherlands called the SICHPA trial (stereotactic treatment of intracerebral hematoma by means of a plasminogen activator).

From 1996 to 1999 , thirteen centers enrolled 71 patients in the study; 36 were randomized into a surgical group and 35 into a conservative treatment group. The surgical treatment consisted of a stereotactically placed catheter that was used to instill urokinase to liquefy and drain the ICH at 6-hour intervals over a period of 48 hours. Follow-up extended to 180 days post-stroke. Although the SICHPA trial is the largest in its field, the patient accrual was so slow that it was prematurely stopped. Differences in mortality and functional outcome, neurological impairment (modified Rankin Scale: mRS, Barthel Index: BI and Scandinavian Stroke Scale: SSS), health-related quality of life (HRQoL, measured with COOP/WONCA charts, EuroQOL 5D, Short Form 36) and costs were assessed using univariate and multivariate (logistic regression analysis) tests.

There was a positive effect of the stereotactic treatment in reducing mortality at 180 days with an Odds Ratio (OR) of 0.23 , but this was not statistically significant (Confidence Interval (Cl) $0.05-1.20, \mathrm{p}=0.08$ ). In addition it showed that stereotactic aspiration can be performed safely and in a relatively uniform manner resulting in a mean $\mathrm{ICH}$ volume reduction of $34 \%$. A signilicant ICH volume reduction ( $25 \%$ or more) is achieved by this method at both day 3 and day 7 post-stroke. Such a volume reduction appeared to be associated with a more favorable outcome (mRS grade $0-3$ ). Greater volume reductions ( $25 \%$ and $50 \%$ or more) and lobar ICH's are associated with larger residual lesions, although the value of these findings is limited due to small patient numbers. Furthermore, the SICHPA method did not lead to an increase in hematoma enlargement in the acute phase of ICH nor did it 
result in an increased rate of rebleeding. From a societal perspective, the total costs in each of the treatment groups were similar. No statistically significant differences in functional outcome (mRS), HRQoL or costs were detected.

Data of small and inconclusive trials can be pooled in a meta-analysis, in order to achieve a greater power in detecting possible treatment-effects. Commonly, generic methodological criteria lists are used to review publications systematically and to determine whether a study is of sufficient quality to be included in a meta-analysis (1-3). In our systematic review, we used a different method, in which one did not focus so much on generic methodological measures themselves as employed by a particular study, but more on their end result, this being the degree of comparability of trial groups. This comparability was evaluated using disease-specific criteria. When the results of the SICHPA study were pooled in a meta-analysis with other surgical (quasi-)randomized controlled trials (RCT), that showed a good comparability between treatment groups (4-8), this resulted in a statistically significant effect in reducing the risk of death (OR: 0.48 , Cl: $0.27-0.84$ ). Moreover, this effect was increased when only RCT"s were included that used stereotactic surgery $(4,7,9)$ to an OR of 0.29 (Cl: $0.14-0.59)$ in contrast to a subgroup with studies that used open craniotomy (5-8) where no beneficial effect of the intervention was detected at all (OR: 1.02 , Cl:0.46-2.63). A meta-analysis with studies that used stereotactic surgery also showed a significant effect in reducing death-rate and dependency at six months follow-up (OR: 0.48, CT:0.24-0.96).

The overall lack of statistical differences in our trial may be due to the relatively small population size related to slow patient accrual. There are several reasons that could have caused this: firstly, patient acquisition had been projected on the basis of an earlier Dutch epidemiological study, but these incidence estimates might have been too optimistic (10), and secondly, the so-called "gray area of uncertainty" (whether to operate or not[11]) that was discussed and agreed upon in advance with participating neurosurgeons, appeared to be much smaller in reallity. The SICHPA trial investigated patients with spontaneous supratentorial intracerebral hemorrhage, but for practical reasons it also included patients with ICH's that used anticoagulants. These anticoagulation-related ICH's are actually not classified as primary ICH's, and are known to have a worse prognosis with a mortality exceeding $60 \%(12-14)$. This could have led to an increased mortality in both groups.

The SICHPA trial specifically selected patients who had a poor prognosis with a high predicted mortality rate of $88 \%(15)$, because its primary goal was to detect a difference in mortality between both arms of the trial. This 
makes it more difficult to translate the results to an everyday general clinical situation. Furthermore, if functional outcome is chosen rather than mortality as a primary outcome measure, a more aspecific trial population selection (i.e. less targeted at a high predicted mortality) will result in more survivors and hence provide more data.

The follow-up period ended at 180 days post-stroke, a sufficient period at least to allow evaluation of mortality. However, for patients who survived it may have been too short in order to properly assess functional outcome, HRQoL and disease-related costs. Most trials in patients with ischemic stroke use a follow-up period of 3 months. Possibly, due to a completely different pathological mechanism, ICH-patients are sometimes observed to require a more prolonged rehabilitation period. Several surviving patients in our trial were still actively rehabilitating at 180 days post-stroke, the end of follow-up may not, therefore, constitute a stable end-situation. This could have led to an underestimation of functional outcome, HRQoL and disease-related costs in the trial.

The surgical intervention in the SICHPA trial was clearly described and regimented. On the other hand, conservative medical care was not uniformly defined. Conservative care modalities were, however, recorded and showed no significant differences between the groups. Recently Becker et al. (16) pointed out that the most important variable predicting poor outcome in ICH patients is the level of medical support provided. Perception of futility of aggressive therapy leads to early withdrawal of medical support, which is less likely in ICH patients who undergo surgical treatment. Mayer et al. reported that, in a neurocritical care service over a 3-year period, of 74 non-brain-dead patients, 32 (43\%) were terminally extubated (17). Although in the present study both groups received the same level of supportive care, in no instance was early withdrawal of supportive care reported. It is, however, entirely possible that there might have been a tendency to withdraw supportive care less easily in the intervention group, and therefore the study may have been influenced by this potential bias.

The achieved ICH volume reduction in our study is at the low end of internationally reported figures (1.8-25). The variance in reported ICH volume reductions may partly reflect variations in the stereotactic aspiration method, indicating in its turn that the technique is still being modified and optimized. Such modifications mainly concern: time to surgery, surgical technique (stereotactic frame or frameless), general or local anesthesia, dosage and type of plasminogen activator, number and frequency of installments/aspirations, open or closed catheter.

The SICHPA method used urokinase, but nowadays many prefer recombinant synthesis tissue plasminogen activator (rtPA, 2 to $8 \mathrm{mg} /$ day) (26-29). 
Recent publications mention a facilitated hematoma drainage by leaving the catheter open between rtPA installments $(18,23,27)$. Aspiration periods of 48 to 72 hours with CT scanning up to twice daily are most common.

Choosing at what time to operate following a stroke is still controversial. The main cause of this uncertainty is the frequent occurrence of hematoma enlargement in the acute phase of ICH (the first hours post-stroke) (23). This often leads to early neurological deterioration and mortality. Some, therefore, argue that early hematoma evacuation is beneficial, whilst others mention an increased risk of early rebleeding(23). Especially in stereotactic techniques which use thrombolytic agents this is obviously an important issue. In our trial, we found $20 \%$ of patients ( $19 \%$ in the conservative and $25 \%$ in the surgical group) had an $1 \mathrm{CH}$ volume increase of $40 \%$ or more during the first week post-stroke. This was unrelated to surgery. In $58 \%$ of the patients with such a substantial hematoma enlargement during the first week (compared to $47 \%$ without) a neurological deterioration was observed. These figures are in accordance with those reported by Mohr et al. (30) who saw early deterioration in $56 \%$ of $115 \mathrm{ICH}$-patients, and Brott et al. (31) with nearly $50 \%$ in patients with hematoma growth, but they are higher than the $23.1 \%$ reported by Qureshi et al. (32). Patients in our trial who were operated within 6 hours or within 12 hours post-stroke had no significantly increased risk of hematoma enlargement.

The results of the SICHPA trial do not provide definite proof of stereotactic aspiration with thrombolysis being superior to conservative treatment alone. Therefore, the use of stereotactic aspiration and thrombolysis of $\mathrm{ICH}$ cannot as yet be recommended in general practice. We established this method to be a safe, easy to use, and effective way of substantially reducing ICH volume. Despite the relatively small trial size, a trend toward efficacy, without deleterious side effects, was found. When the results of our trial were pooled with other RCTs that used stereotactic surgery, a clearly significant effect in reducing the risk of death and of dependency was demonstrated. All of this justifies the need for further larger trials on stereotactic surgery in ICH to definitely establish its usefulness in a clinical setting.

The largest obstacle in our trial was the painstakingly slow patient accrual. The multicenter design did not improve this very much. A larger future trial could probably best be designed as a single center study with an extended period of inclusion of 5 years or more, avoiding many logistical problems associated with the multicenter approach, and having the advantage of a more homogeneous trial population with fewer co-interventions. Patients that are selected should reflect the real-life situation (not only patients with a bad prognosis), so that a more accurate assessment of functional outcome can be made. The inclusion rate could be augmented by 
only including patients with deep ICHs, as these are generally not considered for clot evacuation by open craniotomy.

The primary effect parameter in any acute stroke study should include functional outcome, possibly construed as a modified Rankin Scale (33) including an extra grade for deceased patients. In order to assess functional outcome, health-related quality of life and costs in a stable end situation, follow-up should be extended to at least one year post-stroke. To allow for analysis of chances in health-related quality of life, a pre-assessment should take place, for example a EuroQol. 5D measurement (by proxy if needed) of the pre-stroke status. A disease-specific HRQoL instrument (such as the stroke-specific quality of life; SS-QoL(34)) needs to be used alongside generic HRQOL instruments (EuroQoL-5D, SF-36), to evaluate small specific health changes that are 'overlooked' by the generic instruments.

Before such a phase III study is conducted, more investigations are needed to optimize the stereotactic treatment. A phase II trial could be done to determine the feasibility and safety of ultra-early clot aspiration (within 6 hours after stroke). The aspiration should continue as long as substantial amounts of thrombolyzed ICH clot or blood are being aspirated. ICH volume reduction during this procedure should be evaluated with daily CT-scans. In between the aspirations, the catheter should remain unclamped, leaving an outlet in case of hematoma enlargement or early rebleeding.

Conservative treatment parameters need to be as well defined as those of the stereotactic treatment. As early withdrawal of supportive care in patients is a sensitive matter that probably does not lend itself to advance regulation by trial protocol, it should be well documented allowing for post hoc analysis of this possible bias.

Based on the meta-analysis in chapter 5 and the overall results of the SICHPA-study it can be concluded that evidence required on costs and consequences of surgical interventions for $₫ \mathrm{CH}$ are difficult to retrieve from a single source. In recent literature, models are often used to synthesize data on costs and consequences regarding one intervention. Models are especially appropriate if there is some uncertainty about the clinical strategy. Future research should also on aim to provide an insight in the trade-off between surgical and non-surgical interventions in the treatment of $\Perp \mathrm{CH}$.

In conclusion, the principal aim of the SICHPA trial was to give evidence of a new minimally invasive neurosurgical treatment in ICH, i.e. stereotactic treatment of intracerebral hematoma by means of a plasminogen activator. Although no definite proof could be provided based on the results of this trial, it is hoped that this thesis will stimulate wider debate, future research and further development of stereotactical surgery to treat patients with ICH. 


\section{REFERENCES}

1. Prasad K, Browman G. Srivastava A, Menon G. Surgery in primary supratentonial intracerebral hematoma: a meta- analysis of randomized trials. Acta Neurol Scand $1997 ; 95(2): 103-10$.

2. Prasad $\mathrm{K}$, Shrivastava A. Surgery for primary supratentorial intracerebral haemorrhage. Cochrane Database Syst Rew 2000;2.

3. Femandes HM, Gregson B, Siddique S, Mendelow AD. Surgery in intracerebral hemorrhage. The uncertainty continues. Stroke 2000;31(10):2511-6.

4. Auer LM, Deinsberger W, Niederkorn K, Gell G, Kleinert R, Schneider G, Holzer P, Bone G. Mokry M, Konner E, et al. Endoscopic surgery versus medical treatment for spontaneous intracerebral hematoma: a randomized study. I Neurosurg 1989; 70(4): 530-5.

5. Batjer HA, Reisch JS, Allen BC, Plaizier LJ, Su CJ. Failure of surgery to improye outcome in hypertensive putaminal hemorhage. A prospective randomized trial. Archives of neurology $1990: 47(10): 1103-6$.

6. Morgenstern LB, Frankowski RF, Shedden P, Pasteur W, Grotta IC, Surgical treatment for intracerebral hemorrage (STICH): a single-center, randomized clinical trial. Neurology $1998 ; 51(5): 1359-63$.

7. Zuccarello M, Brott T, Derex L, Kothar $R$, Sauerbeck L, Tew J, Van Loveren $H_{\text {, }}$ Yeh HS, Tomsick T, Pancioli A Khoury J, Broderick J. Early surgical treatment for supratentorial intracerebral hemorhage: a randomized feasibility study. Stroke 1999;30(9):1833-9.

8. Tan SH, Ng PY, Yeo TT, Wong SH, Ong PL, Venketasubramanian N. Hypertensive basal ganglia hemorrhage: a prospective study comparing surgical and nonsurgical management. Surg Neurol 2001;56(5):287-92; discussion 292-3.

9. Teernstra OPM, Evers SMAA, Lodder I, Leffers P, Franke CL, Blaauw G. Stereotactic treatment of Intracerebral Hematoma by means of a Plasminogen Activator: $A$ multicenter randomized controlled trial (SICHPA). Stroke accepted 2002.

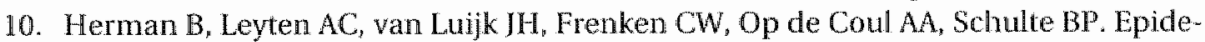
miology of stroke in Tilburg, the Netherlands. The population-based stroke incidence register: 2 Incidence, initial clinical picture and medical care, and three-week case fatality. Stroke 1982;13(5):629-34.

11. Fernandes HM, Mendelow $\mathrm{AD}$. Spontaneous intracerebral haemonhage; a surgical dilemma. Br J Neurosurg 1999;13(4):389-94.

12. Franke $\mathrm{CL}$, de Jonge I, wan Swieten JC, Op de Coul AA, van Gijn 1. Intracerebral hematomas during anticoagulant treatment. Stroke 1990:21 (5):726-30.

13. Hart RG, Boop BS, Anderson DC. Oral anticoagulants and intracranial hemonthage. Facts and hypotheses. Stroke 1995;26(8):1471-7.

14. Kase CS, Robinson RK, Stein RW, DeWitt LD, Hier DB, Harp DL, Willams JP, Caplan LR, Mohr IP. Anticoagulant-related intracerebral hemorrhage. Neurology 1985; 35(7):943-8.

15. Franke CL, van Swieten JC, Ngra $A_{p}$ wan Gijn J. Prognostic factors in patients with intracerebral haematoma. Journal of neurology, neurosurgery, and psychiatry 1992 ; $55(8): 653-7$.

16. Becker KJ, Baxter AB, Cohen WA. Bybee HM, Tirschwell DL, Newell DW, Winn HR, Longstreth WT, Jr. Withdrawal of support in intracerebral hemorrhage may lead to self- fulfilling prophecies. Neurology $2001 ; 56(6): 766-72$. 
17. Mayer $S A$, Kossoff $\mathrm{SB}$. Withdrawal of life support in the neurological intensive care unit. Neurology $1999 ; 52(8): 1602-9$.

18. Lippitz BE, Mayfrank L, Spetzger U, Warnke IP, Bertalanffy H, Gilsbach JM. Lysis of batsal ganglia haematoma with recombinant tissue plasminogen activator (rtPA) after stereotactic aspiration: initial results. Acta Neurochir 1994;127(3-4):157-60.

19. Liu $2 \mathrm{H}$, Kang $G Q$, Chen XH, Tian $Z M$, Cai HZ, Zhang $X$, Li $S Y$. Evacuation of hypertensiwe intracerebral hematoma by a stereotactic technique. Stereotactic and functional neturosurgieny $1990 ; 54-55: 451-2$.

20. Matsumoto $K$, Hondo H. Crguided stereotaxic evacuation of hypertensive intracerebral hematomas. J Neurosurg 1984;61(3):440-8.

21. Miller DW, Barnett GH, Kormos DW, Stener CP. Stereotactically guided thrombolysis of deep cerebral hemorhage: preliminary results. Cleve Clin J Med 1993;60(4):321-4.

22. Mohadjer M, Braus DF, Myers A, Scheremet R, Krauss JK. CT_stereotactic fibrinolysis of spontaneous intracerebral hematomas. Neurosurg Rev 1992;15(2):105-10.

23. Montes JM, Wong IH, Fayad PD, Awad LA. Stereotactic computed tomographicguided aspiration and thrombolysis of intracerebral hematoma: protocol and preliminary experience. Stroke 2000;31(4);834-40.

24. Nguyen JP, Deeq P, Brugieres P, Yepes C, Melon E, Gaston A, Keravel Y. A technique for stereotactic aspiration of deep intracerebral hematomas under computed tomographic control using a new clevice. Neurosurgery 1992;31. (2):330-4.

25. Nitzuma H, Shimizu $\mathrm{X}$, Yonemitsu T, Nakasato $\mathrm{N}$, Suzuki I. Results of stereotactic aspiration in 175 cases of putaminal hemorrhage. Neurosurgery 1989;24(6):814-9.

26. Rohde V, Rohde I, Reinges MH, Mayfrank L, Gillsbach IM. Frameless stereotactically guided catheter placement and fibrinolytic therapy for spontaneous intracerebral hematomas: technical aspects and initial clinical results. Minim Invasive Neurosurg $2000 \cdot 43(1): 9-17$.

27. Schaller C, Rohde V, Meyer B, Hassler W. Stereotactic puncture and lysis of spontaneous intracerebral hemorthage using recombinant tissue-plasminogen activator. Neurosurgery 1995,36(2):328-33.

28. Wagner KR, Xi G, Hua Y, Zuccarello M, de Courten-Myers GM, Broderick IP, Brott TG. Ultra-early clot aspiration after lysis with tissue plasminogen activator in a porcine model of intracerebral hemorrhage: edema reduction and blood-brain barrier protection. J Neurosurg, 1999;90(3):491-8.

29. Deinsberger W, Vogel I, Fuchs C. Auer LM, Kuschinsky W. Boker DK. Fibrinolysis and aspiration of experimental intracerebral hematoma reduces the volume of ischenic brain in rats. Neurol Res 1999;21 (5):517-23.

30. Mohr JP, Caplan LR, Melski JW, Goldstein RI, Duncan GW, Kistler JP, Pessin MS, Bleich HL. The Harvard Cooperative Stroke Registry: a prospective registry. Neturology 1978;28(8):754-62.

31. Brott T, Broderick J, Kothari R, Barsan W, Tomsick T, Sauerbeck L, Spilker J, Duldner J, Khoury J. Early hemorrhage growth in patients with intracerebral hemon hage. Stroke $1997 ; 28(1): 1-5$.

32. Qureshi $\mathrm{M}$, Safdar K, Weil f, Barch C, Bliwise DL, Colohan AR, Mackay B, Frankel MR. Predictors of early deterioration and mortality in black Americans with spontaneous intracerebral hemorthage. Stroke 1995;26(10):1764-7.

33. Rankin J. Cerebral vascular accidents in patients over the age of 60: II. Progrosis. Scot Med I 1957;2:200-215.

34. Williams LS, Weinberger M, Harris LE, Clark DO, Biller J. Development of a stroke-specific quality of life scale. Stroke 1999;30(7):1362-9. 
CHADTER Summary 
Stroke is a common disease ( 30.000 new cases each year) with a high impact on both society and the individual. Around 10 percent of strokes concern primary intracerebral hemorthage ( $\mathrm{ICH}$ ). Primary $\mathrm{ICH}$ is a disease with an even higher mortality rate (around 50\%) and morbidity than stroke in general. Because of an aging population it is expected that the consequences of stroke and more in particular ICH constitute a growing burden. There are two main treatment modalities in $\mathrm{ICH}$, namely surgery and conservative supportive medical treatment alone. Up to this date, there is no proof that surgery is better than conservative treatment alone. The absence of efficacy in a traditional ICH evacuation procedure (by open craniotomy), is attributed to the collateral damage that is inflicted on an already traumatized brain. Minimal invasive surgical procedures have therefore gained interest over the last decades. One such procedure involves stereotactical treatment of $\mathrm{ICH}$ by means of a plasminogen activator (SICHPA). From 1996 to 1999, a multicenter randomized controlled trial (RCT) was conducted to investigate the efficacy of the SICHPA method. This thesis mainly concerns the results of this trial. Its chapters consider: the efficacy of the SICHPA method in terms of mortality and functional outcome, the association between ICH volume reduction and outcome, the association with ICH enlargement and rebleeding as its main possible complication, costs (from a societal perspective) and effects (mortality, functional outcome and quality of life) and finally efficacy of this method when pooled in a meta-analysis.

Chapter 1 presents a general introduction to the disease ICH. It outlines its etiology and epidemiology and discusses the way in which ICH leads to progressive brain damage, neurological deterioration and death. The presence of an $\mathrm{ICH}$ constitutes a mass lesion that initially frequently enlarges and furthermore is known to induce edema formation in its later stages. The theoretical advantages of a stereotactical approach such as the SICHPA method in preventing the occurrence of these consequences of $\mathrm{ICH}$, are discussed. It concludes in stating the necessity of a RCT, like the SICHPA trial, to provide definite clinical proof on efficacy of relatively new and potentially beneficial stereotactical surgical procedures in $\mathrm{ICH}$.

In chapter 2 the main findings of the SICHPA trial are discussed. From 1996 to 1999 , thirteen centers entered 71 patients into the study. A blinded randomization procedure allocated patients to a surgical group $(n=36)$ and a non-surgical group $(n=35)$. Prior to enrolment, patients were stratified according to the severity of illness (EM-score) and neurosurgical center. The surgical method consisted of a stereotactically placed catheter, which was 
used to instill urokinase to liquefy and drain the $1 \mathrm{CH}$ in 6 - hour intervals over the next 48 hours. The primary endpoint was death at 6 months. Secondary endpoints were ICH-volume reduction and overall functional outcome (mRS: modified Ranking Scale). Due to a slow patient accrual and the results of an interim analysis that indicated no efficacy, the trial was prematurely stopped. Overall mortality at day 180 post-stroke was $57 \%$. (56\% in the surgical and $59 \%$ in the non-surgical group). A significant $1 C H$ volume reduction (10 to 20\%, $p<0.05$ ) was achieved by the intervention. Logistic regression analysis was used to correct for possible confounding (due to larger hematomas and more lobar ICHs in the surgical group). It indicated the possibility of efficacy, however not statistically significant, for surgical treatment with an Odds Ratio (OR) of 0.23 and a $95 \%$ confidence interval (95\% CI) of 0.05 to $1.20(\mathrm{p}=0.08)$. The OR of mortally combined with mRS grade 5 (severe handicap, total dependency) at 180 days was also not statistically significant (OR: $0.52,95 \% \mathrm{Cl} 1.2-2.3, \mathrm{p}=0.38$ ). It is concluded that stereotactic aspiration of $\mathrm{TCH}$ using urokinase can be performed salely and leads to a reduction of ICH volume. The magnitude of $1 \mathrm{CH}$ volume reduction however was smaller than those reported by other small trials. Better potential benefits might be achieved by a greater reduction in hematoma volume over a shorter period of time. It is recommended to conduct a phase 2 study by which insight should be gained in the optimal dosage and time span in which urokinase should administered.

In Chapter 3 the efficacy of the STCHPA method in reducing ICH volume (which is a known prognostic factor) is further investigated. In addition, the association between a substantial $\mathbb{C} \mathrm{CH}$ volume reduction and a favorable outcome in patients of the SICHPA trial is analyzed.

Sixty-three patients that adhered to the study protocol were analyzed. ICH volumes were assessed on CT-scan images with a validated rule of thumb ( $\left.\mathrm{ABC} / \mathrm{2}^{\prime}\right)$. Characteristics of patients with a substantial ICH volume reduction (25\% or more and $50 \%$ or more at day 3 and day 7 post-stroke) were compared to those without such a volume reduction, usimg uni-and multivariate analyses. The main conclusion is that stereotactic $\mathbb{C H}$ fibrinolysis and aspiration leads to a significant ICH volume reduction (25\% or more) at both day 3 and day 7 post-stroke. Furthemore that such a volume reduction significantly reduces chances for an unfavorable clinical outcome (mRS 4,5,6). Greater volume reductions (25\% and $50 \%$ or more) and lobar ICHs are associated with larger residual lesions, although the value of these findings is limited due to small patient numbers. Different points of interest are mentioned for future research, which is needed to improve the stereotactic technique in order to maximize volume reduction. 
Chapter 4 addresses the question whether a stereotactic method that uses thrombolytic agents is associated with hematoma enlargement or rebleeding. Recent evidence has shown that spontaneous intracerebral hematoma (ICH) is not a monophasic event. In up to $50 \%$ of cases, hematoma enlargement occurs in the acute phase, mostly by ongoing bleeding within the first hours post-stroke. In a quarter of these, it will result in early neurological deterioration. The data from the SICHPA trial were analyzed to identify a possible increased risk for hematoma enlargement or early rebleeding. Patients were divided in a group with substantial hematoma enlargement ( $\geq 40 \%$ ) during the first week and one without. Apart from the treatment variable, several others variables that are reported to relate to an increased risk for hematoma enlargement were included and analyzed uni- and multivariate testing. In the overall analysis, as well as the surgical subgroup analysis, none of the variables could be identified as a statistically significant, independent risk factor for hematoma enlargement during the first week post-stroke.

From the 8 cases that were reported to have rebleeding, 4 patients with actual rebleeding were verified after case by case analysis, $3(10 \%$, all in the surgical group) with early rebleeding (defined as renewed bleeding from 48 hours to 30 days post-stroke) and one ( $3 \%$, in the conservative group) recurrent bleeding (ICH occurring 1 month or more after the first $\mathrm{ICH}$ ).

The $20 \%$ rate for early hematoma enlargement, with a $58 \%$ rate for early neurological deterioration in these patients, and $10 \%$ early rebleeding in surgical patients, is well within the range of figures reported by previous studies. The stereotactic treatment with urokinase used in the SICHPA trial, could not be linked to an increase in either hematoma enlargement or rebleeding. Possibly the number of patients $(n=59)$ was too small too detect such a relationship. Stereotactic treatment of ICH using thrombolytic agents theoretically potentially pose a risk for hematoma enlargement. However, it also provides an opportunity to drain the ICH in the acute phase, preventing hematoma enlargement and subsequent neurological deterioration. Future research will determine if this holds true.

In chapter 5 differences in costs and effects between the stereotactic and the conservative treatment group in the SICHPA trial were analyzed. During the follow-up period of 6 months of the SICHPA trial, the functional status (Scandinavian Stroke Scale, Barthel Index, and Modified Rankin Scale/Oxford Handicap Scale) and the quality of life of patients (EuroQoL, COOP/WONCA charts and SF-36) in both groups were monitored. In addition, all expenses incurred by these patients related to the trial were measured. This costs analysis was performed from a societal perspective, 
and included both direct and indirect costs. Statistical testing for both functional outcome measures and costs consisted of non-parametric univariate testing (Mann Whitney $U$-test). The study estimated the treatment costs to be $€ 68,131$ for the stereotactically treated group and $€ 70,535$ for the conservative treatment group. The total direct health care costs of the stereotactically treated group were $€ 275$ higher than those of the conservative treatment group. Indirect costs for the two groups were not significantly different. At 3 and 6 months there were no significant difference both functional status and quality of life. A sensitivity analysis demonstrated these results of the base-case analysis to be robust. Although the study population was small, making it hard to detect statistically significant differences, it could be concluded that there is no indication that patients with an intracerebral hemorrhage treated by means of the stereotactic aspiration method are better of than their conservatively treated counterparts in terms of (functional) outcome, health related quality of life or costs from at societal perspective. Several points of potential bias to this costs and effectiveness analysis are discussed. They concern mainly the rationale for the use of Friction Costs Method as opposed to Human Capital Approach, the follow-up period of 180 days being possibly too short to adequately measure costs and effects, the use of mean (instead of median) costs in asymmetrical costs distributions, and the fact that possibly our instruments for measuring health related quality of life were too crude to detect small but relevant changes. In order to detect changes in the quality of life in both patients and their close relatives, it is suggested that future larger trials, should use disease-specific instruments next to generic ones.

Chapter 6 concerns a systematic review and meta-analysis of surgery in ICH. Optimall treatment in ICH is to this date still a matter of debate. Only a few randomized controlled trials (RCT) and quasi-RCT's exist that investigate the role of surgery in ICH. None of these RCTs shows surgery to be beneficial over conservative treatment alone, in terms of reduced death and dependency. Systematic reviews that pooled these RCTs were also inconclusive. The systematic review in this chapter updates previous meta-analyses, and presents an alternative manner of reviewing. Instead of the conventionally used generic criteria, disease specific methodological criteria were employed to evaluate studies. The resulting selection of studies was compared to that of previous systematic reviews. 7 RCTs and 1 quasi-RCT in the English language were identified with a systematic literature search. Reservations on applicability existed in one RCT dating from a pre-CT era. In the ensuing methodological evaluation, this RCT and another (with a good methodological design but unfortunately not leading to good compa - 
rability in prognostic factors between trial groups) were marked as doubtul and were entered separately in the meta-analysis. Apart from the inclusion of two new studies, our selection differed from the two previous systematic reviews mainly in respect to the $\mathrm{RCT}$ that was excluded from base-case analysis because of our methodological evaluation; this resulted in a different conclusion. The six remaining studies, pooled in the base-case meta-analysis, showed a statistically significant reduction in the odds of death (OR: 0.48 , 95\% CI: $0.27-0.84)$, and a trend toward improved survival and independency (OR: $0.63,95 \% \mathrm{Cl}: 0.36-1.08$ ). Subgroup-analysis demonstrated a statistically significant effect of stereotactic surgery in reducing the chance of death (OR: $0.29,95 \% \mathrm{Cr}: 0.14-0.59$ ) and death and dependency (OR: 0.48 , 95\%CI: 0.24-0.96). Our disease specific methodological evaluation focusing on the achieved comparability between intervention and control group in a (Q-)RCT, led 1 RCT to be excluded from base case meta-analysis that was included in two previously conducted systematic reviews. Separate inclusion of this RCT in the meta-analysis markedly reduced the significant effect found in the base-case meta-analysis. This demonstrates that the manner in which studies are methodologically evaluated in a systematic review has a great impact on its conclusions. This meta-analysis is the first to report a clear and significant beneficial effect of stereotactical surgery in ICH with respect to mortality and dependency. New RCTs specifically on stereotactical treatment of $1 \mathrm{CH}$ are therefore warranted to consolidate this finding. In future RCTs improved concealment, especially in effect-measurement is recommended. Based on our results, we feel that achieved comparability of prognostic factors, co-interventions and effect measurements between the trial groups in a RCT, and also the use of disease specific criteria are important issues to be considered in future systematic reviews.

In chapter 7, the general discussion, the findings of all the analyses in the previous chapters are summarized and discussed. In addition possible drawbacks and problems of the SICHPA trial are discussed: the small trial size due to an untimely ending of the trial, the follow-up period of 180 days possibly being too short, the inclusion of patients with anti-coagulant use related $\mathrm{ICH}$, treatment in the conservative arm of the trial not being regimented, the relatively modest ICH volume reduction achieved by the SICHPA method and the use of generic instruments in quality of life assessment. Based on these criticisms, recommendations are given on possible ways to optimize the surgical technique and on the design of a future RCT needed to confirm the efficacy of stereotactic surgery with the use of thrombolytics in ICH. 
CHAPTER Samenvatting 
Een beroerte is een veelvoorkomende aandoening (incidentie 30.000 per jaar) met een grote weerslag op zowel de maatschappij als de individuele patiënt. Rond de 10 procent van alle beroertes betreft een primair intracerebraal hematoom (ICH). Het mortaliteits percentage (van rond de $50 \%$ ) en morbiditeits percentage van een primair $\mathbb{I C H}$ liggen boven die van de aandoening beroerte over het geheel genomen. Doordat de bevolking vergrijst, wordt verwacht dat de gevolgen van de aandoening beroerte en meer specifiek van de aandoening $\mathrm{ICH}$, een toenemende last zullen gaan vormen. Er zijn hoofdzakelijk twee behandelvormen van ICH, namelijk chirurgisch en conservatief. Tot op heden is er geen bewijs dat een chirurgische behandeling voordelen biedt boven een conservatieve. De reden dat traditionele chirurgie (in de zin van een craniotomie met hematoom evacuatie) niet effectiever is, wordt toegedicht aan de extra schade die er door wordt toegebracht aan de hersenen welke door het $\mathrm{ICH}$ reeds beschadigt zijn. De laatste jaren zijn hierdoor minimaal invasieve chirurgische procedures meer en meer in belangstelling komen te staan. Een voorbeeld van zo'n minimaal invasieve methode is de stereotactische aspiratie van een ICH met gebruikmaking van een plasminogeen activator (SICHPA). Van 1996 tot en met 1999 werd er een multi-center gerandomiseerde gecontroleerde studie (RCT) gedaan naar de effectiviteit van deze behandeling. Dit proefschrift omvat onder andere de resultaten van deze RCT. De hoofdstukken betreffen: de effectiviteit van de SICHPA methode in termen van mortaliteit en mate van afhankelijkheid (functional outcome), de relatie tussen ICH volumereductie en overleven en mate van afhankelijkheid, met ICH toename en herbloeding als belangrijkste mogelijke complicatie, kosten (vanuit een maatschappelijk perspectief) en effectiviteit (mortaliteit, mate van afhankelijkheid, en kwaliteit van leven), en tenslotte wordt de effectiviteit van deze methode bekeken wanneer zij samengevoegd wordt met de resultaten van andere RCTs in een meta-analyse.

Hoofstuk 1 vormt een algemene introductie bij de aandoening ICH. Etiologische en epidemiologische aspecten als wel langs welke wijze een ICH leidt tot hersenbeschadiging, neurologische achteruitgang en overlijden worden besproken. De aanwezigheid van een $\mathrm{ICH}$ vormt een ruimte innemend proces dat vaak in grootte toeneemt en ook vaak resulteert in oedeemvorming in een later stadium. De theoretische voordelen van een stereotactische chirurgische methode als de SICHPA methode in de preventie van zulke processen bij een ICH worden belicht. Geconcludeerd wordt dat er een RCT nodig is, zoals de SICHPA trial, om hiervan een definitief bewijs boven tafel te brengen. 
In hoofdstuk 2 worden de belangrijkste bevindingen van de SICHPA trial besproken. Van 1996 tot en met 1999 werden door 13 medische centra 71 patiënten geïncludeerd. Een geblindeerde randomisatie procedure wees patiënten toe aan een chirurgische groep $(n=36)$ en een niet-chirurgische groep $(n=35)$. Er vond een prestratificatie plaats naar de bewrustzijnstoestand van de patiënt en naar het neurochirurgisch centrum waar deze werd geincludeerd. De chirurgische behandeling bestond uit een stereotactisch geplaatste drain waarmee een urokinase oplossing kon worden ingebracht en opgelost hematoom kon worden geaspireerd met intervallen van 6 uur gedurende 2 dagen. De primaire uitkomstmaat was mortaliteit na zes maanden. Secundaire uitkomstmaten waren ICH volume reductie en mate van afhankelijkheid (mRS: modified Ranking Scale). Door een trage patiënten inclusie met daarbij tegenvallende resultaten van een interim analyse, werd de trial voortijdig gestaakt. De mortaliteit van de gehele studie populatie bedroeg $57 \%$ na zes maanden ( $56 \%$ in de chirurgische en $59 \%$ in de conservatieve groep). Met de SICHPA methode werd een significante ICH volume reductie $(10$ tot $20 \%, \mathrm{p}<0,05)$ bereikt. Logistische regressie analyse werd gebruikt om voor mogelijke confounding te corrigeren (door overrepresentatie van grotere bloedingen en lobaire ICHs in de chirurgische groep). Hieruit bleek een mogelijke effectiviteit van de SICHPA methode met een Odds Ratio (OR) van 0,23 en een $95 \%$ betrouwbaarheidsinterval $(95 \% \mathrm{CI})$ van 0.05 tot $1.20(\mathrm{p}=0,08)$. De OR van sterfte gecombineerd met mRS graad 5 (zwaar gehandicapt, totaal afhankelijk) was evenmin statistisch significant (OR: 0,52 95\% CI: $1,2-2,3, p=0,38$ ). Geconcludeerd wordt dat de SICHPA methode een veilige manier is waarmee het ICH volume succesvol kan worden gereduceerd. De grootte van deze volume reductie echter, was kleiner dan bij veel andere onderzoeken. Betere resultaten kunnen misschien geboekt worden indien er meer van het ICI volume in een kortere periode kan worden geaspireerd. Geaclviseerd wordt om een fase II studie te starten om tot een optimale dosering en tijdspanne te komen waarin urokinase toegediend word.

In hoofdstuk 3 wordt de effectiviteit van de SICHPA methode in ICH volume reductie (een erkende prognostische factor) verder onderzocht. Daarnaast wordt de relatie tussen een substantiële ICH volume reductie een gunstig resultaat bij patiënten van de SICHPA trial geanalyseerd. 63 patiënten die volgens het studie protocol waren behandeld, werden geanalyseerd. $\mathrm{ICH}$ volumes werden bepaald met CT-scans aan de hand van een gevalideerde vuistregel $\left({ }^{A} \mathrm{ABC} / 2^{\prime}\right)$. Karakteristieken van patiënten met een substantiële ICH volume reductie (25\% of meer en $50 \%$ of meer op dag 3 en dag 7 na ontstaan) werden vergeleken met die van patiẻnten zonder substantiële 
volume reductie, m.b.v. uni- en multi-variate analyses. De belangrijkste conclusie is dat stereotactische ICH fibrinolyse en aspiratie leidt tot een significante ICH volume reductie ( $\geq 25 \%$ ) zowel op dag 3 als dag 7 na het ontstaan van het ICH. Verder geeft zo'n volume reductie aanleiding tot een significante afname van de kans op een ongunstig klinisch resultaat (mRS graad 4, 5 en overlijdenj. Grotere ICH volumereducties en lobaire ICHs resulteren vaker in grotere restlaesies, hoewel hierbij opgemerkt dient te worden dat de onderzochte patiënten groep klein was. Verschillende aandachtspunten worden genoemd voor toekomstig onderzoek, dat nodig is om de stereotactische ICH evacuatie procedure verder te verbeteren zodat de bereikte ICH volumereductie gemaximaliseerd wordt.

Hoofdstuk 4 behandelt de vraag of een stereotactisch methode die thrombolytica gebruikt aanleiding geeft tot hematoom toename of herbloeding. Recentelijk werd aangetoond dat ICH niet een monofasisch gebeuren is. Tot in de helft van de gevallen treedt hematoom toename op gedurende de acute fase, meestal door het voortduren van de bloeding tijdens de eerste uren na het ontstaan ervan. In een kwart van deze gevallen resulteert dit in een neurologische verslechtering. De gegevens van de SICHPA trial zijn geanallyseerd om een mogelijk verhoogd risico op hematoom toename of herbloeding te identificeren. Patiënten werden verdeeld in een groep met substantiële hematoom toename $(\geq 40 \%)$ tijdens de eerste week na het ontstaan van het ICH, en een andere groep zonder zo'n ICH toename. Naast de variabele 'stereotactische interventie' werden anderen geselecteerd waarvan eerder een associatie met hematoom toename gerapporteerd was en deze werden geanalyseerd met uni- en multi-variate testen. In de analyse van de gehele groep als wel in de analyse van enkel de chirurgische patiënten kon geen van de getoetste variabelen worden aangemerkt als een onafhankelijke risicofactor voor ICH volume toename in de eerste week na het ontstaan ervan. In 4 van de acht gerapporteerde patiënten kon een eigenlijke herbloeding worden vastgesteld, $3(10 \%$, alle in de chirurgische groep) van deze hadden een vroege herbloeding (vanaf 48 uur tot 30 dagen na het onstaan van het IVH gerekend) en eentje ( $3 \%$, in de conservatieve groep) had een recidief bloeding (bloeding onstaan minstens 30 dagen na eerste bloeding).

Het percentage van patiënten methematoom toename van $20 \%$ waarvan $58 \%$ een gelijktijdige neurologische verslechtering ondervond, en de $10 \%$ vroege herbloedingen, ligt ruim binnen de internationaal gepubliceerde cijfers hiervoor. De stereotactische aspiratie met gebruik van urokinase in de SICHPA trial kon niet geassocieerd worden met een verhoogde kans op hematoom toename of herbloeding. Het is mogelijk dat het patiënten aantal 
te gering was om zo"n relatie te kumnen ontdekken. Hoewel een stereotactische methode die thrombolytica toepast mogelijk een risico kan vormen voor hematoom toename, biedt het daarentegen ook de mogelijkheid om een ICH in de acute fase te ontlasten en daamee ook hematoom toename juist tegen te gaan en neurologische verslechtering te voorkomen. Toekomstig onderzoek zal moeten uitwijzen of dit daadwerkelijk het geval is.

In hoofdstuk 5 worden verschillen in kosten en effectiviteit tussen de stereotactische en de conservatieve groep in de SICHPA trial geanalyseerd. Gedurende de follow-up periode van 6 maanden in de SICHPA trial werd de functionele status van de patiënt (Scandinavian Stroke Scale, Barthel Index en modified Rankin Scale/Oxford Handicap Scalej en de kwaliteit van leven (EuroQo\, COOP/WONCA kaarten en SF-36) in beide onderzoeksgroepen gemeten. Daarnaast werden alle ziekte gerelateerde kosten van deze patiënten opgenomen. Deze kosten analyse werd gedaan vanuit een maatschappelijk perspectief waarbij zowel directe als indirecte kosten werden gebruikt. Er werd statistische getoetst met een non-parametrische uni-variate test (Mann Whitney U-test). De uiteindelijke totale kosten waren in de stereotactische groep $€ 68.131$ en $€ 70.535$ in de conservatieve groep. De directe zorg gerelateerde kosten waren $€ 275$ hoger in de stereotactische groep. Indirecte kosten waren evenmin onderling afwijkend. Zowel op 3 als maanden follow-up, was er geen significant verschil in functionele status van de patiënt en in de kwaliteit van leven. Een gevoeligheids analyse toonde aan dat deze resultaten van de base-case analyse robuust waren.

Hoewel de onderzoekspopulatie klein was, waardoor het moeilijker is om statistisch significante verschillen te detecteren, kon worden geconcludeerd dat er geen indicatie is dat ICH patiënten beter af zijn met de stereotactische methode dan met de conservatieve aanpak, gelet op functionele status, kwaliteit van leven en kosten vanuit een maatschappelijk perspectief. Een aantal punten die mogelijk verstorend hebben gewerkt in deze analyse worden toegelicht. Aandacht wordt besteed aan de verschillen die optreden door het gebruik van de Human Capital Approach (HCA) in plaats van de Frictie Kosten Methode (FCM), de mogelijkheid dat de follow-up van 6 maanden misschien te kort was om op adequate manier kosten en effectiviteit te kunnen inschatten, het gebruik van een gemiddelde (i.p.v. mediane) waarde bij asymmetrisch verdeelde kosten per groep en het feit dat de door ons gebruikte instrumenten voor kwaliteit van leven meting misschien te grof waren om kleine, maar relevante verschillen aan het licht te brengen. Om veranderingen in de kwaliteit van leven in kaart te brengen zowel bij de patiënten als hun naasten, is het aan te raden in toekomstige 
grotere onderzoeken op dit gebied, naast generieke ook ziekte specifieke kwaliteit van leven instrumenten te gebruiken.

Hoofdstuk 6 betreft een systematische review en meta-analyse over het gebruik van chirurgie in ICH. Er zijn maar een paar gerandomiseerde gecontroleerde onderzoeken (RCT) die de rol van chirurgie in ICH evalueren. Geen van deze RCTs laat zien dat chirurgie te verkiezen is boven conservatieve behandeling alleen, in termen van verminderde sterfte en afhankelijkheid. Systematische reviews die de resultaten van deze RCTs bundelden konden ook geen uitsluitsel geven. De systematische review in dit hoofdstuk actualiseert voorgaande reviews en demonstreert daarbij een alternatieve wijze van reviewen. In plaats van de traditioneel gebruikte generieke criteria, worden ziekte specifieke criteria gebruikt om de kwaliteit van onderzoeken te beoordelen. De selectie van studies die hiermee werd bereikt, werd met die van voorgaande systematische reviews vergeleken.

7 RCT's en 1 Quasi-RCT werden geïdentificeerd in de internationale engelse literatum. Bij 1 onderzoek dat nog stamde uit het tijdperk voordat de CT-scanner werd geïntroduceerd, waren er twijfels over de toepasbaarheid. In een daarop volgende methodologische evaluatie werd deze studie en daarnaast nog een ander (met een overigens goed methodologisch ontwerp, dat ongelukkig genoeg niet resulteerde in een goede vergelijkbaarheid tussen de onderzoeksgroepen) als twijfelachtig aangemerkt, besloten werd ze allebei apart in de meta-analyse te includeren. Naast het toevoegen van twee nieuwe studies, verschilde onze selectie van studies met die van twee voorgaande systematische reviews, door met name de exclusie van 1 RCT in de base-case meta-analyse, op grond van onze methodologische evaluatie, resulterend in een andere conclusie. De 6 overgebleven studies, samengevoegd in een base-case meta-analyse lieten een statistisch significante reductie zien van de kans op sterfte (OR: 0,48 $95 \% \mathrm{Cl}: 0,27-0,84)$, en daarbij een trend naar een verbeterde kans op overleven en onafhankelijkheid (OR: 0,63 95\%Cl: 0,36-1,08). Subgroep analyse liet bij stereotactische behandeling een statistisch significante vermindering van de kans op sterfte zien (OR: $0,2995 \% \mathrm{Cl}: 0,14-0,59)$ en ook op sterfte of afhankelijkheid (OR: $0,48,95 \% \mathrm{Cl}: 0,24-0,96)$. Onze ziektespecifieke methodologische evaluatie welke gericht was op de in een onderzoek bereikte vergelijkbaarheid tussen onderzoeksgroepen, leidde tot het buiten beschouwing laten van twee RCTs in onze base-case meta-analyse. Afzonderlijke inclusie in een meta-analyse van deze RCTs, verminderde de grootte van het eerder gevonden statistisch significante effect. Dit demonstreert dat de manier waarop een systematische review studies methodologisch selecteert van grote invloed is op haar conclusies. 
De meta-analyse in dit hoofdstuk is de eerste die een statistisch significant gunstig effect van een stereotactische ingreep in ICH rapporteert. Nieuwe RCTs speciaal met betrekking tot de effectiviteit van stereotactische chirurgie in $\mathrm{ICH}$ in termen van sterfte en afhankelijkheids vermindering, zijn derhalve nodig om deze resultaten te bekrachtigen. Aangeraden wordt om in toekomstige RCTs blindering te verbeteren, speciaal bij de effectmeting. Gebaseerd op onze resultaten, zijn we van mening dat her beoordelen van de bereikte vergelijkbaarheid ussen de onderzoeksgroepen. voor prognostische factoren, co-interventies en effectmeting, en daarnaast het gebruik van ziekte specifieke methodologische criteria, belangrijke aandachtspunten moeten vormen voor toekomstige systematische reviews.

In hoofdstuk 7, de algemene discussie, worden de resultaten van de in dit proefschrift beschreven analyses samengevat en bediscussieerd. Daamaast worden mogelijke punten van kritiek en problemen die de SICHPA trial ondervond toegelicht: de kleine patiènten populatie door een voortijdig stoppen van de trial, een mogelijk te korte follow-up periode, de keuze om patiënten met anti-coagulantia gerelateerde ICHs te includeren, het niet protocoliseren van de conservatieve behandeling, het feit dat de bereikte ICH volume reductie relatief beperkt was, en het gebruik van enkel generieke kwaliteit van leven instrumenten. Voortvloeiend vanuit deze punten van kritiek worden een aantal aanbevelingen gedaan voor toekomstig onderzoek. Meest belangrijk hierbij zijn mogelijke aandachtspunten bij het verder optimaliseren van de chirurgische procedure en bij het ontwerp van een toekomstige RCT nodig om de effectiviteit van stereotactische aspiratie met gebruik van thrombolytica in ICH, te bevestigen. 



\section{RPREDK}

\section{ICH surgery specific criteria list}

(Items are graded as excellent $(++)$, good $(+)$, doubtul $( \pm)$ or poor $(-)$ or unclear $(?))$

\section{APPLICABILITY CRITERLA}

Relevant patient population:

Age $\geq 15$, spontaneous supratentorial $1 \mathrm{CH}>10 \mathrm{~m}$,

grade:

Use of anti-coagulants acceptable, treatment $<72$ hours

Adequate intervention:

Surgical ICH evacuation (any method) + best medical treatment

grade:

Compared to: best medical treatmen (well described/defined)

Relevant effect measurement:

Mortality

Functional outcome

Frequent effect measurements

Listing of side effects' complications (per group)

grade:

Adequate follow-up period: (at least 2 months)

grade

\section{METHODOLOGICAL CRITERLA}

Comparability of intervention and control group

Achieved homogeneity for prognostic factors:

Level of consciousness (GCS)

grade:

Initial ICH volume

Intraventricular extension of ICH (IVH)

Age

Baseline characteristics well-presented

Use of prestratification

Use of randomization: blinded

details of procedure

Trial group size ( $>50$ patients?)

Drop out rate per group $(<5 \%$ \%

Comparability of co-interventions/confounders

Concealment of treatment to caregiver and patient

Regimented treatment modalities (ar least described in detail per group)

grade:

Comparability of effect measurement

Concealment of treatment to evaluator and patient

GENERAL DATA PRESENTATION AND STATISTICAL ANALYSIS

Good data presentation (mean, standard deviation, median)

Adequate statisticall analysis

Intention to treat analysis

Missing data analysis (correction for dropouts)

Multivariate analysis (correction for base-line differences)

gracte:

grade

grade:

grade: 

The SICHPA trial was supported by a grant from the Fund for Developmental Medicine, Health Insurance Executive Board; Project OG94/042. Participating medical centers in the trial were Amsterdam Medical Center (AMC), University Medical Center Utrecht (UMCU), Erasmus Medical Center Rotterdam (EMCR) and University Hospital Maastricht / Atrium Medical Center Heerlen (UHM/AMCH). Many unmentioned general hospitals in the affiliation area of these neurosurgical centers also participated by actively including or transferring ICH patients.

The SICHPA trial group consisted of the following members: SMAA Evers PhD (Trial office UHM/AMCH), OPM Teernstra MD (Trial office UHM/AMCH), A Bok MD, (Trial office UHM/AMCH until 1997), Prof. EAM Beuls MD (Head department of Neurosurgery UHM/AMCH, Trial office), J. Lodder MD (vascular neurologist, Trial office UHM), G. Blaauw MD (neurosurgeon UHM/AMCH, Trial office), P. Leffers MSc (epidemiologist, Maastricht University, Trial office), GL Engel MD (Trial office, until 1997), S. Maris (Trial office UHM), W. van Dijk MSc (Trial office UHM), E.J. Janson MSc (Trial Office until 1998), SRHEM Meerhoff (research assistant, trial office), Prof. R Braakman MD (monitoring committee, emeritus professor, neurosurgeon), AGH Kessels Ir MSc (monitoring committee UHM, epidemiologist), AAW Op de Coul MD (monitoring committee, neurologist St. Elisabeth Hospital Tilburg, +2000 ).

The advisory committee consisted of: Prof.of neurosurgery CIJ Avezaat (EMCR), MW Berfelo MD neurosurgery (UHM/AMCH), JH van den Berge $\mathrm{MD}$ neurosurgery (EMCR), Prof. of neurosurgery, emeritus DA Bosch MD (AMC), Prof. of neurology I van Gijn MD (UMCU), Prof. of neurology PI Koudstaal MD (EMCR), Prof. of neurosurgery, emeritus CWM van Veelen MD (UMCU), Prof. of neurology M Vermeulen MD (AMC), GlE Rinkel MD neurology (UMCU), Prof. of neurosurgery CAT Tulleken MD (UMCU), A Algra PhD, epidemiologist (UMCU), Prof. of neurosurgery EAM Beuls MD (UHM/AMCH), J Branje PhD farmacology (UHM), Prof. of neurology, emeritus J Troost MD (UHM), J van Wersch PhD, clinical chemist (AMCH). Lamepro B.V., Raamsdonkveer provided the urokinase for the trial. 

Zonder de hulp, inspiratie en het vertrouwen van een heleboel mensen zou dit proefschrift niet het daglicht hebben gezien. Speciaal deze mensen wil ik bedanken.

Jan Lodder. Jan bedankt voor het Taoïstisch geduld dat je betoond hebt door mijn co-promotor te zijn. Je geduld en nuchterheid waren voor mij noodzakelijke factoren om van mijn 'wollig spinsel' zuiver garen te maken. Je bent voor mij een inspiratie als complexloze wetenschappelijke autoriteit.

Silvia Evers. Als geen ander was je deelgenoot in de vele ups and downs van de SICHPA trial. Behoudens het feit dat je een van de oorzaken bent dat 'de thermometer' vaak boven de 80 staat (VAS), is je bijdrage voor mij instrumenteel geweest in het schrijven van deze thesis. Je bescheidenheid makt diepe indruk.

Fons Kessels. Fons we kennen elkaar al lang, en altijd heb je me verwonderd over je geniale vermogen om me te laten nadenken. Je bent in belangrijke mate verantwoordelijk voor het gedeelte 'wijsheid' in mijn "eigen-wijsheid.' Je hebt gelijk: 'Luisteren helpt, denken ook.'

Gerhard Blaauw. Gehard bedankt voor het vertrouwen dat je (vaak hoofdschuddend) in me stelde met het begeleiden, analyseren, internationaal presenteren en publiceren van de SICHPA trial voor wiens ontstaan jij hoofdzakelijk verantwoordelijk bent.

Prof.dr E.A.M. Beuls. Emile bedankt voor je vriendschap, inspiratie en vertrouwen. 'Belgisch onderhandelen' is een kunst, je bent een ware kunstenaar.

De leden van de beoordelingscommissie: Prof.dr. J. Troost (voorzitter), Prof.dr. H.W.M. Steinbusch, Prof.dr. J. Wilmink, Prof.dr. W.P. Vandertop (Vrije Universiteit van Amsterdam) en Dr. C.L. Franke (Atrium Medisch Centrum Heerlen). Ik ben zeer erkentelijk voor hun inspanning om het manuscript in zo'n korte tijd te willen beoordelen.

Alle mensen die zich hebben ingezet voor het welslagen van de SICHPA trial (zie ook Acknowledgements). Met name leden van de stuurgroep: Prof. dr. E.A.M. Beuls, Dr. J. Lodder, Dr. G. Blaauw, Dr. S.M.A.A. Evers, Dr. C.L. Franke, Drs. P.Leffers, Drs. A.W.J. Bok (tot 1997), Dhr S. Maris, Dr. G.L. Engel (tot 1997) en Drs. W. Van Dijk, en leden van de Veiligheidscommissie te weten: Prof.dr. R.Braakman, Drs. ir. A.G.H. Kessels en Dr. A.A.W. Op de Coul $(+2000)$.

Alle patiënten woor hun medewerking. 
De neurochirurgen, assistenten en de secretariaten van de vakgroep neurochirurgie. Bedankt voor jullie interesse, ondersteuning en vriendschap.

Brenda Vollers-King en Datawyse. Very useful, but most of all very expeditious suggestions, thanks! Niet alleen Data-wise maar ook Data-fast.

Mijn paranimfen Silvia Evers en Ingrid Brussé. Natuurlijk niet zomaar mijn paranimfen.

Tenslotte Ilona, mam en Ger, Ans en Leo: bedankt voor alles. 


\section{CURRICUTMM VTAME}

Onno Teernstra werd geboren op 11 september 1968 te Amstelveen. In 1986 deed hij eindexamen VWO-B aan de Bouwmeester Scholengemeenschap te Haaksbergen. In 1986 begon hij met de studie biologie aan de Rijksuniversiteit Leiden. In 1987 stapte hij over naar de studierichting Psychologie aan dezelfde universiteit. Na het behalen van het propaedeutisch examen Psychologie, begon hij aan de vervulling van zijn militaire dienstplicht bij de geneeskundige troepen, begin 1989. Na viermaal uitgeloot te zijn kon hij in 1990 met de studie Geneeskunde beginnen aan de Rijksuniversiteit Maastricht. In 1994 werd het Doctoraal examen Geneeskunde gehaald met het predicaat 'met genoegen.' De daarop volgende co-schappen werden in 1997 afgesloten met Artsexamen, met het predicaat 'met genoegen.' Gedurende zijn gehele studie stond het specialisme Neurochirurgie centraal in zijn belangstelling en vanaf 1992 werden de eerste wetenschappelijke schreden op gebied van epilepsiechirurgie gezet onder leiding van Prof. dr E.A.M. Beuls, Drs. Ir. A.G.H. Kessels, Dr. M.W. Berfelo, Dr H.J.M. Majoie en Dr. Herpers van de toen kersvers opgerichte vakgroep Neurochirurgie in het Acadlemisch Ziekenhuis Maastricht. In 1997 ging hij als assistent geneeskunde niet in opleiding (AGNIO) aan de slag in het Academisch Ziekenhuis Rotterdam "Dijkzigt," bij Prof.dr. C. Avezaat. In het daarop volgende jaar keerde hij terug naar Maastricht om als arts-onderzoeker bij de vakgroep Neurochirurgie om thet SICHPA onderzoek (Stereotactic Treatment of IntraCerebral Hematoma by means of a Plasminogen Activator) te behartigen onder leiding van Dr. G. Blaatuw. Vanaf eind 1998 functioneerde hij aldaar als AGNIO. Medio 2000 startte hij onder leiding van Prof.dr. E.A.M. Beuls met zijn opleiding tot Neurochirurg, welke hij in 2006 hoopt te voltooien. 